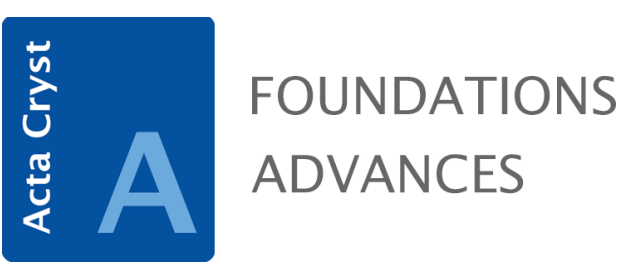

Volume 78 (2022)

Supporting information for article:

Vanishing of the atomic form factor derivatives in non-spherical structural refinement - a key approximation scrutinized in the case of Hirshfeld atom refinement

Laura Midgley, Luc J. Bourhis, Oleg V. Dolomanov, Simon Grabowsky, Florian Kleemiss, Horst Puschmann and Norbert Peyerimhoff 


\title{
Supplementary information for Vanishing of the atomic form factor derivatives in non-spherical structural refinement - A key approximation scrutinised in the case of Hirshfeld Atom Refinement
}

\author{
Laura Midgley, Luc J. Bourhis, Oleg V. Dolomanov, Simon Grabowsky, Florian Kleemiss, \\ Horst Puschmann, Norbert Peyerimhoff
}

This supplementary information is organised in accordance with the sections of the main article. Largely we present graphs and tables which are useful for understanding and confirming our findings, or are of interest for curiosity's sake, but were not necessary for the main body of the article.

Sections without additional information are omitted.

\section{Contents}

1 Details of datasets $\quad$ S2

2 The three main refinement procedures S3

2.1 Flowcharts side-by-side . . . . . . . . . . . . . . . . . . . . . . . S3

3 The quality of numerical nonspherical refinement S4

3.1 Shift/esd diagrams . . . . . . . . . . . . . . . . . . . . . . . . . . . . S4

3.2 wR2 diagrams (ammonia) . . . . . . . . . . . . . . . . . . . . . . . . . S6

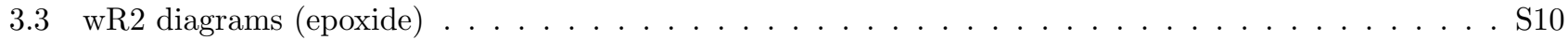

3.4 wR2 diagrams (L-alanine) . . . . . . . . . . . . . . . . . . . . . . . . . . . . . S14

3.5 L-Alanine by TAAM . . . . . . . . . . . . . . . . . . . . . . . . . S18

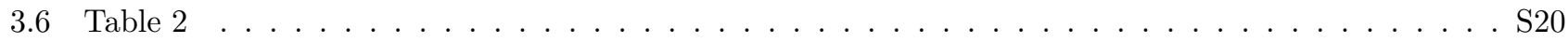

4 Comparison of refinement minima S21

4.1 Basis set dependence . . . . . . . . . . . . . . . . . . . . . . . . S21

$5 \quad$ Bringing In Uncertainties S23

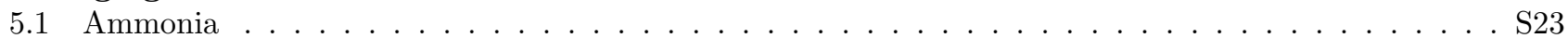

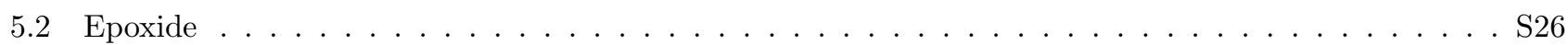

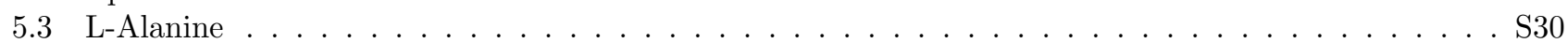

6 Conclusion \& Outlook S36

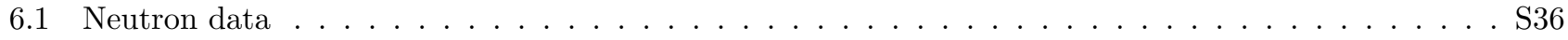

B Uncertainty balls $\mathbf{S 4 1}$

B.1 The matrix $J$ for ammonia . . . . . . . . . . . . . . . . . . . . . . . . . S41 


\section{Details of datasets}

Table S1: Crystalllographic data for datasets used. Since all data was literature reported we summarize the data from the original sources in combination with the results from numerical refinement.

\begin{tabular}{|c|c|c|c|}
\hline Compound & $\begin{array}{l}\text { Epoxide } \\
\text { (Grabowsky et al., 2010) }\end{array}$ & $\begin{array}{l}\text { Ammonia } \\
\text { (Boese et al., 1997) }\end{array}$ & $\begin{array}{l}\text { L-Alanine } \\
\text { (Destro et al., 1988) }\end{array}$ \\
\hline Formula & $\mathrm{C}_{2} \mathrm{H}_{4} \mathrm{O}$ & $\mathrm{NH}_{3}$ & $\mathrm{C}_{3} \mathrm{H}_{7} \mathrm{NO}_{2}$ \\
\hline$D_{\text {calc. }} / \mathrm{g} \mathrm{cm}^{-3}$ & 1.162 & 0.838 & 1.405 \\
\hline$\mu / \mathrm{mm}^{-1}$ & 0.092 & 0.064 & 0.117 \\
\hline Formula Weight & 44.053 & 17.031 & 89.095 \\
\hline Size $/ \mathrm{mm}^{3}$ & $0.30 \times 0.30 \times 0.30$ & not reported & not reported \\
\hline$T / \mathrm{K}$ & $100(2)$ & $160(2)$ & $23(2)$ \\
\hline Crystal System & monoclinic & cubic & orthorhombic \\
\hline Space Group & $P 2_{1} / n$ & $P 2_{1} 3$ & $P 2_{1} 2_{1} 2_{1}$ \\
\hline$a / \AA$ & $4.633(5)$ & $5.1305(8)$ & $5.9279(10)$ \\
\hline$b / \AA$ & $8.400(1)$ & $5.1305(8)$ & $12.2597(17)$ \\
\hline$c / \AA$ & $6.577(3)$ & $5.1305(8)$ & $5.7939(9)$ \\
\hline$\alpha^{\circ}$ & 90 & 90 & 90 \\
\hline$\beta^{\circ}$ & $100.37(6)$ & 90 & 90 \\
\hline$\gamma^{\circ}$ & 90 & 90 & 90 \\
\hline $\mathrm{V} / \AA^{3}$ & $251.8(3)$ & $135.05(4)$ & $421.07(11)$ \\
\hline$Z$ & 4 & 4 & 4 \\
\hline$Z$ & 1 & 0.333333 & 1 \\
\hline Wavelength/A & 0.71068 & 0.71069 & 0.71073 \\
\hline Radiation type & Mo $\mathrm{K}_{\alpha}$ & Mo $\mathrm{K}_{\alpha}$ & Mo $\mathrm{K}_{\alpha}$ \\
\hline$\Theta_{\min }$ & 3.98 & 5.62 & 3.32 \\
\hline$\Theta_{\max }$ & 34.99 & 29.96 & 50.14 \\
\hline Measured Refl's. & 2081 & 1762 & 2519 \\
\hline Indep't Refl's & 1109 & 136 & 2519 \\
\hline Refl's $\mathrm{I} \geq 2 \sigma(\mathrm{I})$ & 899 & 133 & 2393 \\
\hline$R_{\text {int }}$ & 0.0286 & 0.0303 & 0.0000 \\
\hline Parameters & 64 & 13 & 118 \\
\hline Restraints & 0 & 0 & 0 \\
\hline
\end{tabular}




\section{The three main refinement procedures}

\section{$2.1 \quad$ Flowcharts side-by-side}

We present here the flow charts for approximate and numerical nonspherical refinements side-by-side to highlight the similarities and differences.

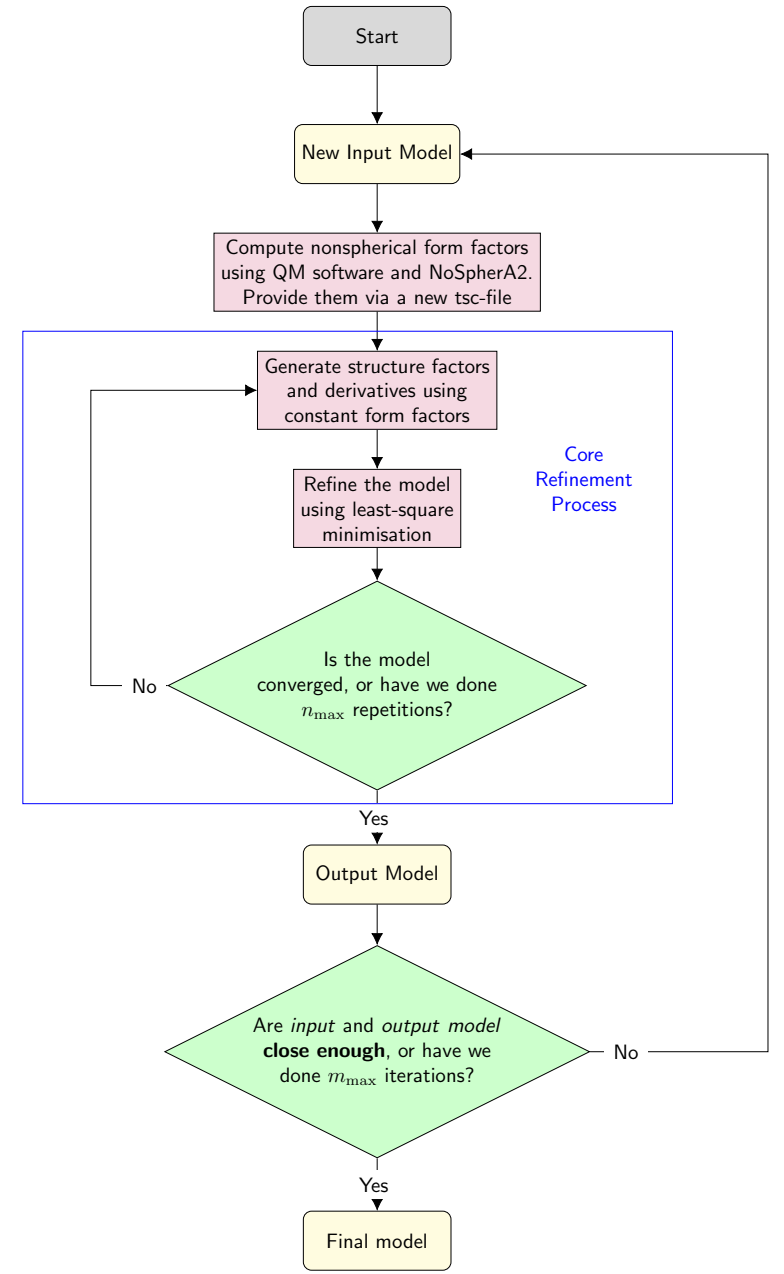

(a) Flow chart illustration of Approximate Nonspherical Refinement

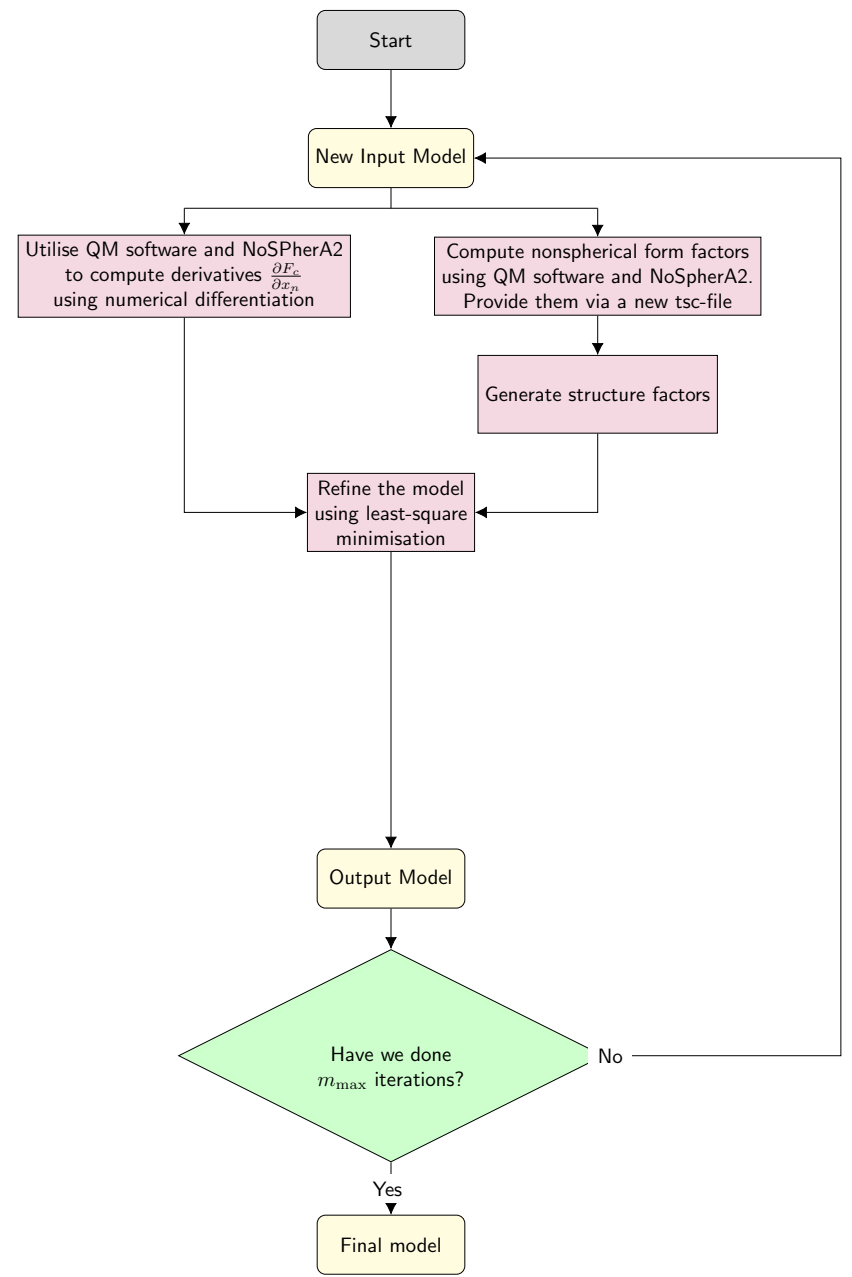

(b) Flow chart illustration of Numerical Nonspherical Refinement

Figure S1: Side-by-side flow charts for approximate and numerical nonspherical refinements 


\section{The quality of numerical nonspherical refinement}

We present graphs for the three molecules (ammonia, epoxide and L-alanine). Figures S2, S3 and S4 show the shift/esd progression for 6 different $\delta$ values, and hybrid refinement. Figures S5 to S22 show the progression of wR2 through numerical nonspherical refinement with the different $\delta$, and hybrid, and comparing the progression when starting from $\mathbf{x}_{\text {spher }}$ or $\mathbf{x}_{\text {appr }}$.

\subsection{Shift/esd diagrams}

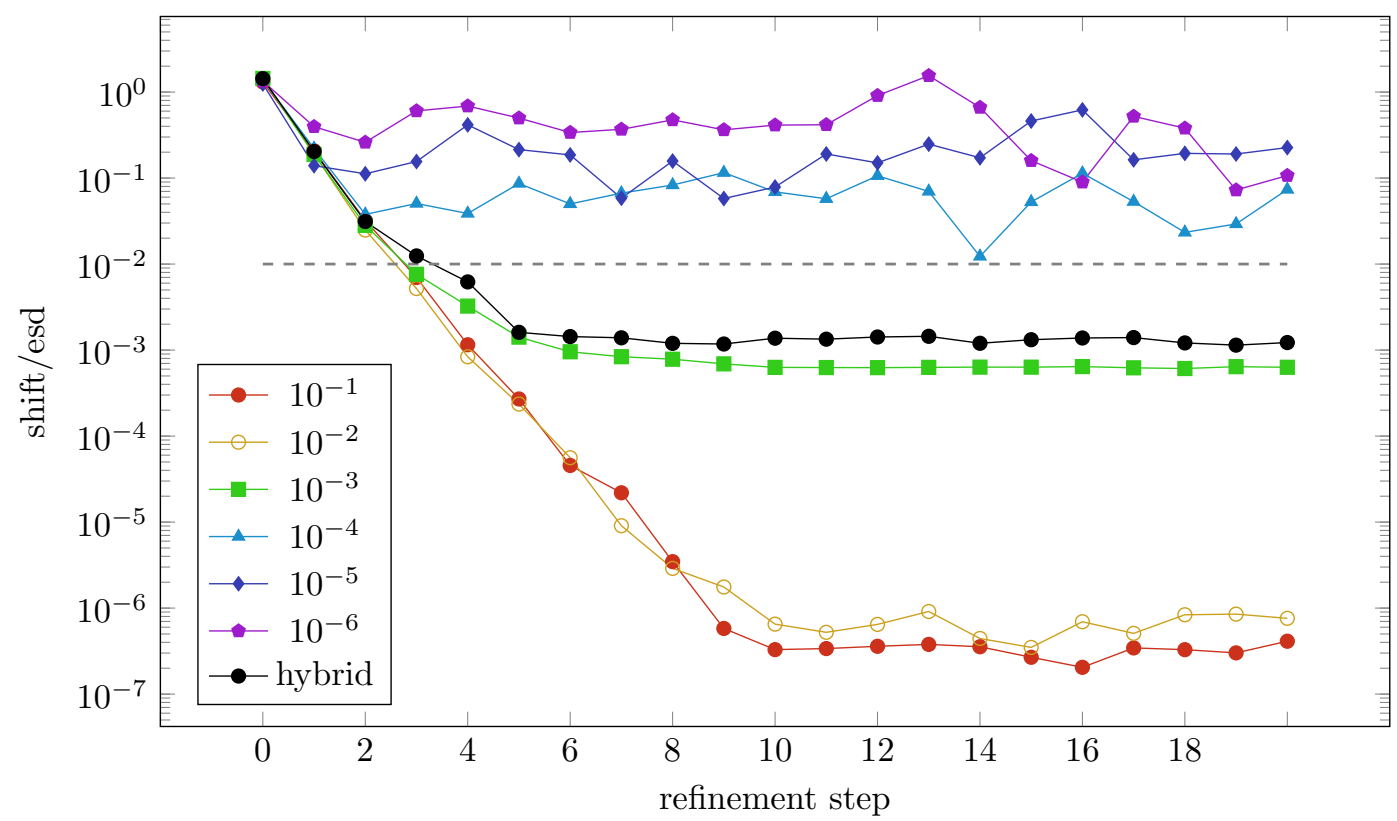

Figure S2: Maximal shift/esd for numerical refinement starting from $\mathbf{x}_{\mathrm{appr}}$ for $\delta=10^{-1}, \ldots, 10^{-6} \AA$, and hybrid at $\delta=10^{-3} \AA$ (ammonia) 


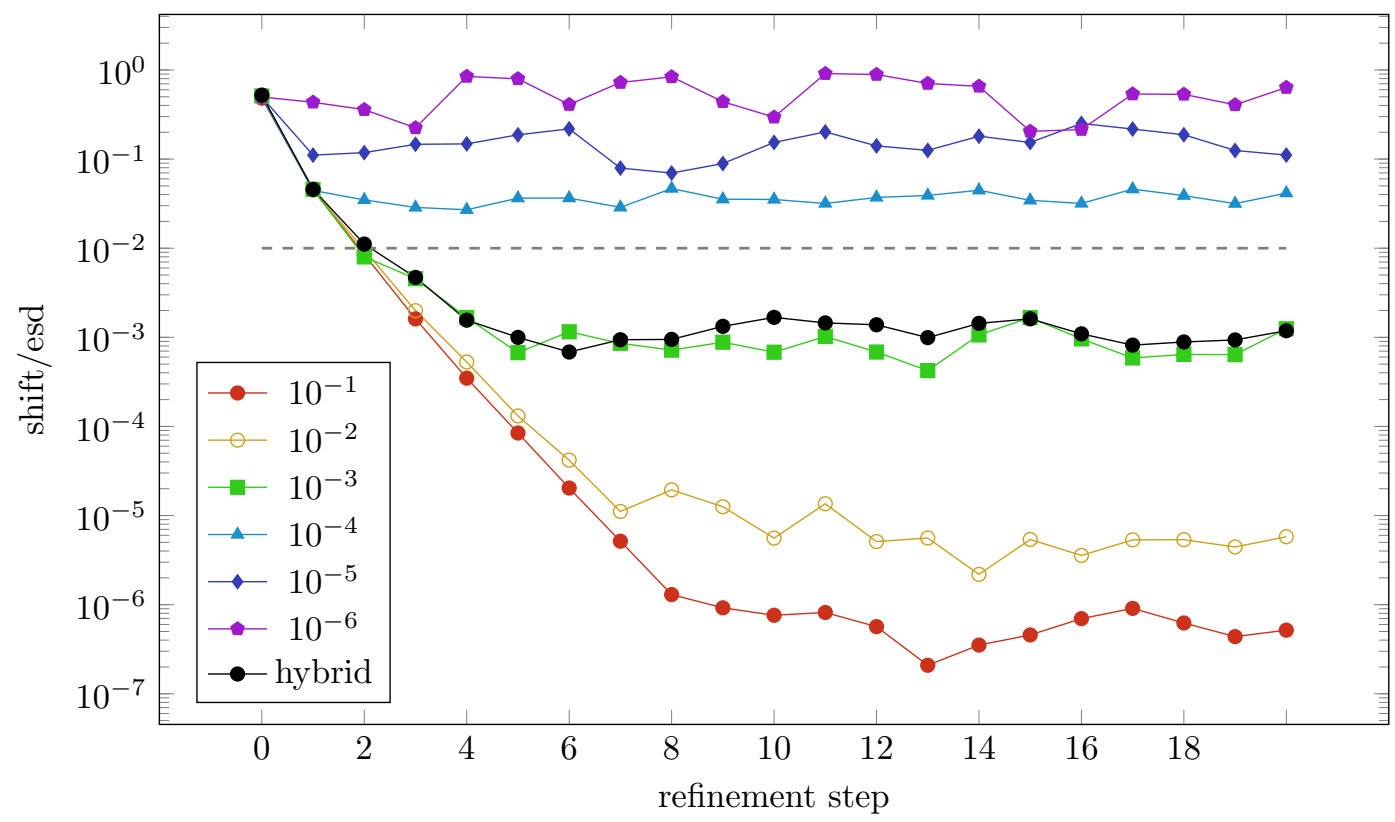

Figure S3: Maximal shift/esd for numerical refinement starting from $\mathbf{x}_{\text {appr }}$ for $\delta=10^{-1}, \ldots, 10^{-6} \AA$, and hybrid at $\delta=10^{-3} \AA$ (epoxide)

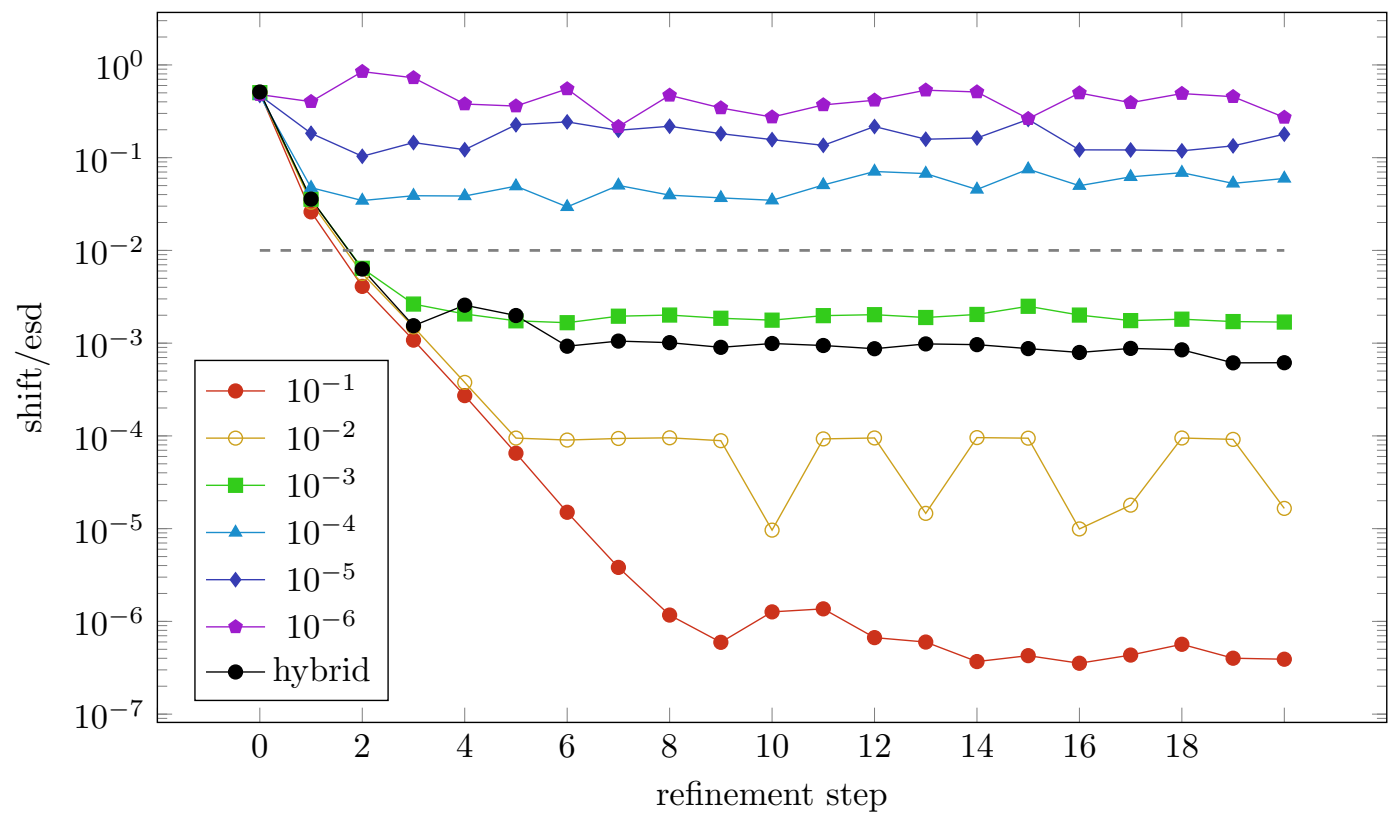

Figure S4: Maximal shift/esd for numerical refinement starting from $\mathbf{x}_{\text {appr }}$ for $\delta=10^{-1}, \ldots, 10^{-6} \AA$, and hybrid at $\delta=10^{-3} \AA$ (L-alanine) 


\section{$3.2 \quad$ wR2 diagrams (ammonia)}

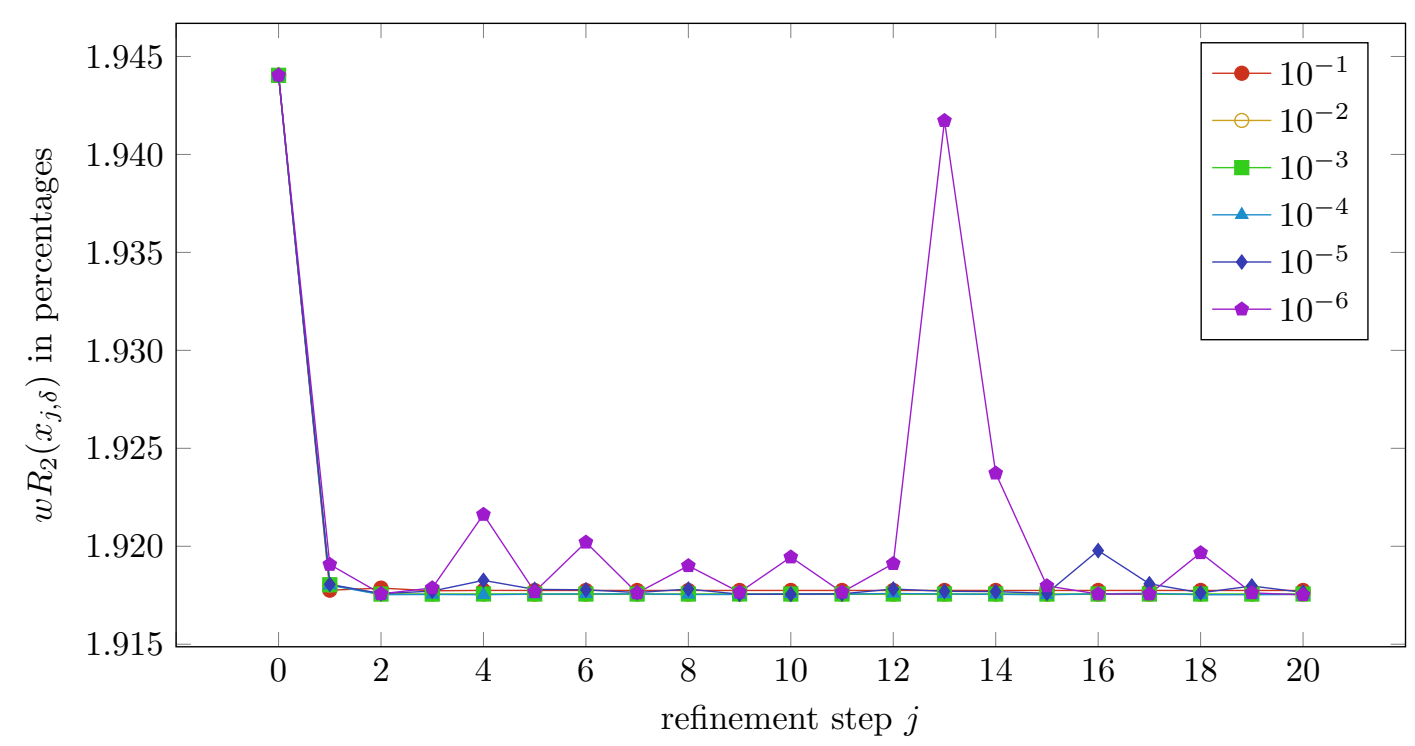

Figure S5: The progression of $w R_{2}\left(x_{j}\right)$ for $j=0,1, \ldots, 20$ and for $\delta=10^{-1}, \ldots, 10^{-6} \AA$ starting from $\mathbf{x}_{\text {appr }}$ (ammonia)

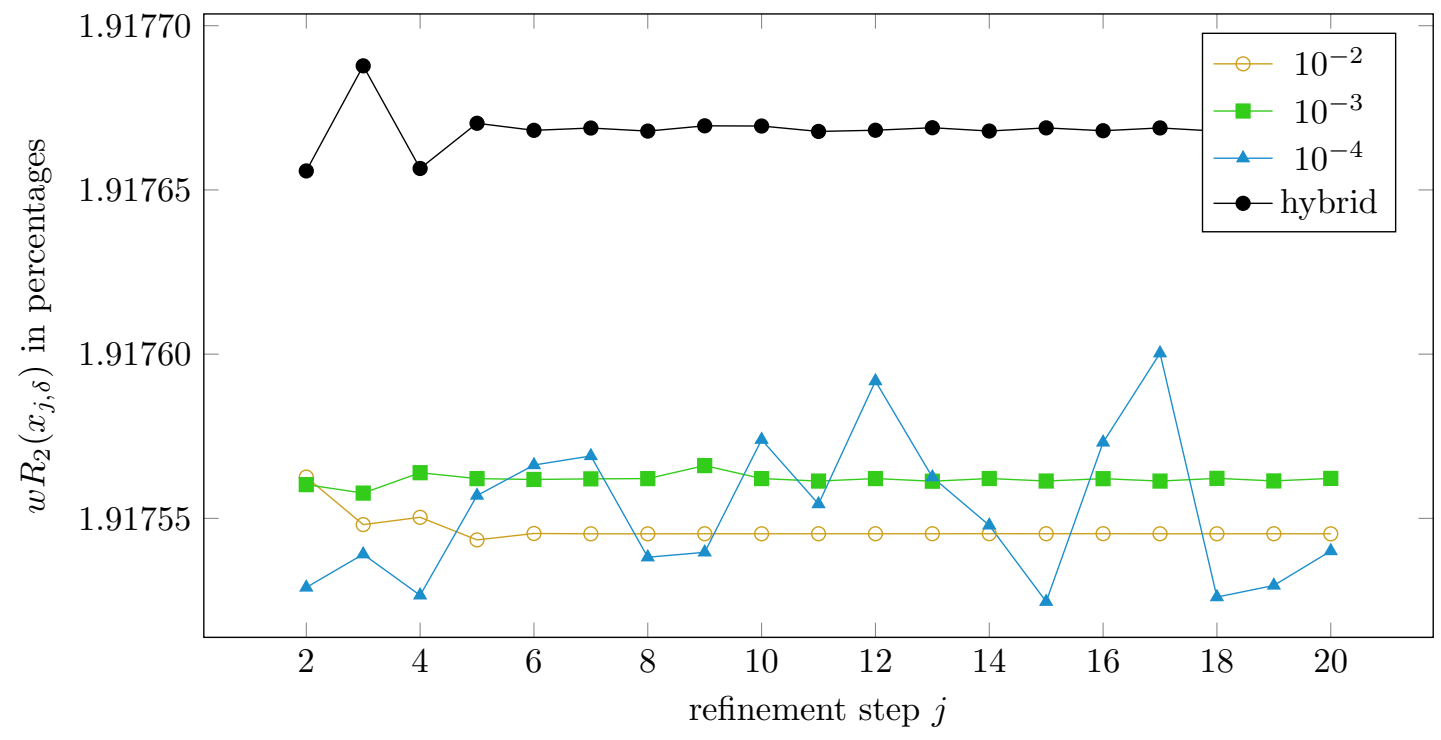

Figure S6: As in Figure S5; the progression of $w R_{2}\left(x_{j}\right)$ for $j=2,3, \ldots, 20$ and for $\delta=10^{-2} \AA, 10^{-3} \AA, 10^{-4} \AA$, and hybrid at $\delta=10^{-3} \AA$ starting from $\mathbf{x}_{\text {appr }}$ (ammonia) 


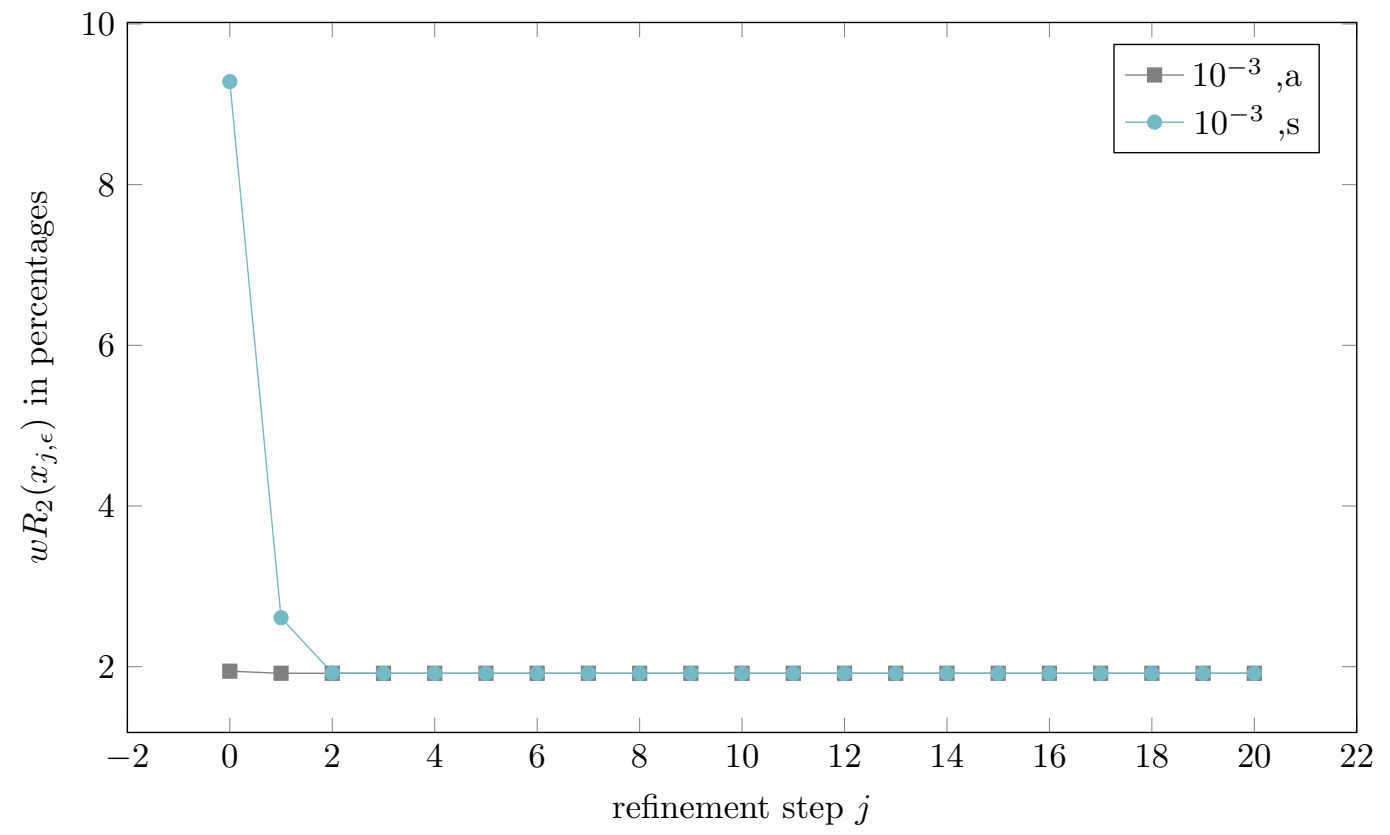

Figure S7: The progression of $w R_{2}\left(x_{j}\right)$ for $j=0,1, \ldots, 20$ and for $\delta=10^{-3} \AA$, with label "a" for refinement journey starting from $x_{\mathrm{appr}}$ and label "s" starting from $x_{\mathrm{spher}}$ - all $\mathrm{wR}_{2}$-factors are calculated with non-spherical form factors (ammonia)

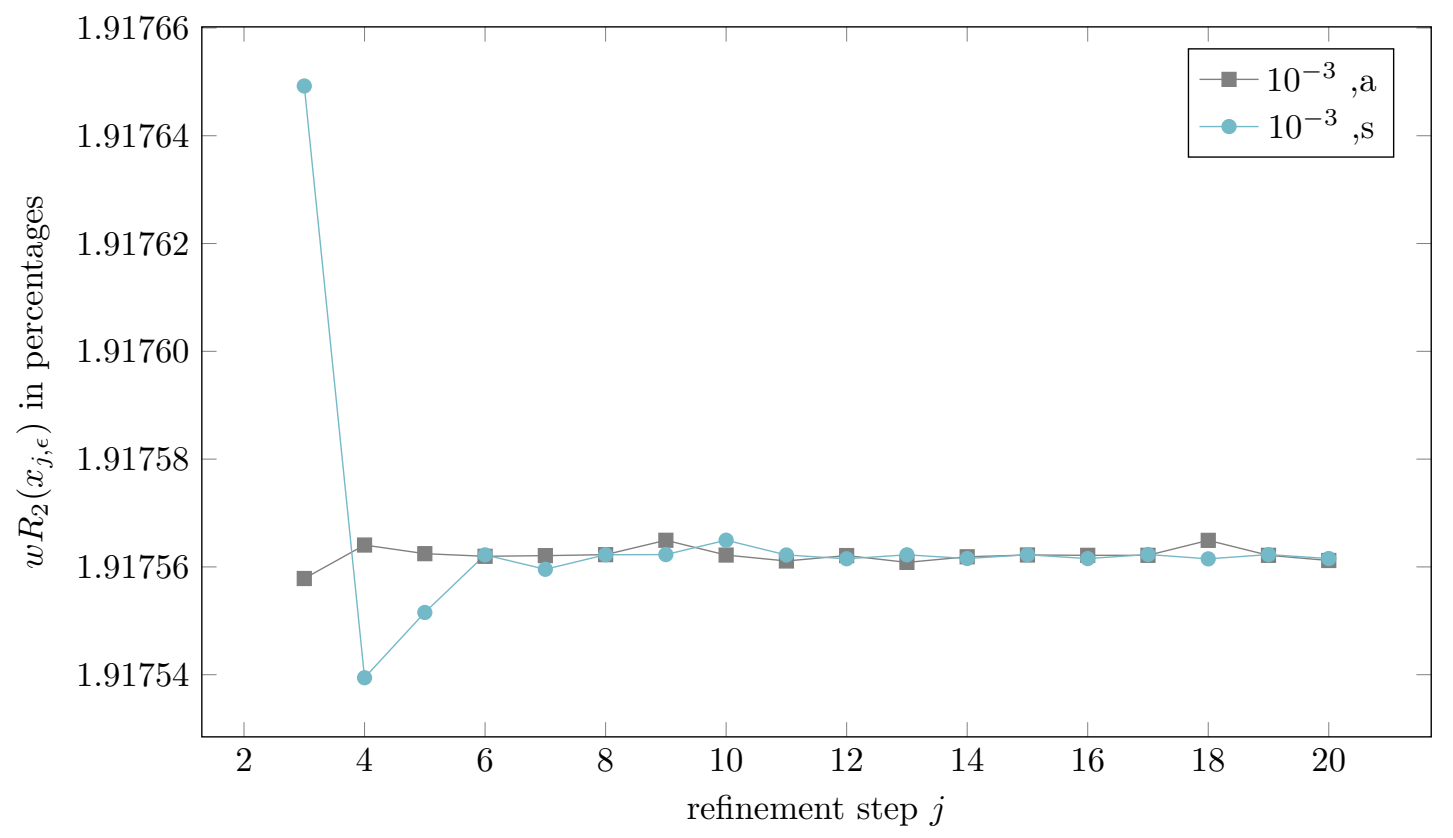

Figure S8: As in Figure S7; the progression of $w R_{2}\left(x_{j}\right)$ for $j=3,4, \ldots, 20$ and for $\delta=10^{-3} \AA$, with label "a" for refinement journey starting from $x_{\text {appr }}$ and label "s" starting from $x_{\text {spher }}$ (ammonia) 


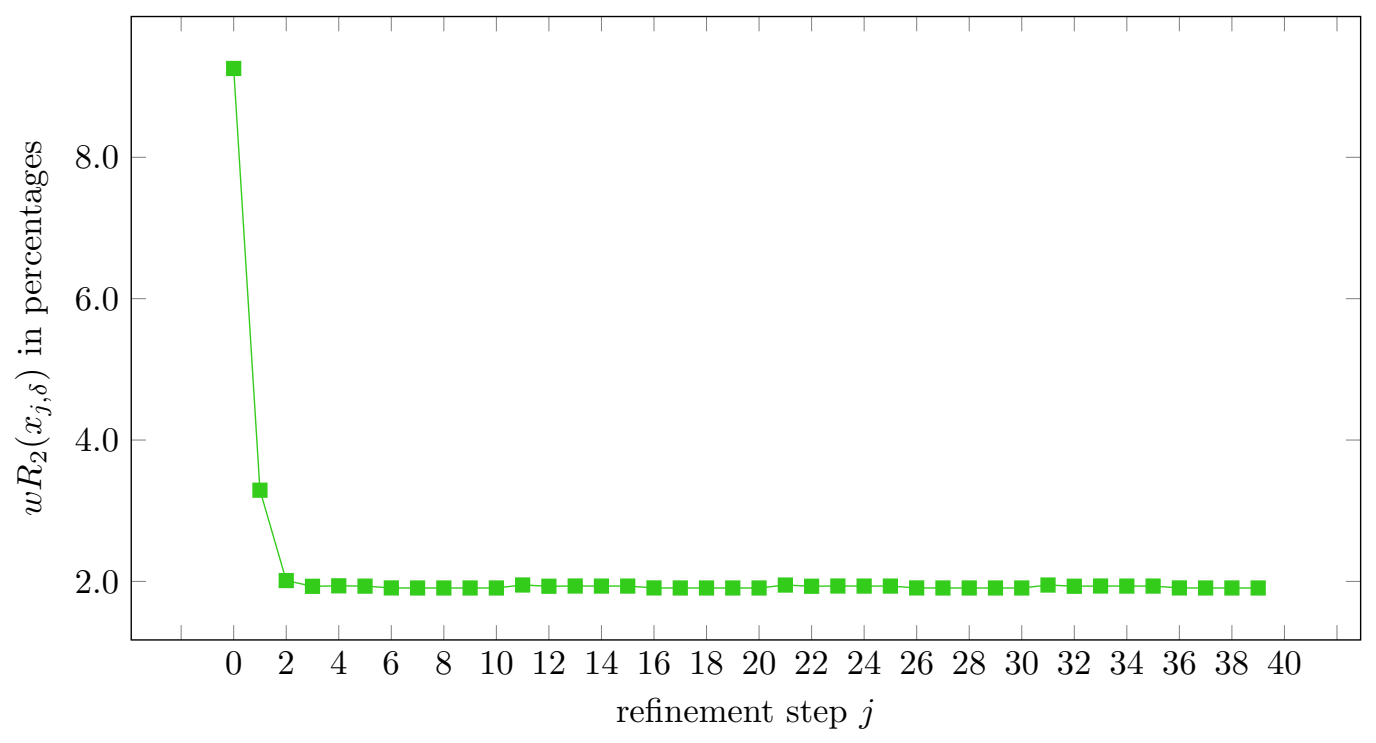

Figure S9: The progression of $w R_{2}\left(x_{j}\right)$ for $j=0,1, \ldots, 40$ and for $\delta=10^{-3} \AA$ starting from $\mathbf{x}_{\mathrm{spher}}$ and alternating between 5 steps of approximate and numerical refinement (ammonia)

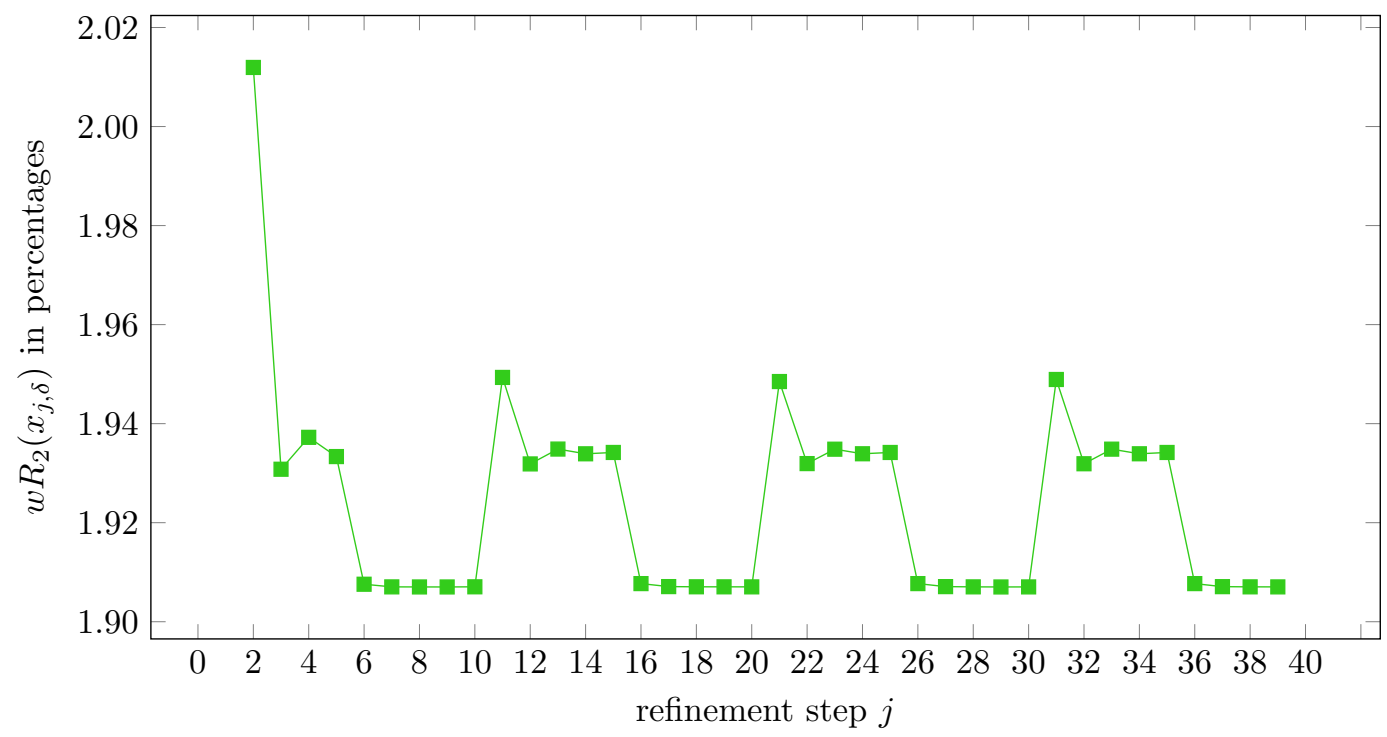

Figure S10: The progression of $w R_{2}\left(x_{j}\right)$ for $j=2,3, \ldots, 40$ and for $\delta=10^{-3} \AA$ starting from $\mathbf{x}_{\mathrm{spher}}$ and alternating between 5 steps of approximate and numerical refinement (ammonia) 


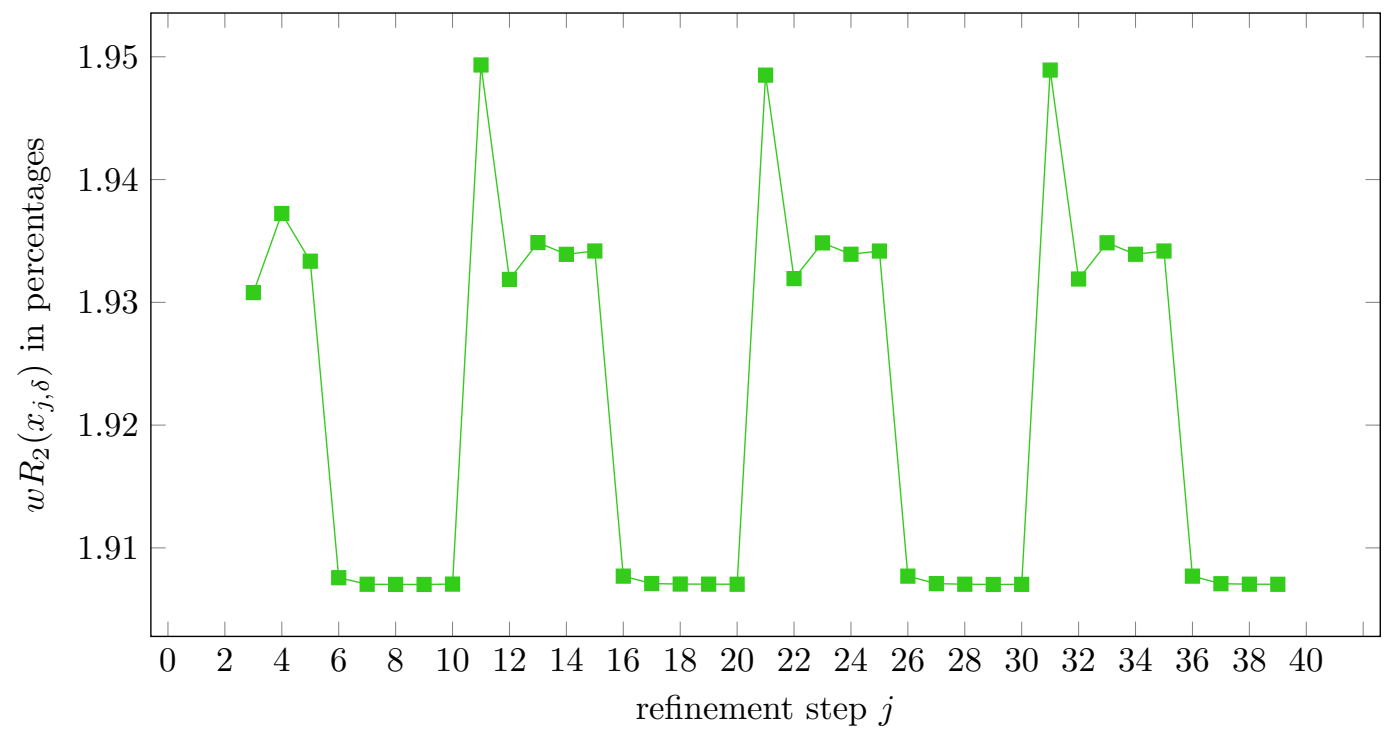

Figure S11: The progression of $w R_{2}\left(x_{j}\right)$ for $j=3,4, \ldots, 40$ and for $\delta=10^{-3} \AA$ and alternating between 5 steps of approximate and numerical refinement (ammonia) 


\section{$3.3 \quad$ wR2 diagrams (epoxide)}

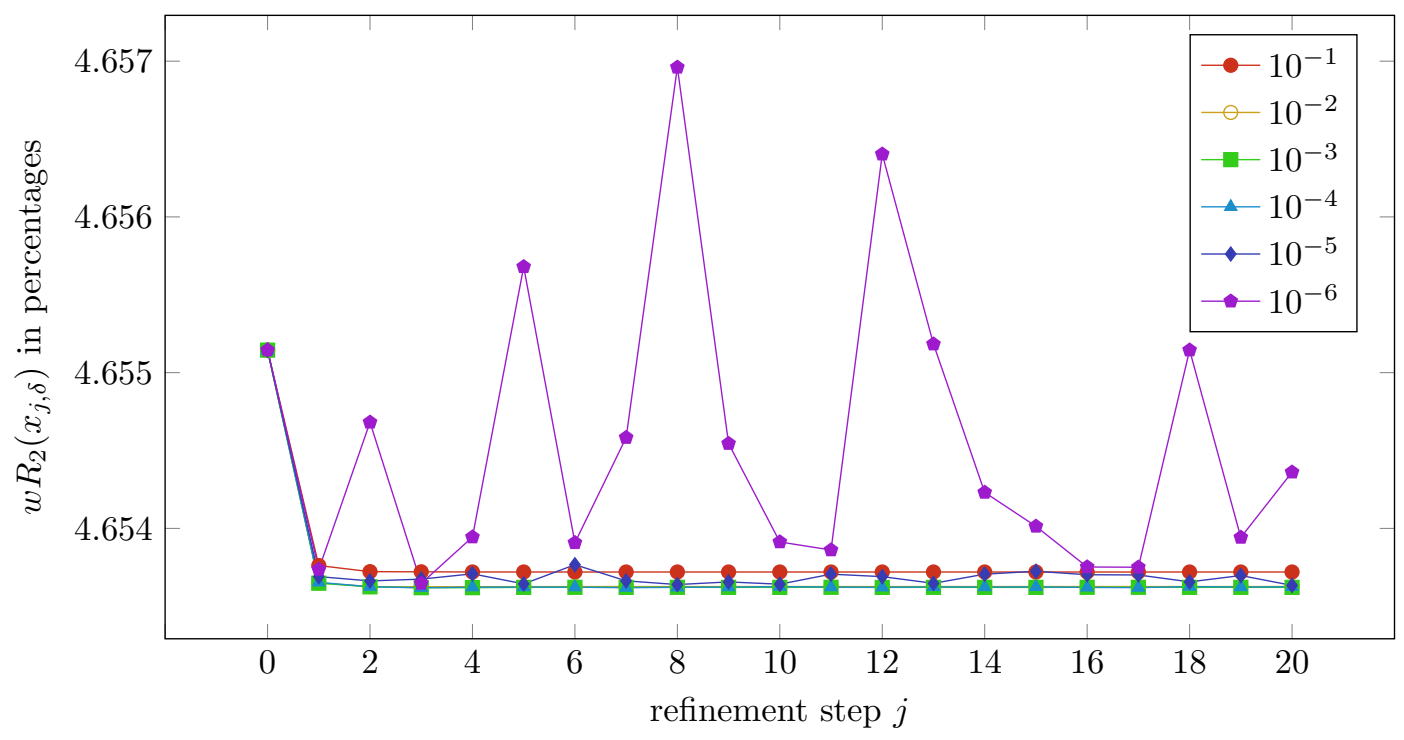

Figure S12: The progression of $w R_{2}\left(x_{j}\right)$ for $j=0,1, \ldots, 20$ and for $\delta=10^{-1}, \ldots, 10^{-6} \AA$ starting from $\mathbf{x}_{\text {appr }}$ (epoxide)

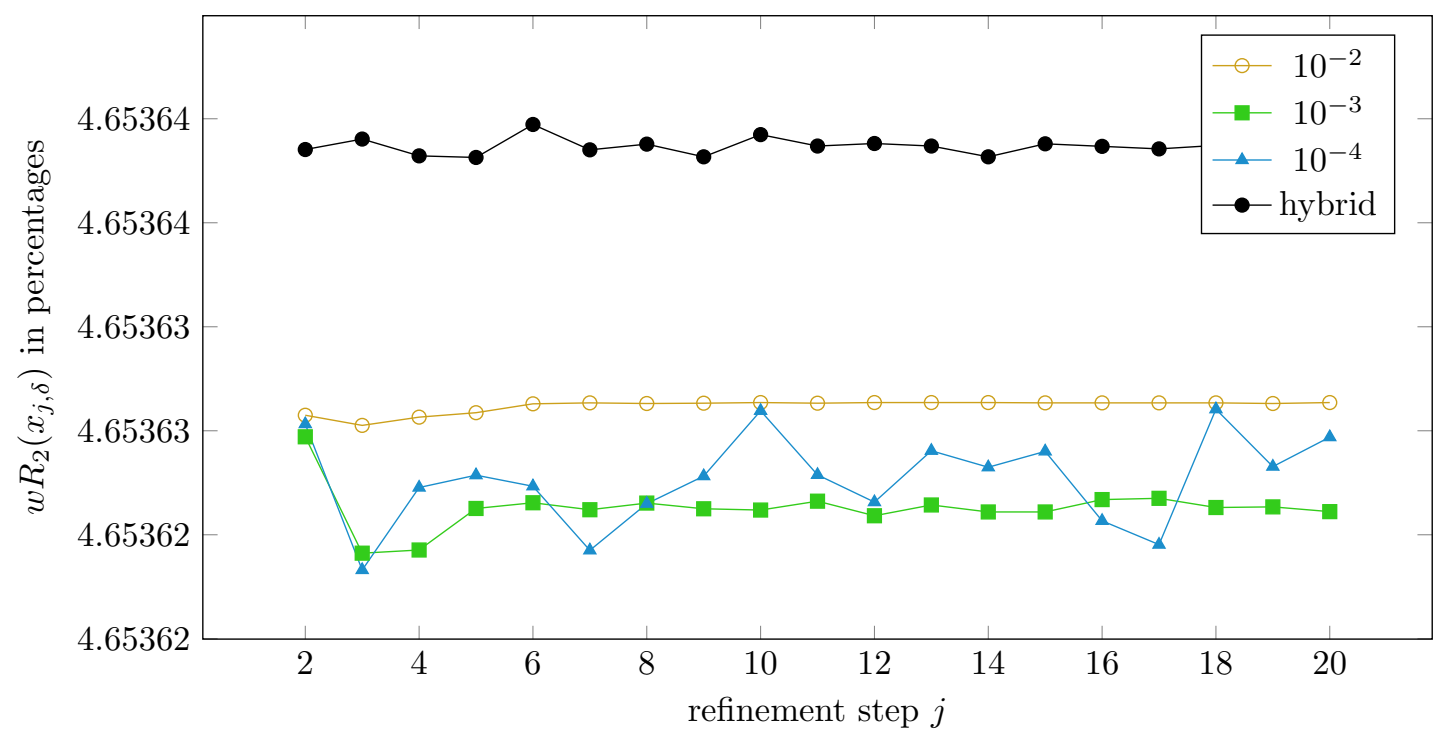

Figure S13: As in Figure S12 The progression of $w R_{2}\left(x_{j}\right)$ for $j=2,3, \ldots, 20$ and for $\delta=10^{-2} \AA, 10^{-3} \AA, 10^{-4} \AA$, and hybrid at $\delta=10^{-3} \AA$ starting from $\mathbf{x}_{\text {appr }}$ (epoxide) 


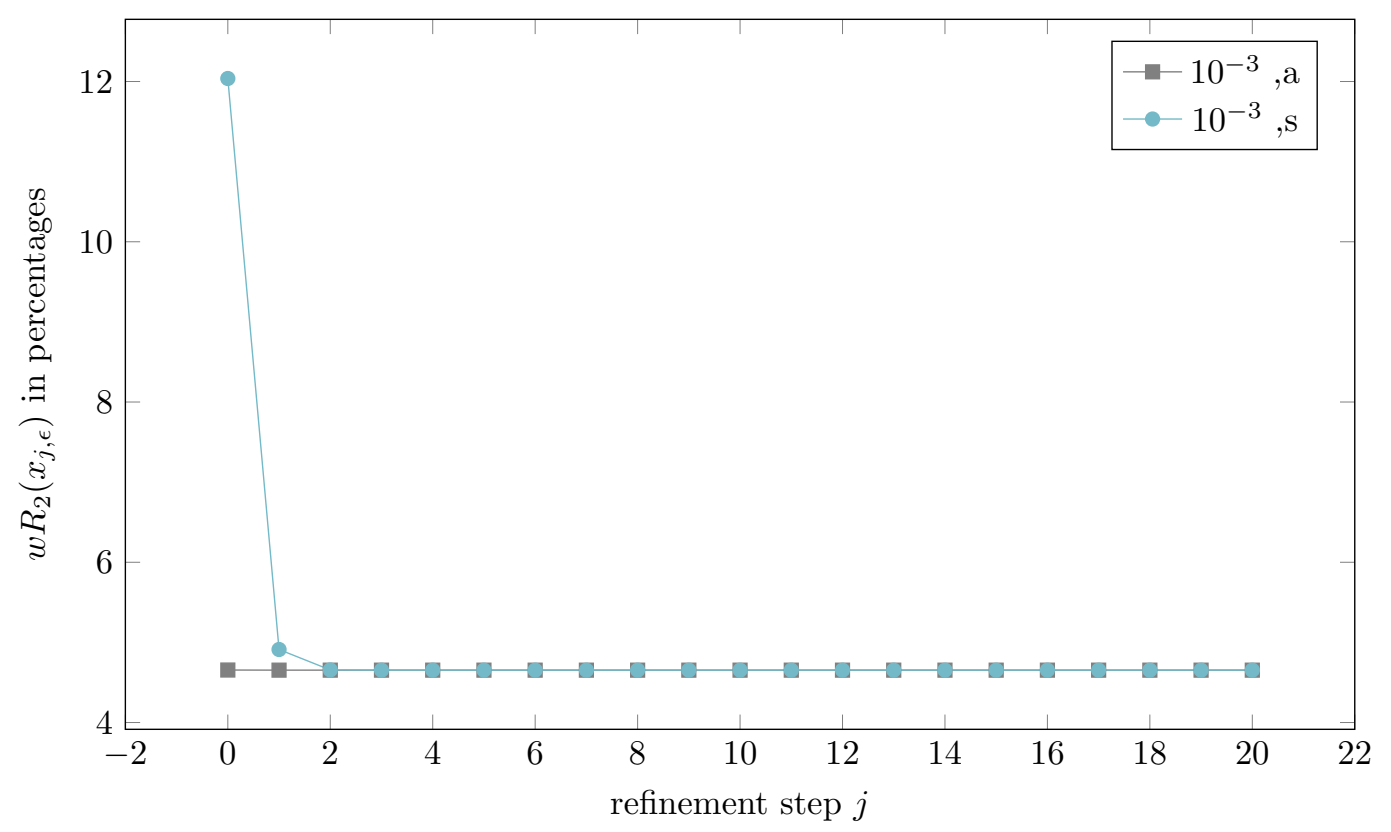

Figure S14: The progression of $w R_{2}\left(x_{j}\right)$ for $j=0,1, \ldots, 20$ and for $\delta=10^{-3} \AA$, with label "a" for refinement journey starting from $x_{\text {appr }}$ and label "s" starting from $x_{\text {spher }}$ - all $\mathrm{wR}_{2}$-factors are calculated with non-spherical form factors (epoxide)

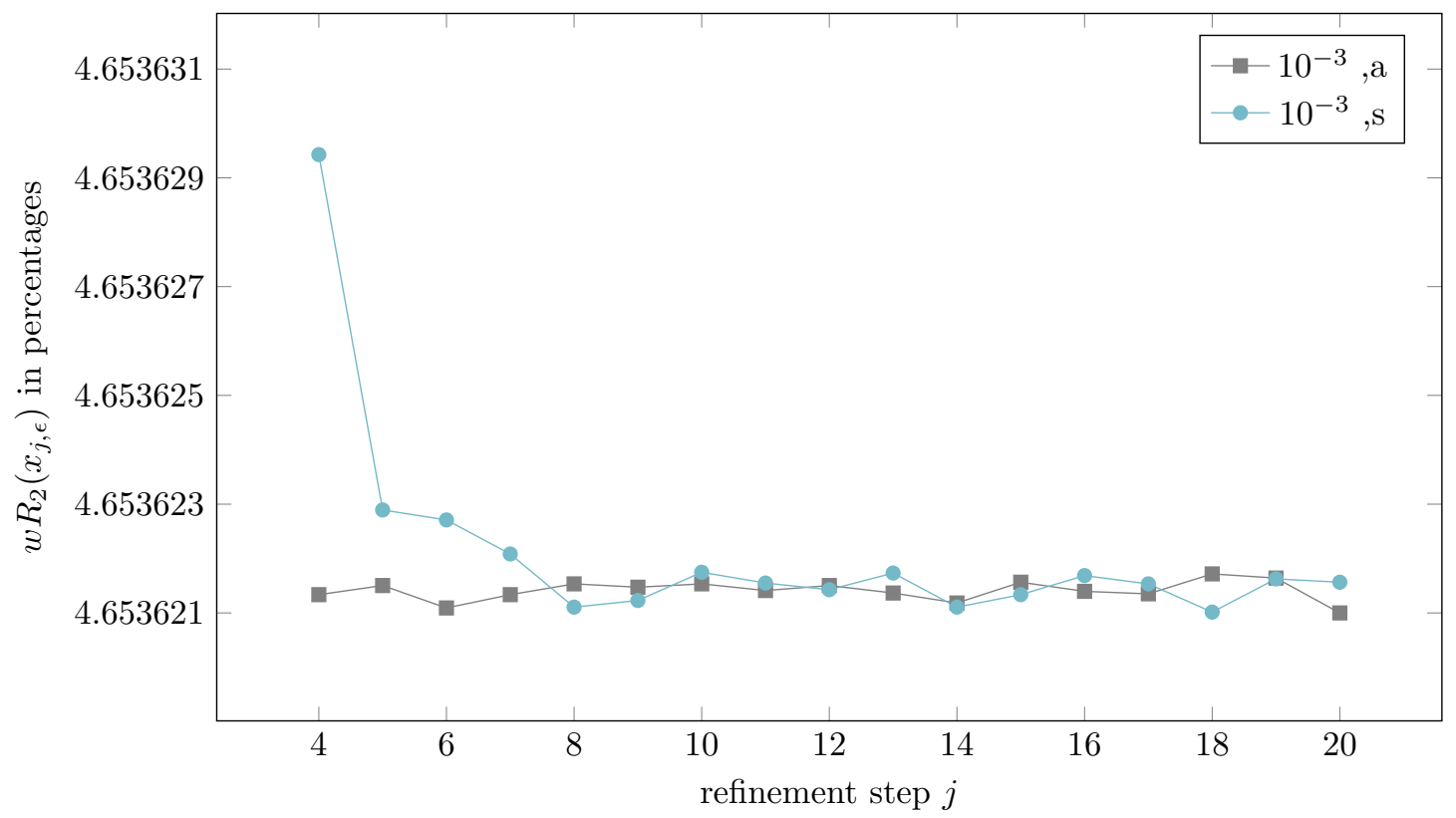

Figure S15: As in Figure S7; the progression of $w R_{2}\left(x_{j}\right)$ for $j=4,5, \ldots, 20$ and for $\delta=10^{-3} \AA$, with label "a" for refinement journey starting from $x_{\text {appr }}$ and label "s" starting from $x_{\text {spher }}$ (epoxide) 


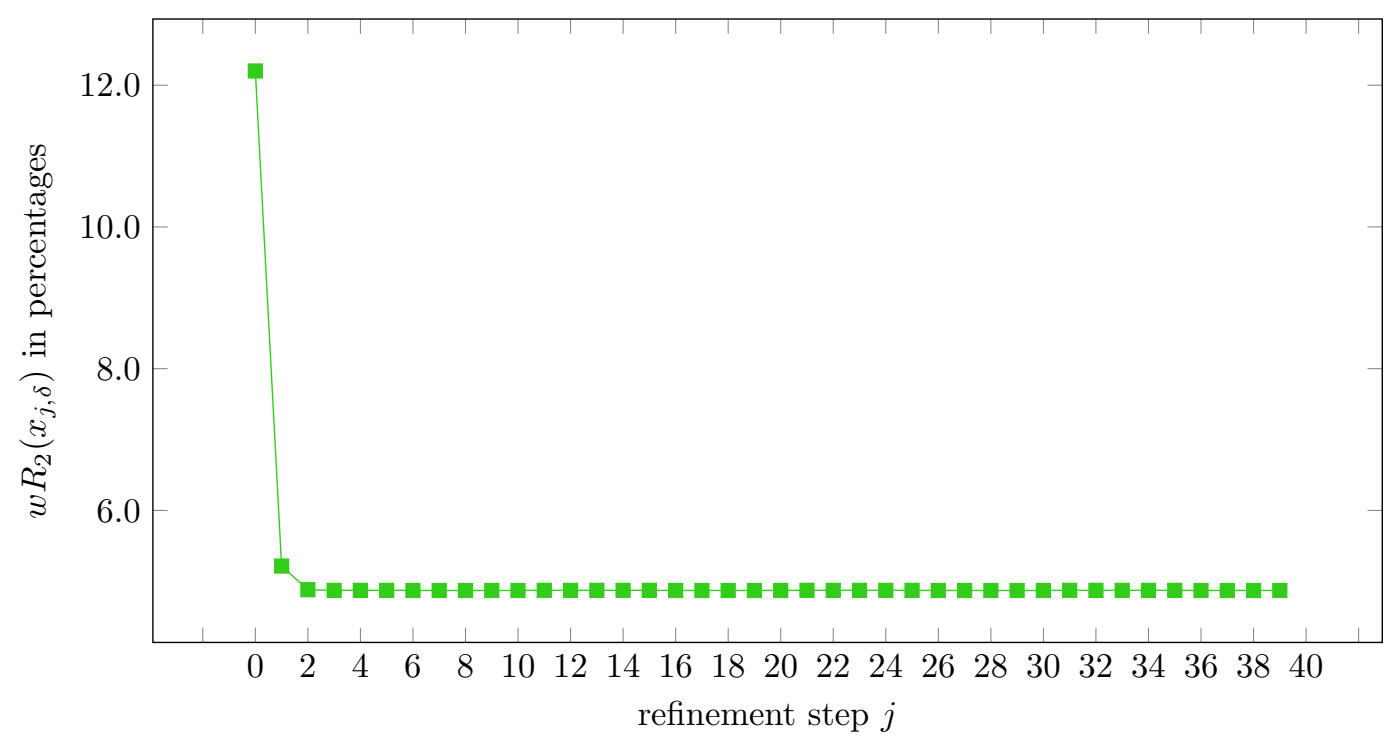

Figure S16: The progression of $w R_{2}\left(x_{j}\right)$ for $j=0,1, \ldots, 40$ and for $\delta=10^{-3} \AA$ and alternating between 5 steps of approximate and numerical refinement starting from $\mathbf{x}_{\text {spher }}$ (epoxide)

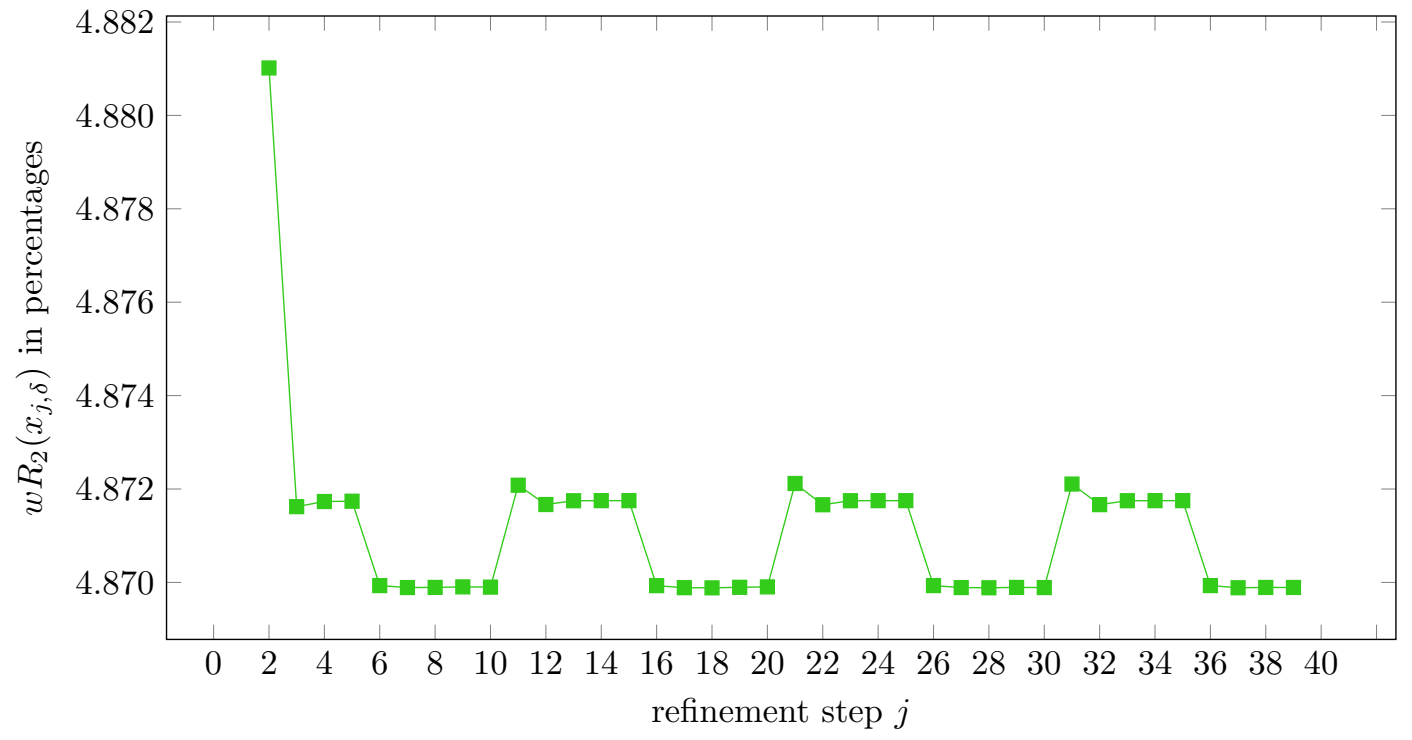

Figure S17: The progression of $w R_{2}\left(x_{j}\right)$ for $j=2,3, \ldots, 40$ and for $\delta=10^{-3} \AA$ and alternating between 5 steps of approximate and numerical refinement starting from $\mathbf{x}_{\text {spher }}$ (epoxide) 


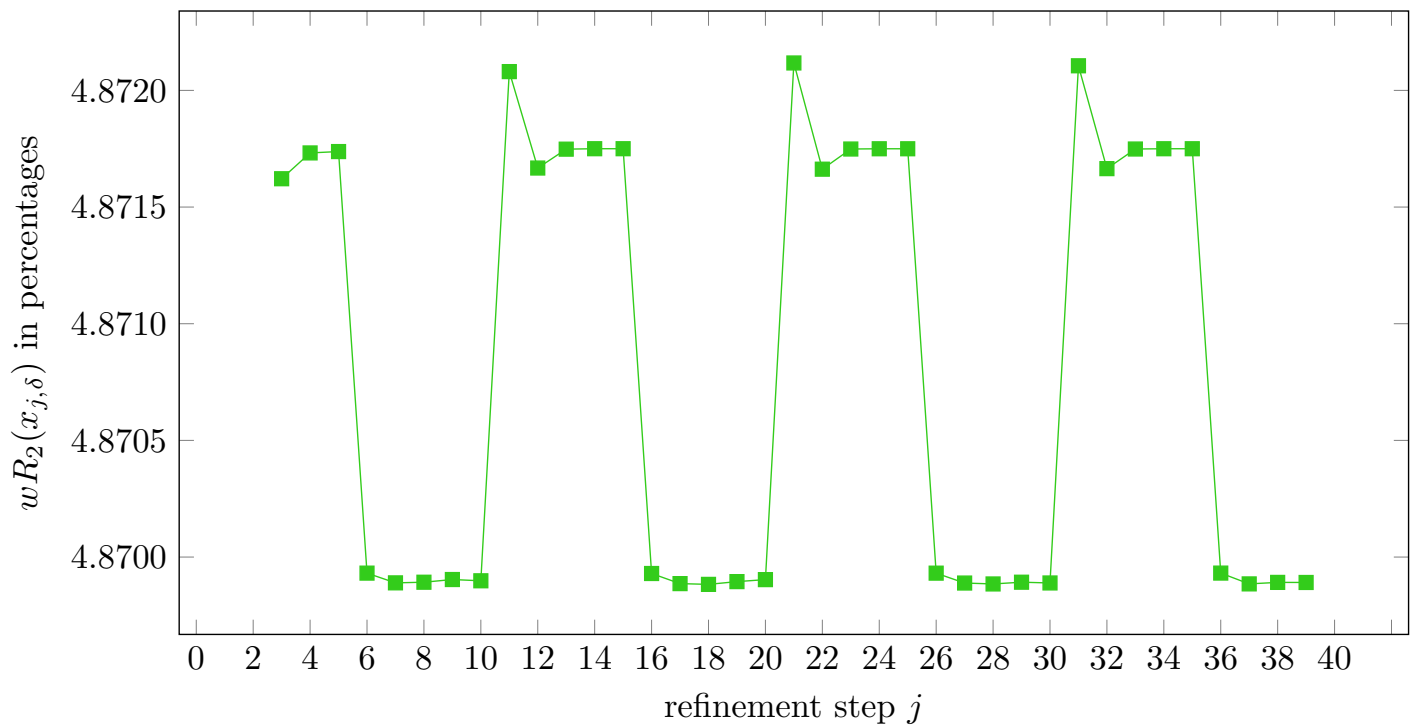

Figure S18: The progression of $w R_{2}\left(x_{j}\right)$ for $j=3,4, \ldots, 40$ and for $\delta=10^{-3} \AA$ and alternating between 5 steps of approximate and numerical refinement (epoxide) 


\section{4 wR2 diagrams (L-alanine)}

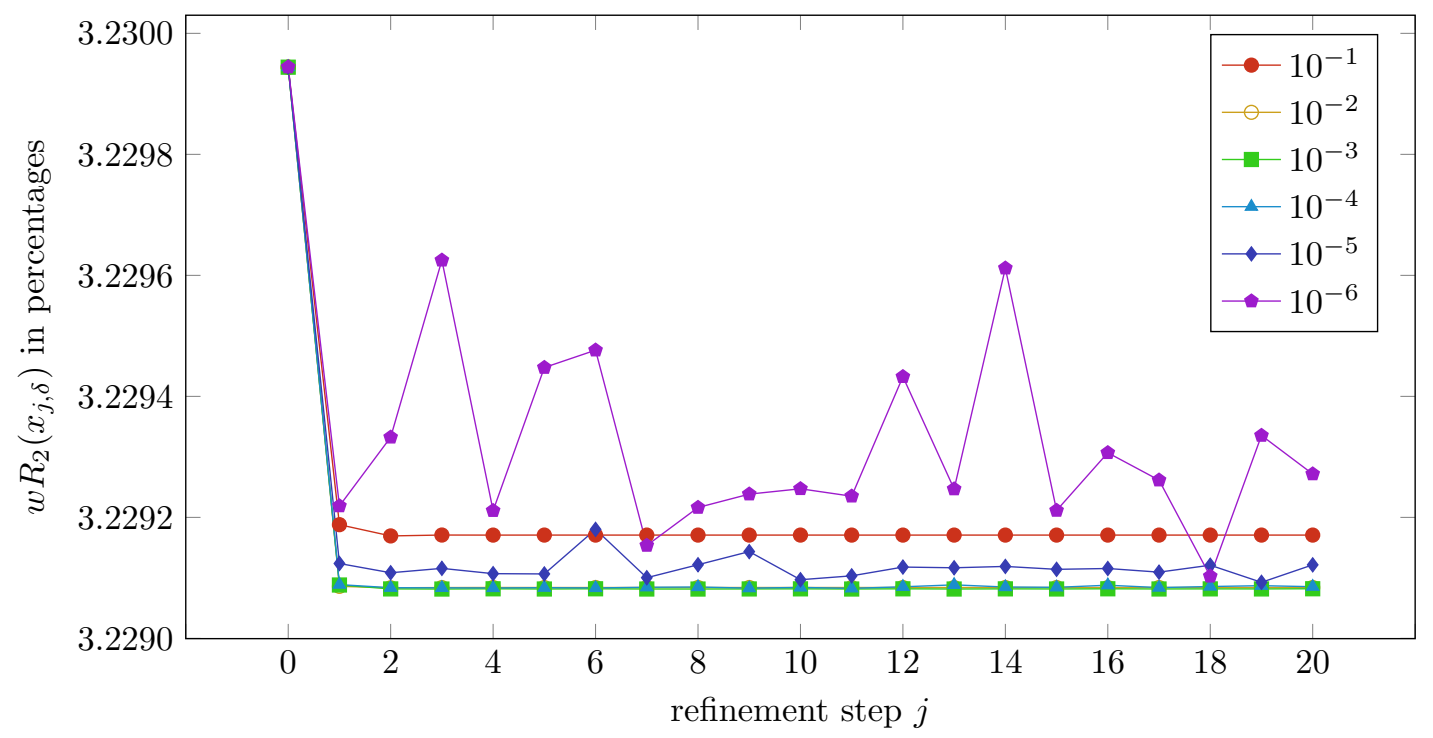

Figure S19: The progression of $w R_{2}\left(x_{j}\right)$ for $j=0,1, \ldots, 20$ and for $\delta=10^{-1}, \ldots, 10^{-6} \AA$ starting from $\mathbf{x}_{\mathrm{appr}}$ (L-alanine)

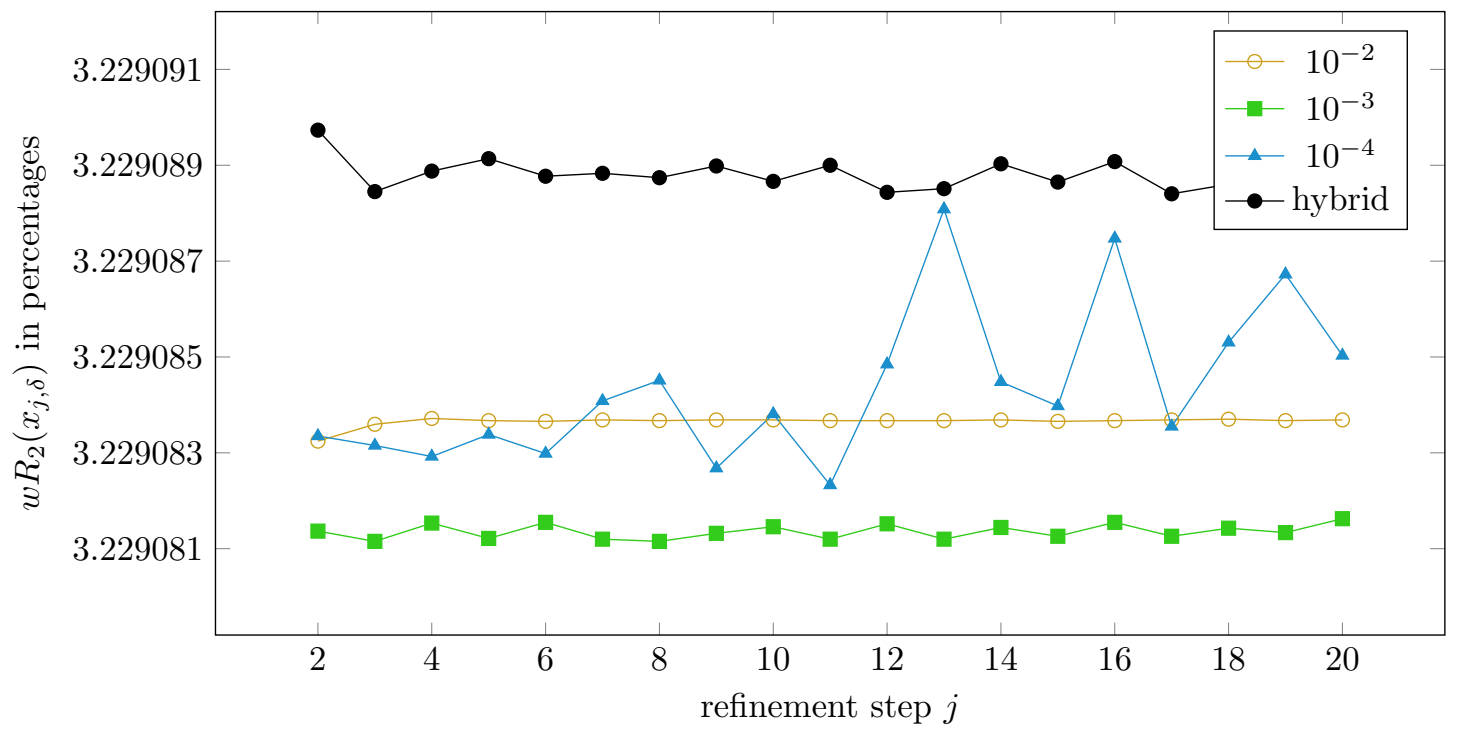

Figure S20: As in Figure S19; the progression of $w R_{2}\left(x_{j}\right)$ for $j=2,3, \ldots, 20$ and for $\delta=10^{-2} \AA, 10^{-3} \AA, \quad 10^{-4} \AA$, and hybrid at $\delta=10^{-3}$ starting from $\mathbf{x}_{\text {appr }}$ (L-alanine) 


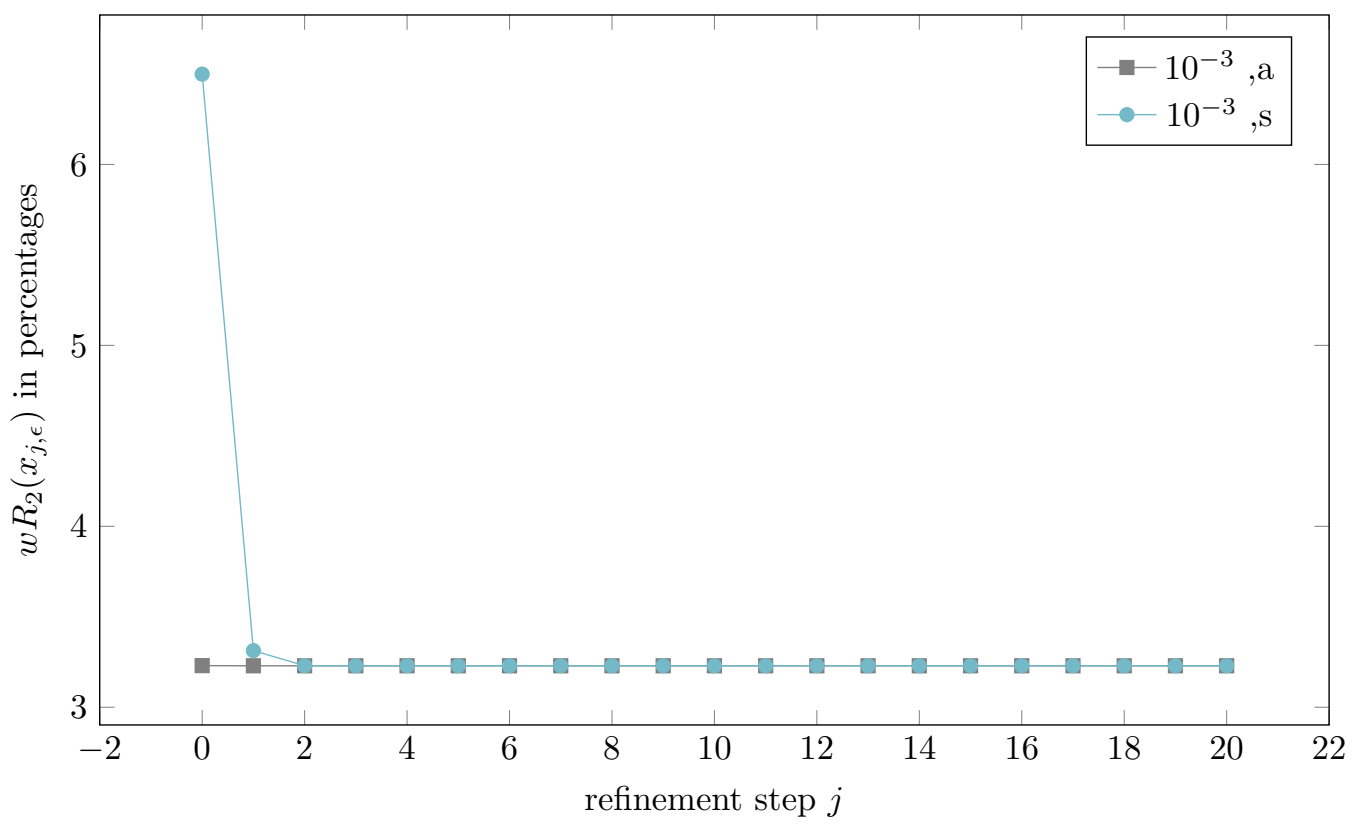

Figure S21: The progression of $w R_{2}\left(x_{j}\right)$ for $j=0,1, \ldots, 20$ and for $\delta=10^{-3} \AA$, with label "a" for refinement journey starting from $x_{\text {appr }}$ and label "s" starting from $x_{\text {spher }}$ - all $\mathrm{wR}_{2}$-factors are calculated with non-spherical form factors (L-alanine)

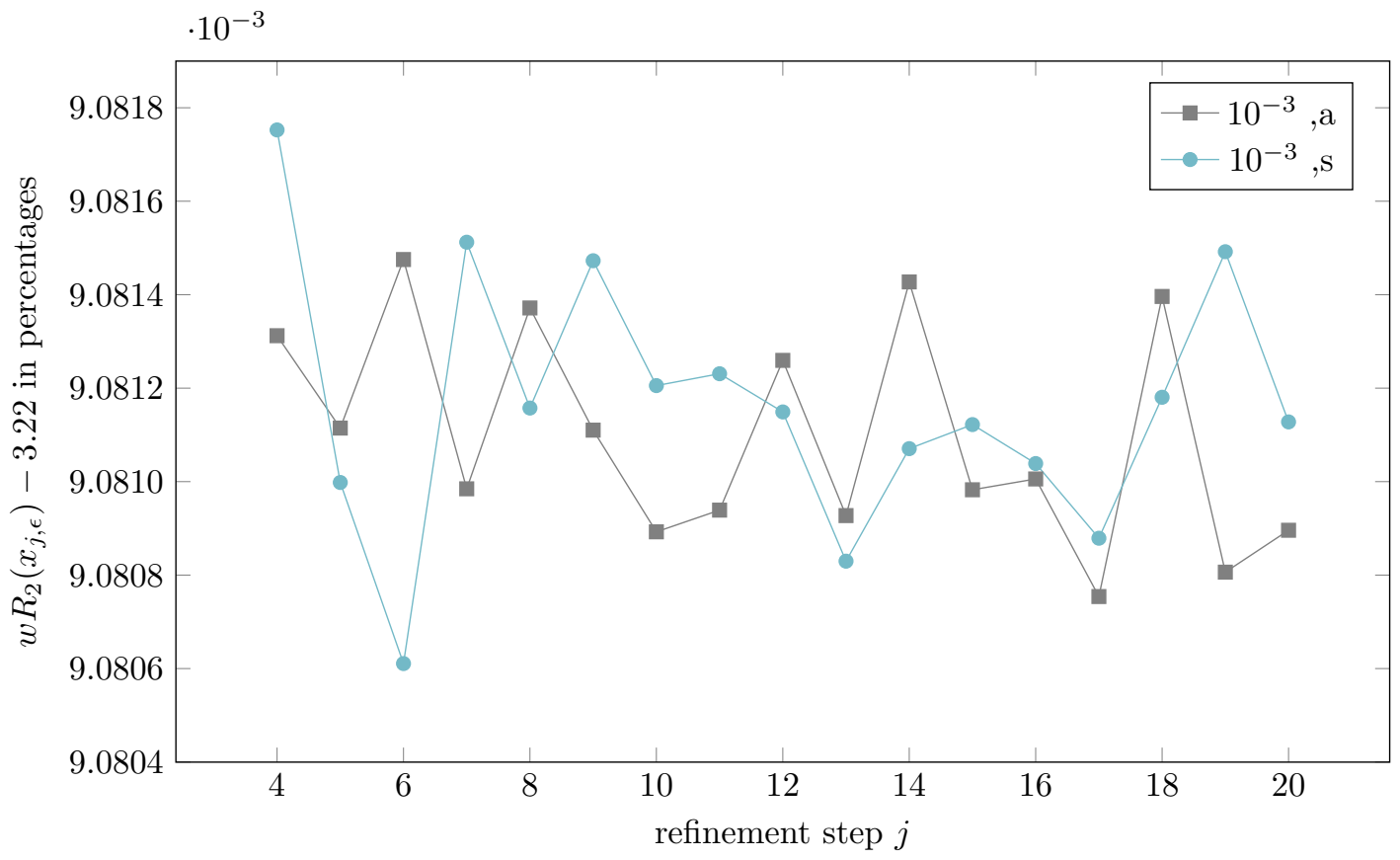

Figure S22: As in Figure S21; the progression of $w R_{2}\left(x_{j}\right)-3.22$ for $j=4,5, \ldots, 20$ and for $\delta=10^{-3} \AA$, with label "a" for refinement journey starting from $x_{\text {appr }}$ and label "s" starting from $x_{\text {spher }}$ (L-alanine) 


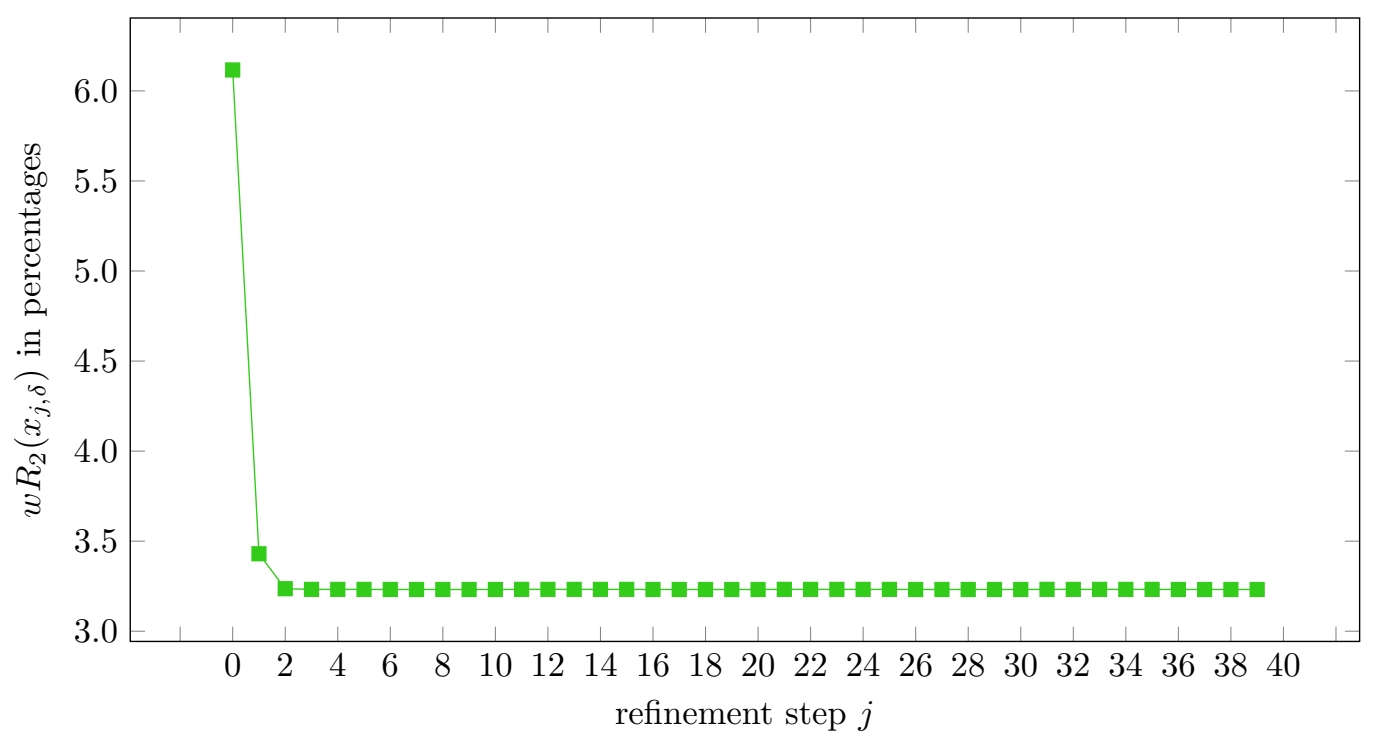

Figure S23: The progression of $w R_{2}\left(x_{j}\right)$ for $j=0,1, \ldots, 40$ and for $\delta=10^{-3} \AA$ and alternating between 5 steps of approximate and numerical refinement starting from $\mathbf{x}_{\text {spher }}$ (L-alanine)

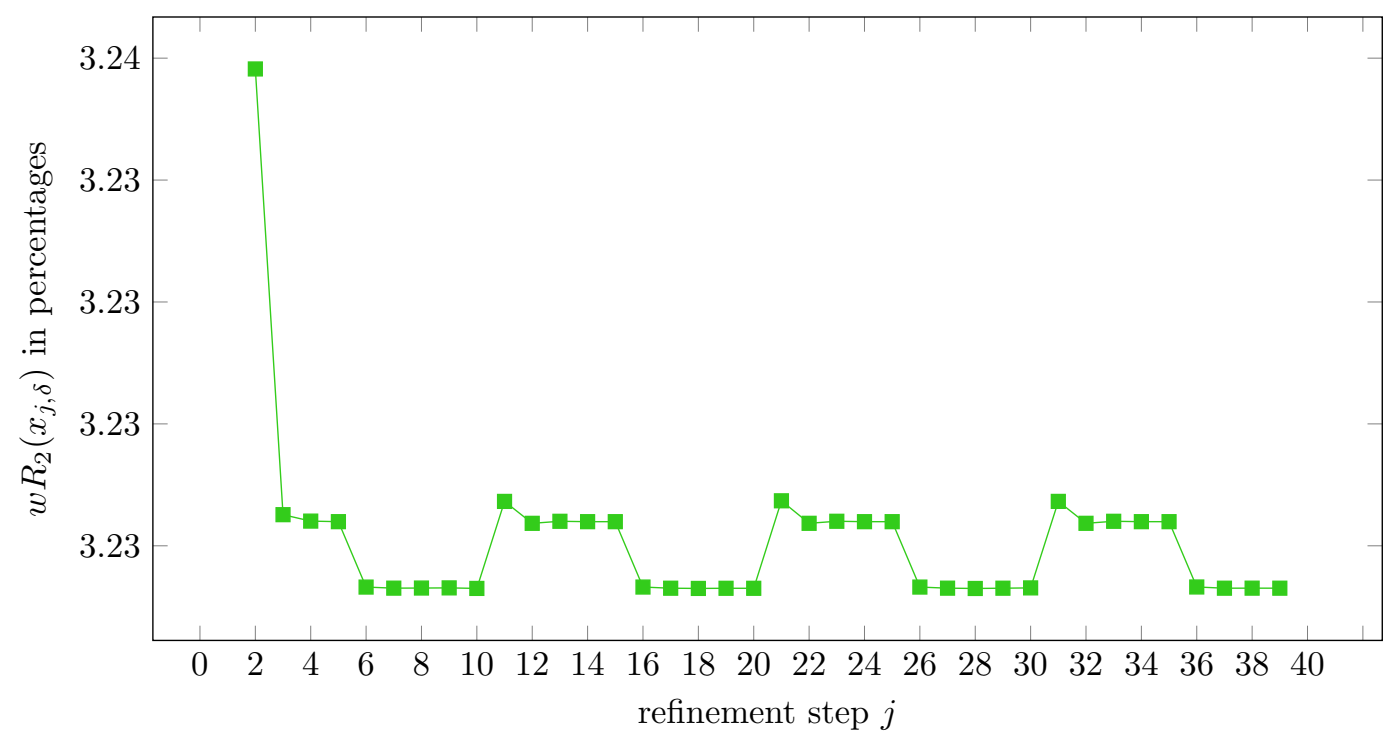

Figure S24: The progression of $w R_{2}\left(x_{j}\right)$ for $j=2,3, \ldots, 40$ and for $\delta=10^{-3} \AA$ and alternating between 5 steps of approximate and numerical refinement starting from $\mathbf{x}_{\text {spher }}$ (L-alanine) 


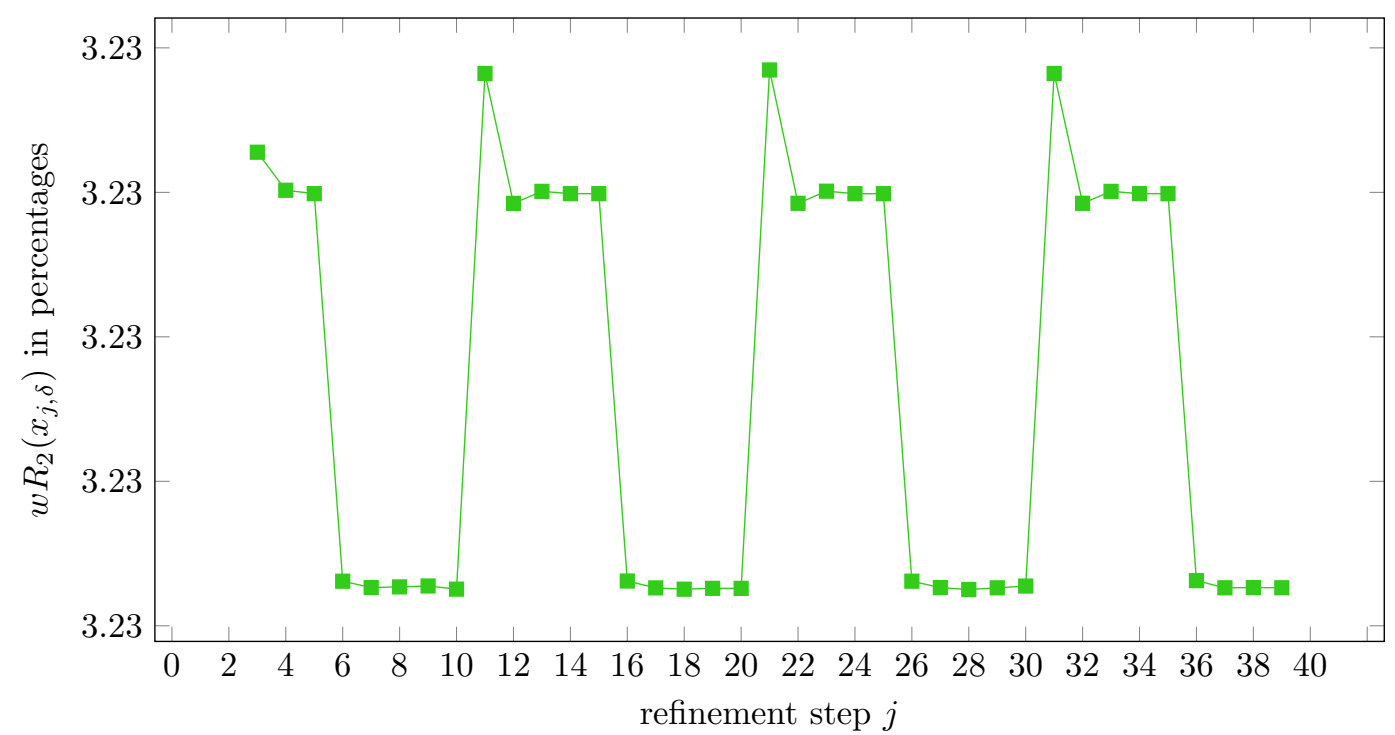

Figure S25: The progression of $w R_{2}\left(x_{j}\right)$ for $j=3,4, \ldots, 40$ and for $\delta=10^{-3} \AA$ and alternating between 5 steps of approximate and numerical refinement (L-alanine) 


\subsection{L-Alanine by TAAM}

Here we present the equivalent of Figures 5 and 6 for numerical non-spherical refinement of L-Alanine utilising DISCAMB rather than ORCA. The improvement from this refinement is smaller and more reliant on the correct choice of $\delta$, but nevertheless provides proof of the principle of numerical refinement beyond ORCA - both of the improvement that may be gained by correctly modelling these derivatives, and of the already present high accuracy of approximate non-spherical refinement.

Figure S26 shows the shift/esd for numerical refinement on L-Alanine via DISCAMB. In this case, $10^{-3}$ joins the other smaller $\delta$ as an unviable choice, but $\delta=10^{-1}$ and $10^{-2}$ remain viable.

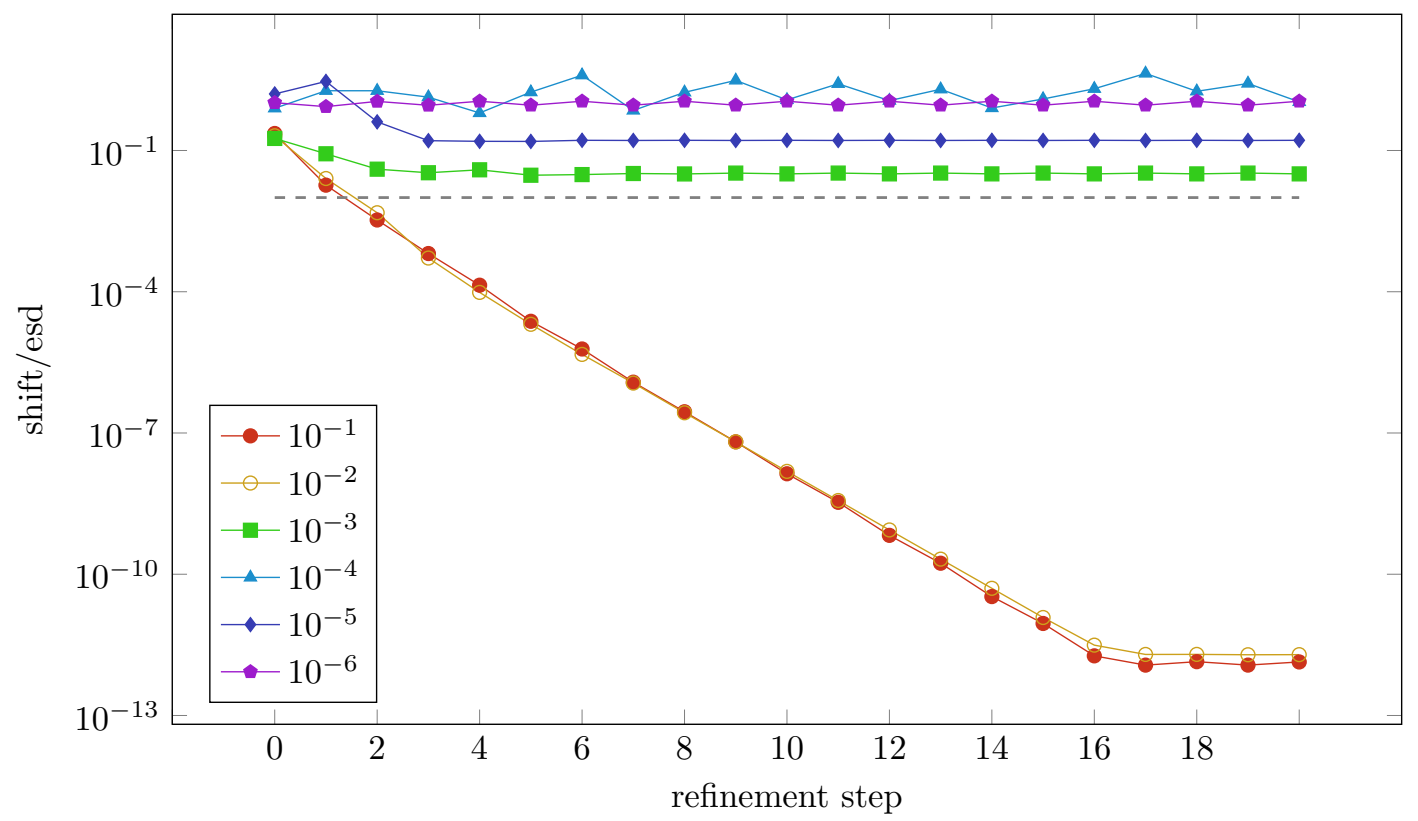

Figure S26: Maximal shift/esd for numerical refinement starting from $\mathbf{x}_{\text {appr }}$ for $\delta=10^{-1}, \ldots, 10^{-6} \AA$, (L-alanine via DISCAMB)

Figure S27 presents the progression of $w R_{2}$ for these tested $\delta$, but the instability of $\delta=10^{-4}, 10^{-5}$ and $10^{-6}$ prevents this diagram from presenting useful information. We look to S28 which shows that $\delta=10^{-2}$ and $10^{-3}$ provide the required drop to $w R_{2}$, and as $\delta=10^{-2}$ satisfies both, we find that our method remains effective. 


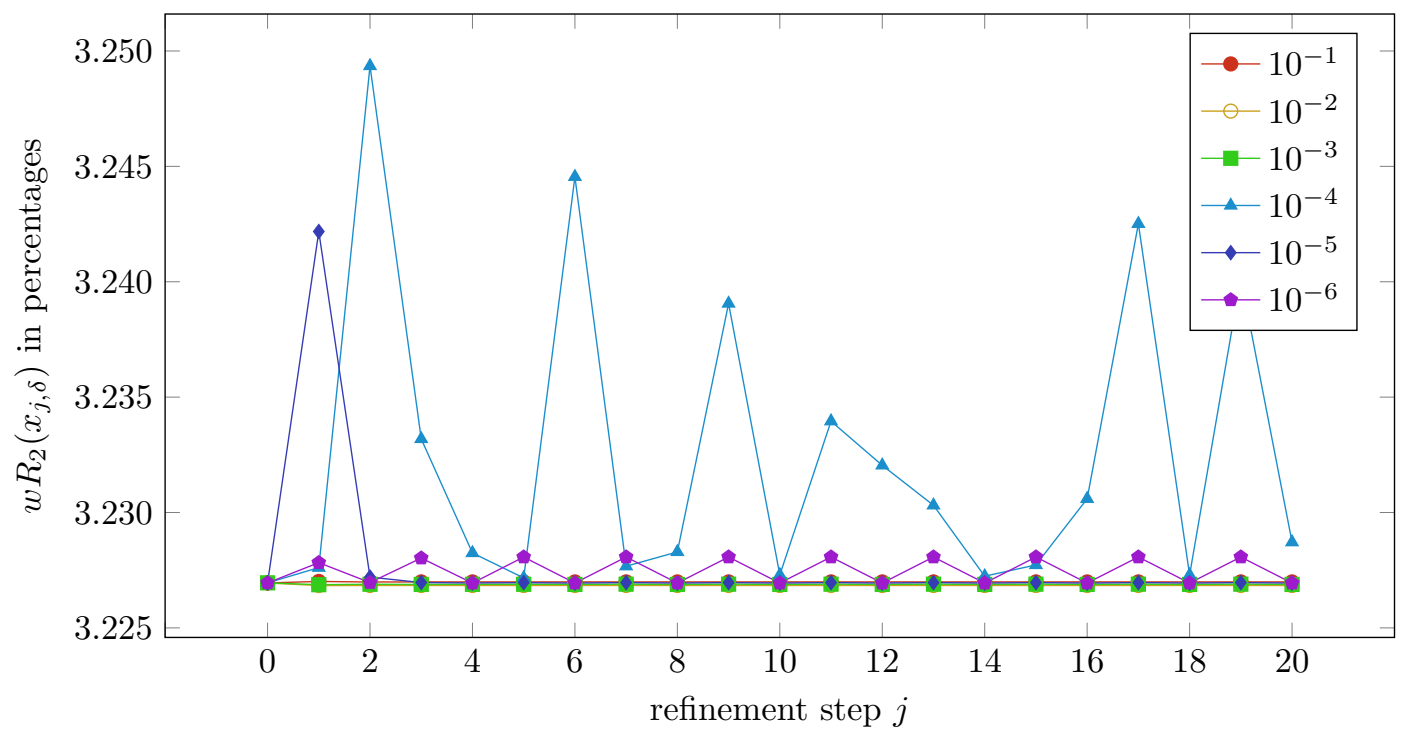

Figure S27: The progression of $w R_{2}\left(x_{j}\right)$ for $j=0,1, \ldots, 20$ and for $\delta=10^{-1}, \ldots, 10^{-6} \AA$ starting from $\mathbf{x}_{\text {appr }}$ (L-alanine via DISCAMB)

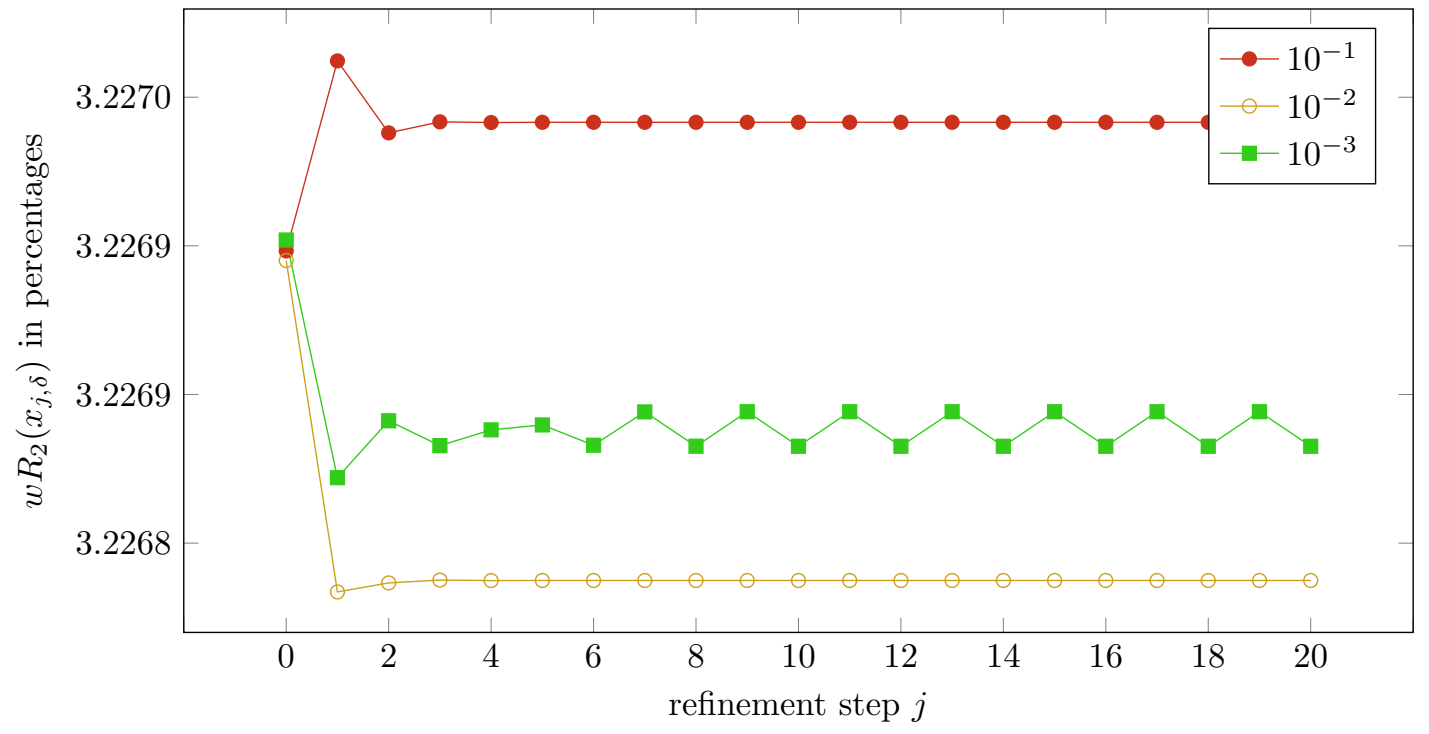

Figure S28: As in Figure S19; the progression of $w R_{2}\left(x_{j}\right)$ for $j=0,1, \ldots, 20$ and for $\delta=10^{-1} \AA, 10^{-2} \AA, 10^{-3} \AA$, starting from $\mathbf{x}_{\text {appr }}$ (L-alanine via DISCAMB) 


\subsection{Table 2}

We present an extended version of Table 2 of the main article. This contains details of which atom attains the largest difference between the two refinements (shown in brackets in each applicable column), as well as columns showing the largest Cartesian atomic shift. This confirms our statements that the difference between the two refinements (starting from $\mathbf{x}_{\text {spher }}$ and $\mathbf{x}_{\text {appr }}$ ) are about the same size as the maximal Cartesian shifts of the individual atoms from the model $\mathbf{x}_{k}$ to the model $\mathbf{x}_{k+1}$, from the 7 th step onward.

\begin{tabular}{|c|c|c|c|c|c|c|c|}
\hline step & $\begin{array}{r}\text { shift/esd } \\
\left(\times 10^{5}\right) \\
\left.\text { (from } \mathbf{x}_{\text {spher }}\right) \\
\end{array}$ & $\begin{array}{r}\text { shift/esd } \\
\left(\times 10^{5}\right) \\
\left(\text { from } \mathbf{x}_{\text {appr }}\right) \\
\end{array}$ & $\begin{array}{c}w_{2} \\
\text { (from } \mathbf{x}_{\text {spher }} \text { ) }\end{array}$ & $\begin{array}{c}w R_{2} \\
\text { (from } \mathbf{x}_{\text {appr }} \text { ) }\end{array}$ & $\begin{array}{r}\text { maximal atomic } \\
\text { distance } \\
\left(\text { in } 10^{-6} \AA\right) \\
\end{array}$ & $\begin{array}{r}\text { maximal Cartesian } \\
\text { atomic shift } \\
\left(\text { in } 10^{-6} \AA\right) \\
\left(\text { from } \mathbf{x}_{\text {spher }}\right)\end{array}$ & $\begin{array}{r}\text { maximal Cartesian } \\
\text { atomic shift } \\
\left(\text { in } 10^{-6} \AA\right) \\
\left(\text { from } \mathbf{x}_{\text {appr }}\right)\end{array}$ \\
\hline \multicolumn{8}{|l|}{ Ammonia } \\
\hline $\mathrm{k}=0$ & 392693 & 143955 & $9.2821 \%$ & $1.9440 \%$ & $126974(\mathrm{H})$ & - & - \\
\hline $\mathrm{k}=1$ & 198189 & 18797 & $2.6092 \%$ & $1.9180 \%$ & $20665(\mathrm{H})$ & $115659(\mathrm{H})$ & $9355(\mathrm{H})$ \\
\hline$k=2$ & 47387 & 2818 & $1.9216 \%$ & $1.9176 \%$ & $2458(\mathrm{H})$ & $21309(\mathrm{H})$ & $981(\mathrm{H})$ \\
\hline$k=3$ & 7724 & 760 & $1.9176 \%$ & $1.9176 \%$ & $380(\mathrm{H})$ & $2457(\mathrm{H})$ & $168(\mathrm{H})$ \\
\hline$k=4$ & 1823 & 324 & $1.9175 \%$ & $1.9176 \%$ & $102(\mathrm{H})$ & $420(\mathrm{H})$ & $44(\mathrm{H})$ \\
\hline$k=5$ & 592 & 142 & $1.9176 \%$ & $1.9176 \%$ & $36(\mathrm{H})$ & $127(\mathrm{H})$ & $15(\mathrm{H})$ \\
\hline $\mathrm{k}=6$ & 140 & 78 & $1.9176 \%$ & $1.9176 \%$ & $11(\mathrm{H})$ & $35(\mathrm{H})$ & $7(\mathrm{H})$ \\
\hline$k=7 \ldots 20$ & $\leq 88$ & $\leq 119$ & $1.9176 \%$ & $1.9176 \%$ & $\leq 5(\mathrm{H})$ & $\leq 8(\mathrm{H})$ & $\leq 6(\mathrm{H})$ \\
\hline \multicolumn{8}{|l|}{ Epoxide } \\
\hline $\mathrm{k}=0$ & 674626 & 51117 & $12.0375 \%$ & $4.6551 \%$ & $130527(\mathrm{H} 3 \mathrm{a})$ & - & - \\
\hline$k=1$ & 281762 & 4568 & $4.9113 \%$ & $4.6536 \%$ & $21095(\mathrm{H} 2 \mathrm{~b})$ & $124253(\mathrm{H3a})$ & 4694 (н3а) \\
\hline $\mathrm{k}=2$ & 35810 & 812 & $4.6561 \%$ & $4.6536 \%$ & 3093 (НЗа) & 21697 (Н3b) & 321 (н3а) \\
\hline$k=3$ & 6868 & 476 & $4.6537 \%$ & $4.6536 \%$ & 461 (H3b) & $2653(\mathrm{H3a})$ & $80(\mathrm{H} 3 \mathrm{a})$ \\
\hline $\mathrm{k}=4$ & 1365 & 152 & $4.6536 \%$ & $4.6536 \%$ & 136 (Н3а) & $458($ (H3b) & 45 (H3a) \\
\hline$k=5$ & 292 & 88 & $4.6536 \%$ & $4.6536 \%$ & 38 (н3а) & $93($ (н3а) & 12 (H2b) \\
\hline$k=6$ & 138 & 102 & $4.6536 \%$ & $4.6536 \%$ & $16($ (н3b) & 27 (н3a) & 9 (Н3b) \\
\hline$k=7 \ldots 20$ & $\leq 99$ & $\leq 126$ & $4.6536 \%$ & $4.6536 \%$ & $\leq 11(\mathrm{H} 3 \mathrm{~b})$ & $\leq 12(\mathrm{H} 3 \mathrm{a})$ & $\leq 13$ (H3b) \\
\hline \multicolumn{8}{|l|}{ L-Alanine } \\
\hline $\mathrm{k}=0$ & 992154 & 50245 & $6.4989 \%$ & $3.2299 \%$ & $126479(\mathrm{H} 2 \mathrm{~b})$ & - & - \\
\hline $\mathrm{k}=1$ & 308603 & 3568 & $3.3127 \%$ & $3.2291 \%$ & $24140(\mathrm{H} 1 \mathrm{a})$ & $110776(\mathrm{H} 2 \mathrm{~b})$ & $4802(\mathrm{H} 1 \mathrm{C})$ \\
\hline $\mathrm{k}=2$ & 32231 & 641 & $3.2298 \%$ & $3.2291 \%$ & $1818(\mathrm{H} 1 \mathrm{a})$ & 22253 (H1a) & 172 (H1a) \\
\hline $\mathrm{k}=3$ & 7711 & 244 & $3.2291 \%$ & $3.2291 \%$ & 237 (H1c) & $1655(\mathrm{H} 1 \mathrm{a})$ & $18(\mathrm{H} 1 \mathrm{~b})$ \\
\hline$k=4$ & 1838 & 176 & $3.2291 \%$ & $3.2291 \%$ & $59(\mathrm{H} 1 \mathrm{~b})$ & $194(\mathrm{H} 1 \mathrm{C})$ & 19 (H1b) \\
\hline$k=5$ & 431 & 202 & $3.2291 \%$ & $3.2291 \%$ & 20 (H1b) & $50(\mathrm{H} 1 \mathrm{~b})$ & $13(\mathrm{H} 1 \mathrm{c})$ \\
\hline $\mathrm{k}=6$ & 214 & 194 & $3.2291 \%$ & $3.2291 \%$ & $16(\mathrm{H} 1 \mathrm{~b})$ & 16 (H1b) & 14(H1c) \\
\hline$k=7 \ldots 20$ & $\leq 190$ & $\leq 267$ & $3.2291 \%$ & $3.2291 \%$ & $\leq 14(\mathrm{H} 1 \mathrm{a})$ & $\leq 19(\mathrm{H} 1 \mathrm{~b})$ & $\leq 14(\mathrm{H} 1 \mathrm{a})$ \\
\hline
\end{tabular}

Table S2: Progression of refinement values from $\mathbf{x}_{\text {spher }}$ and $\mathbf{x}_{\text {appr }}$ via numerical nonspherical refinement with $\delta=10^{-3} \AA$. In the first two columns, if the shift/esd is below 0.01, it is colored green, else red. The 3rd last column represents the maximal distance between sites of corresponding atoms through numerical nonspherical refinement from these two start points, whilst the last two columns represent the maximal Cartesian atomic shift within the given refinement path. 


\section{Comparison of refinement minima}

\subsection{Basis set dependence}

The following Figures S29 and S30 add in the 'High' integration grid (shown as a lightened colour) and the 'Low' integration grid (shown as a darkened colour) to Figure 8 from the main paper. It is clear that the impact of these is minimal compared to the other differences

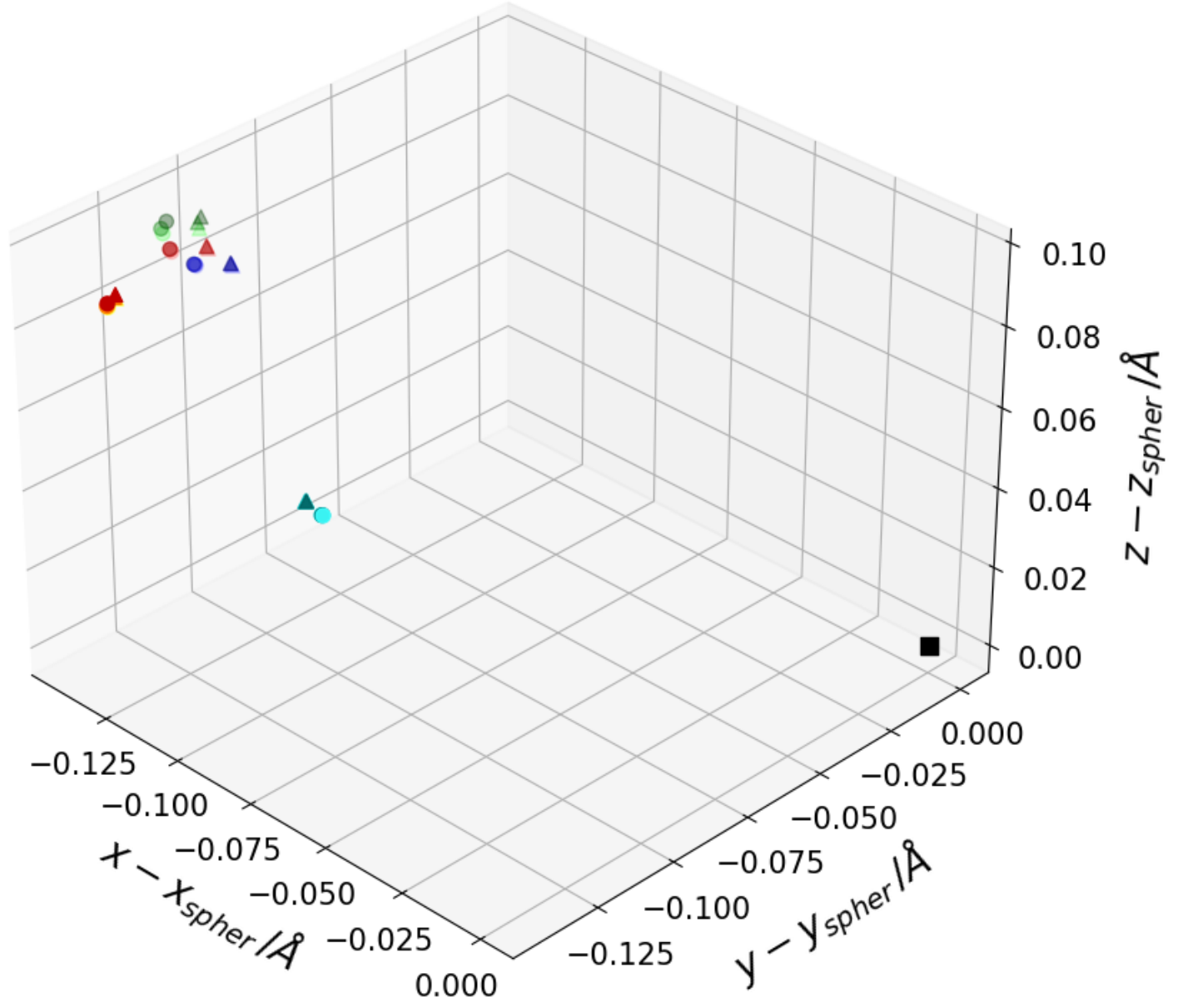

Figure S29: The position of the hydrogen atom (in $\AA$ ) at the final model, obtained through classical spherical refinement ( $\mathbf{\square})$ and non-spherical refinement processes (approximate $\boldsymbol{\Delta}$ and numerical $\bullet$ ) using various basis sets, where the hydrogen atom in the classical spherical model is shifted to the origin $(0,0,0)$.

The colours are as follows: cc-pVQZ (top), cc-pVTZ (second-top), def2-TZVP (third top), 3-21G (lower cluster), def2-SVP (left cluster), with darkened and lightened versions of these colours corresponding to 'low' or 'high' rather than 'normal' integration accuracy, respectively. (ammonia) 


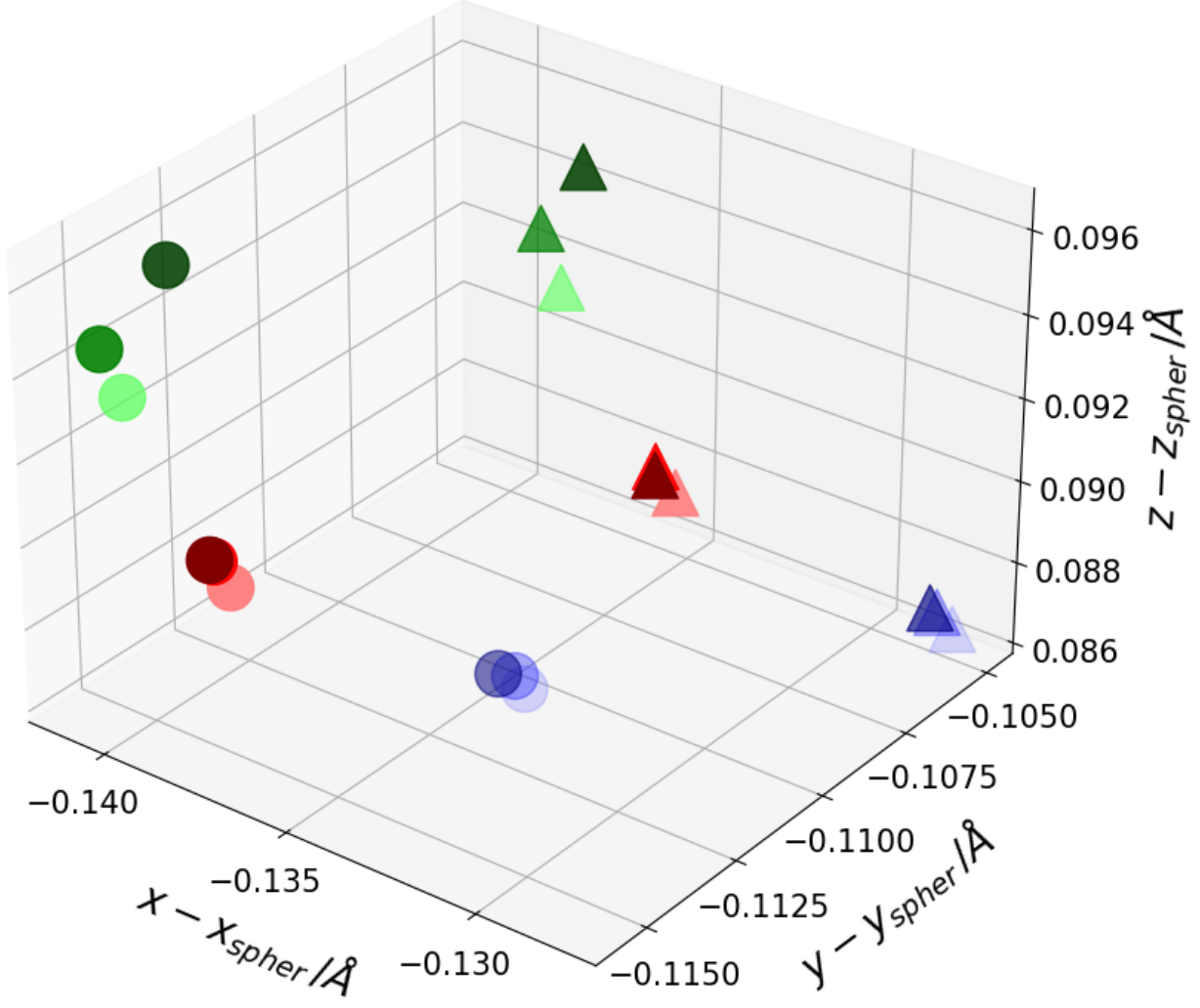

Figure S30: A small area of Figure S29: The position of the hydrogen atom at the final model, obtained with the larger three basis sets, cc-pVQZ (top), cc-pVTZ (middle), def2-TZVP (bottom), relative to the position of the hydrogen in the classical spherical model (which would appear at $(0,0,0)$ ). (ammonia) 


\section{$5 \quad$ Bringing In Uncertainties}

We present the uncertainty ball diagrams for all atoms of our three molecules, with diagrams comparing the ADPs in a matching fashion. Tables providing the uncertainty radii are presented alongside the relevant diagrams. In all cases, the white dot represents the numerical nonspherical refinement's final model, the black dot represents the approximate nonspherical refinement's final model, the red dot represents the spherical final model.

\subsection{Ammonia}
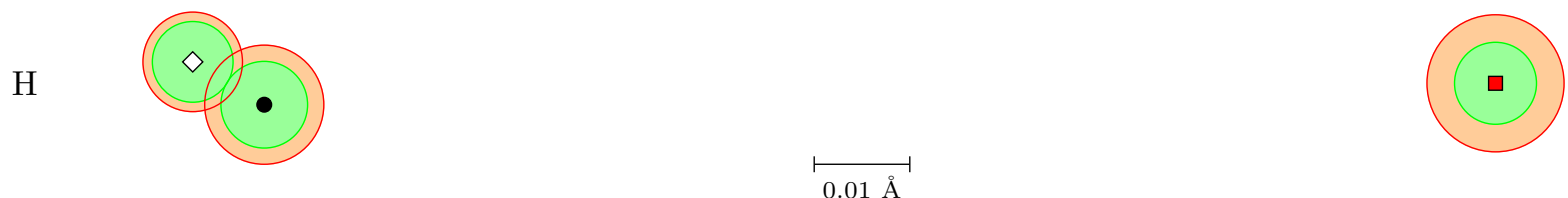

Figure S31: Positions of the hydrogen atoms in $\mathbf{x}_{\text {num }}$ (white $\left.\diamond\right), \mathbf{x}_{\text {appr }}$ (black $\bullet$ ) and $\mathbf{x}_{\text {spher }}($ red $\boldsymbol{\nabla})$, and their uncertainty balls. Green balls represent inner uncertainty balls and red balls represent outer uncertainty balls. (ammonia)
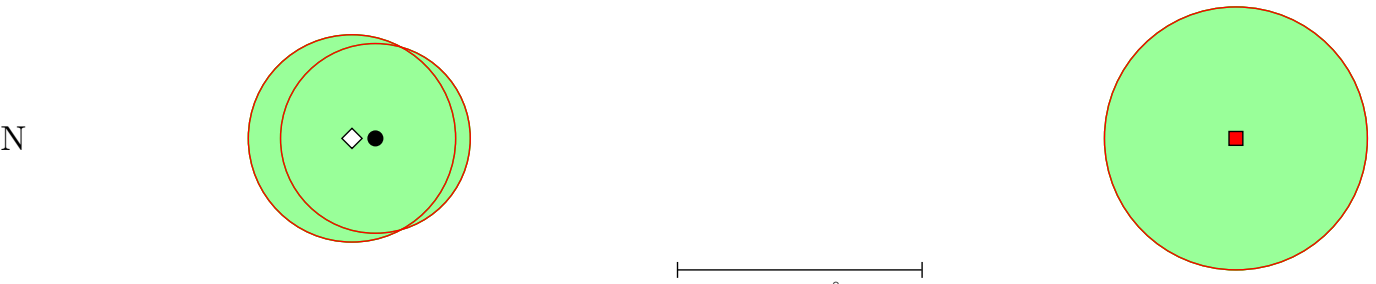

$0.001 \AA$

Figure S32: Positions of the non-hydrogen atoms in $\mathbf{x}_{\text {num }}($ white $\diamond), \mathbf{x}_{\text {appr }}$ (black $\bullet$ ) and $\mathbf{x}_{\text {spher }}($ red $\boldsymbol{\square})$, and their uncertainty balls. Green balls represent inner uncertainty balls and red balls represent outer uncertainty balls. (ammonia)

\begin{tabular}{c|c|cccc} 
& $\left\|A_{\text {num }}-A_{\text {spher }}\right\|$ & $r\left(A_{\text {num }}\right)$ & $R\left(A_{\text {num }}\right)$ & $r\left(A_{\text {spher }}\right)$ & $R\left(A_{\text {spher }}\right)$ \\
\hline $\mathrm{A}=\mathrm{N}$ & $3.592 \mathrm{e}-03$ & $4.214 \mathrm{e}-04$ & $4.214 \mathrm{e}-04$ & $5.344 \mathrm{e}-04$ & $5.344 \mathrm{e}-04$ \\
$\mathrm{~A}=\mathrm{H}$ & $1.343 \mathrm{e}-01$ & $4.160 \mathrm{e}-03$ & $5.131 \mathrm{e}-03$ & $4.225 \mathrm{e}-03$ & $7.067 \mathrm{e}-03$ \\
\hline \hline & $\left\|A_{\text {num }}-A_{\text {appr }}\right\|$ & $r\left(A_{\text {num }}\right)$ & $R\left(A_{\text {num }}\right)$ & $r\left(A_{\text {appr }}\right)$ & $R\left(A_{\text {appr }}\right)$ \\
\hline $\mathrm{A}=\mathrm{N}$ & $9.513 \mathrm{e}-05$ & $4.214 \mathrm{e}-04$ & $4.214 \mathrm{e}-04$ & $3.856 \mathrm{e}-04$ & $3.856 \mathrm{e}-04$ \\
$\mathrm{~A}=\mathrm{H}$ & $8.598 \mathrm{e}-03$ & $4.160 \mathrm{e}-03$ & $5.131 \mathrm{e}-03$ & $4.468 \mathrm{e}-03$ & $6.141 \mathrm{e}-03$
\end{tabular}

Table S3: Positional difference (in $\AA$ ) between atoms in $\mathbf{x}_{\mathrm{num}}, \mathbf{x}_{\mathrm{appr}}$, and $\mathbf{x}_{\mathrm{spher}}$ and their comparison with uncertainty bounds. Red indicates a bound smaller than the difference, whilst green represents a bound larger than the difference (ammonia). 
H
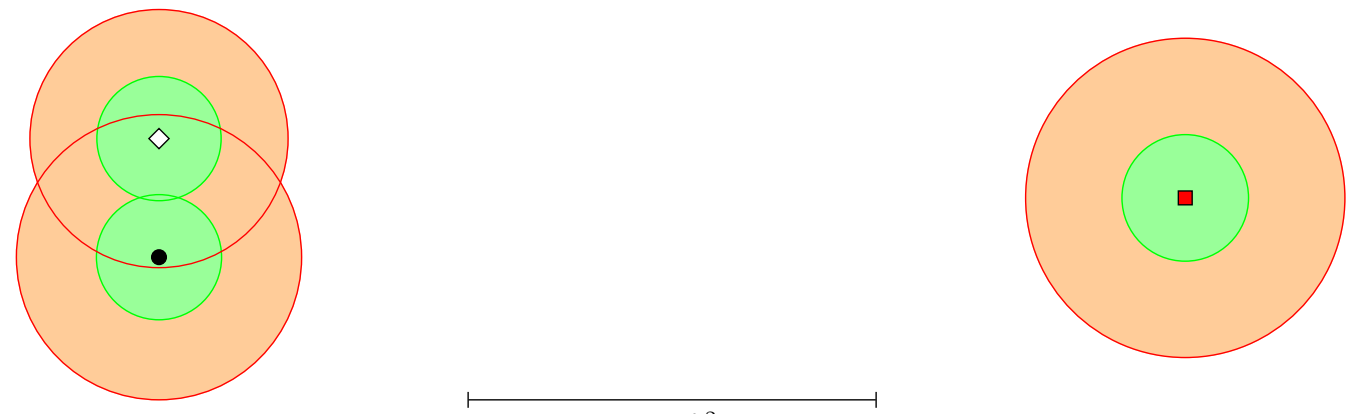

$0.01 \AA^{2}$

Figure S33: ADPs of the hydrogen atoms in $\mathbf{x}_{\text {num }}$ (white $\left.\diamond\right), \mathbf{x}_{\text {appr }}$ (black $\bullet$ ) and $\mathbf{x}_{\text {spher }}$ (red $\boldsymbol{\square}$ ), and their uncertainty balls. Green balls represent inner uncertainty balls and red balls represent outer uncertainty balls. (ammonia)

$\mathrm{N}$
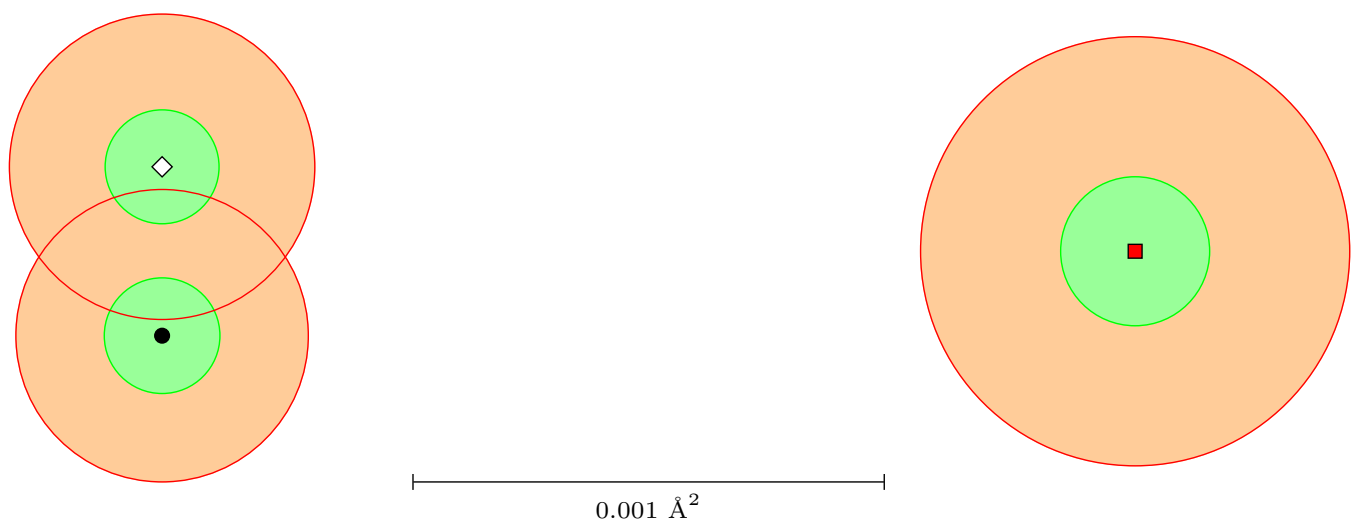

Figure S34: ADPs of the non-hydrogen atoms in $\mathbf{x}_{\text {num }}($ white $\diamond), \mathbf{x}_{\text {appr }}$ (black $\bullet$ ) and $\mathbf{x}_{\text {spher }}$ (red $\left.\boldsymbol{\square}\right)$, and their uncertainty balls. Green balls represent inner uncertainty balls and red balls represent outer uncertainty balls. (ammonia) 


\begin{tabular}{c|c|cccc} 
& $\left\|A_{\text {num }}-A_{\text {spher }}\right\|$ & $r\left(A_{\text {num }}\right)$ & $R\left(A_{\text {num }}\right)$ & $r\left(A_{\text {spher }}\right)$ & $R\left(A_{\text {spher }}\right)$ \\
\hline $\mathrm{A}=\mathrm{N}$ & $1.972 \mathrm{e}-03$ & $1.205 \mathrm{e}-04$ & $3.230 \mathrm{e}-04$ & $1.576 \mathrm{e}-04$ & $4.539 \mathrm{e}-04$ \\
$\mathrm{~A}=\mathrm{H}$ & $2.536 \mathrm{e}-02$ & $1.517 \mathrm{e}-03$ & $3.153 \mathrm{e}-03$ & $1.546 \mathrm{e}-03$ & $3.899 \mathrm{e}-03$ \\
\hline \hline & $\left\|A_{\text {num }}-A_{\text {appr }}\right\|$ & $r\left(A_{\text {num }}\right)$ & $R\left(A_{\text {num }}\right)$ & $r\left(A_{\text {appr }}\right)$ & $R\left(A_{\text {appr }}\right)$ \\
\hline $\mathrm{A}=\mathrm{N}$ & $3.572 \mathrm{e}-04$ & $1.205 \mathrm{e}-04$ & $3.230 \mathrm{e}-04$ & $1.223 \mathrm{e}-04$ & $3.093 \mathrm{e}-04$ \\
$\mathrm{~A}=\mathrm{H}$ & $2.896 \mathrm{e}-03$ & $1.517 \mathrm{e}-03$ & $3.153 \mathrm{e}-03$ & $1.529 \mathrm{e}-03$ & $3.483 \mathrm{e}-03$
\end{tabular}

Table S4: ADP difference (in $\AA^{2}$ ) between atoms in $\mathbf{x}_{\text {num }}, \mathbf{x}_{\text {appr }}$, and $\mathbf{x}_{\text {spher }}$ and their comparison with uncertainty bounds. Red indicates a bound smaller than the difference, whilst green represents a bound larger than the difference (ammonia). 


\subsection{Epoxide}

$\mathrm{H} 3 \mathrm{~b}$
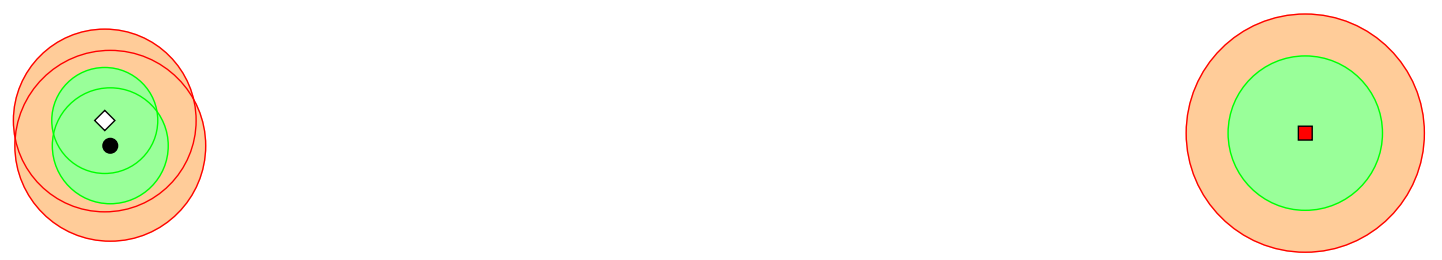

H3a
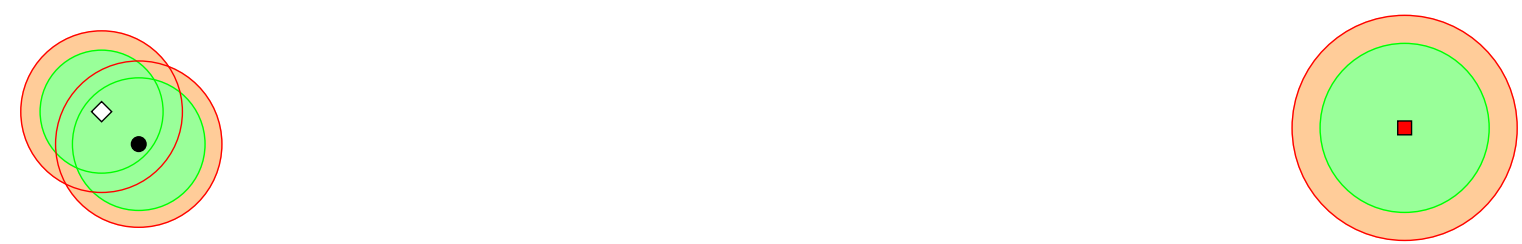

$\mathrm{H} 2 \mathrm{~b}$

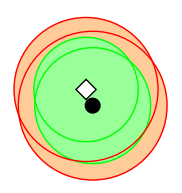

$\stackrel{\longmapsto}{ } \AA$

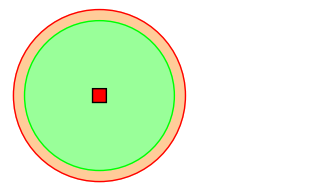

$\mathrm{H} 2 \mathrm{a}$
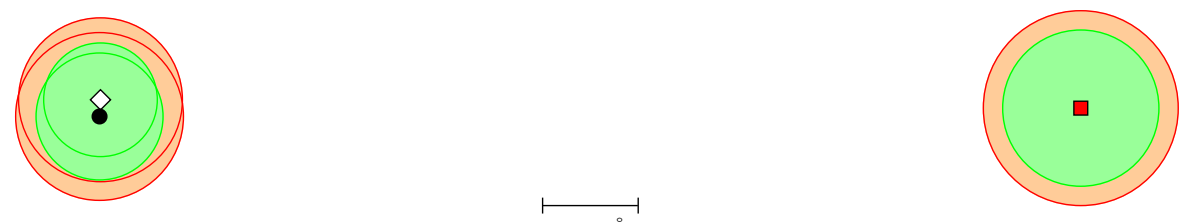

Figure S35: Positions of the hydrogen atoms in $\mathbf{x}_{\text {num }}$ (white $\diamond$ ), $\mathbf{x}_{\text {appr }}$ (black $\bullet$ ) and $\mathbf{x}_{\text {spher }}$ (red $\boldsymbol{\square}$ ), and their uncertainty balls. Green balls represent inner uncertainty balls and red balls represent outer uncertainty balls. (epoxide) 
$\mathrm{C} 3$
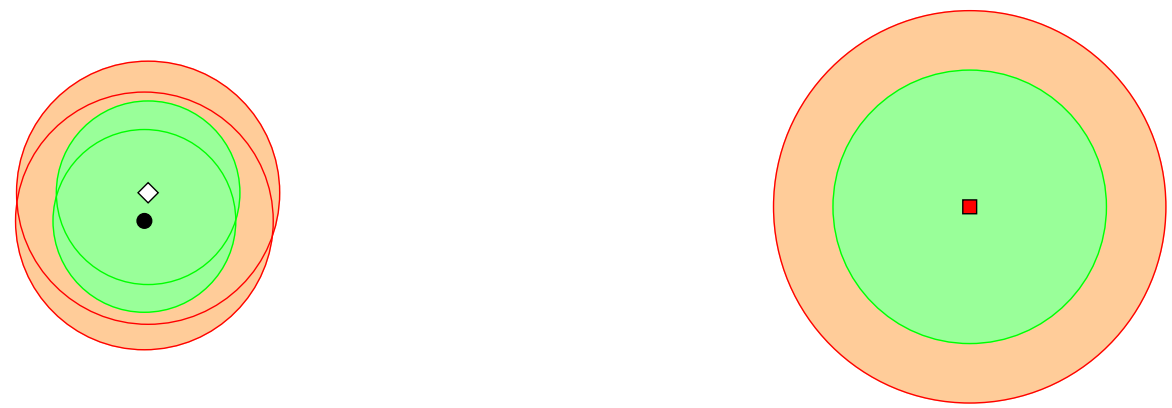

$\mathrm{C} 2$
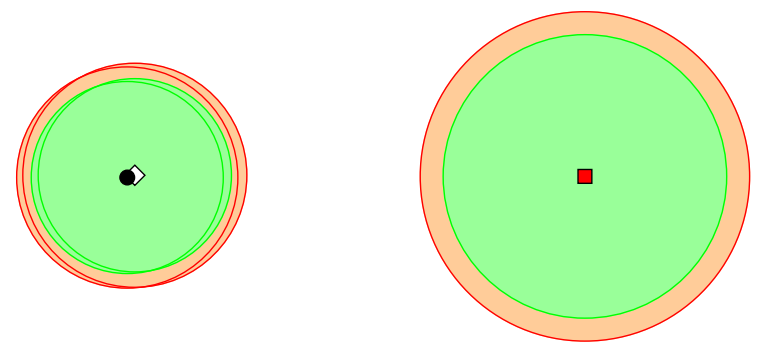

O1
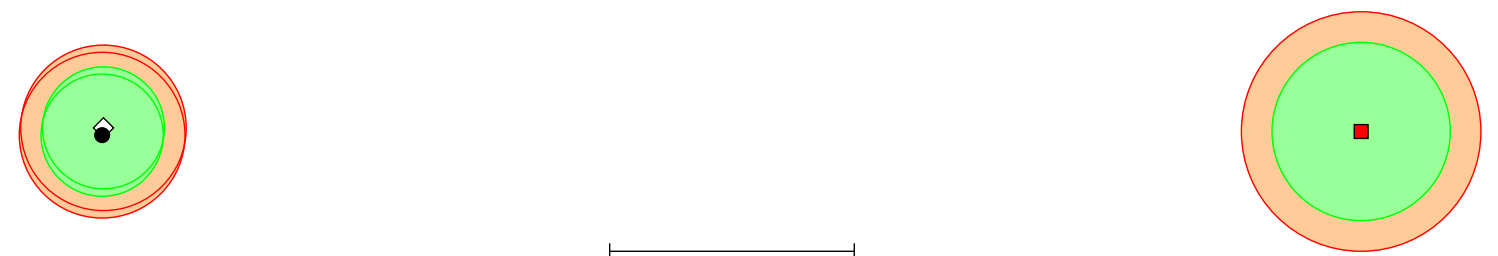

$0.001 \AA$

Figure S36: Positions of the non-hydrogen atoms in $\mathbf{x}_{\text {num }}($ white $\diamond), \mathbf{x}_{\text {appr }}$ (black $\bullet$ ) and $\mathbf{x}_{\text {spher }}($ red $\mathbf{\square})$, and their uncertainty balls. Green balls represent inner uncertainty balls and red balls represent outer uncertainty balls. (epoxide)

\begin{tabular}{c|c|cccc} 
& $\left\|A_{\text {num }}-A_{\text {spher }}\right\|$ & $r\left(A_{\text {num }}\right)$ & $R\left(A_{\text {num }}\right)$ & $r\left(A_{\text {spher }}\right)$ & $R\left(A_{\text {spher }}\right)$ \\
\hline $\mathrm{A}=\mathrm{O} 1$ & $5.112 \mathrm{e}-03$ & $2.479 \mathrm{e}-04$ & $3.363 \mathrm{e}-04$ & $3.624 \mathrm{e}-04$ & $4.868 \mathrm{e}-04$ \\
$\mathrm{~A}=\mathrm{C} 2$ & $1.829 \mathrm{e}-03$ & $3.928 \mathrm{e}-04$ & $4.554 \mathrm{e}-04$ & $5.763 \mathrm{e}-04$ & $6.695 \mathrm{e}-04$ \\
$\mathrm{~A}=\mathrm{H} 2 \mathrm{a}$ & $1.011 \mathrm{e}-01$ & $5.859 \mathrm{e}-03$ & $8.449 \mathrm{e}-03$ & $8.055 \mathrm{e}-03$ & $1.005 \mathrm{e}-02$ \\
$\mathrm{~A}=\mathrm{H} 2 \mathrm{~b}$ & $1.131 \mathrm{e}-01$ & $5.380 \mathrm{e}-03$ & $7.425 \mathrm{e}-03$ & $7.726 \mathrm{e}-03$ & $8.868 \mathrm{e}-03$ \\
$\mathrm{~A}=\mathrm{C} 3$ & $3.340 \mathrm{e}-03$ & $3.731 \mathrm{e}-04$ & $5.349 \mathrm{e}-04$ & $5.559 \mathrm{e}-04$ & $7.975 \mathrm{e}-04$ \\
$\mathrm{~A}=\mathrm{H} 3 \mathrm{a}$ & $1.344 \mathrm{e}-01$ & $6.341 \mathrm{e}-03$ & $8.333 \mathrm{e}-03$ & $8.716 \mathrm{e}-03$ & $1.160 \mathrm{e}-02$ \\
$\mathrm{~A}=\mathrm{H} 3 \mathrm{~b}$ & $1.238 \mathrm{e}-01$ & $5.464 \mathrm{e}-03$ & $9.420 \mathrm{e}-03$ & $7.960 \mathrm{e}-03$ & $1.228 \mathrm{e}-02$ \\
\hline \hline & $\left\|A_{\text {num }}-A_{\text {appr }}\right\|$ & $r\left(A_{\text {num }}\right)$ & $R\left(A_{\text {num }}\right)$ & $r\left(A_{\text {appr }}\right)$ & $R\left(A_{\text {appr }}\right)$ \\
\hline $\mathrm{A}=\mathrm{O} 1$ & $3.014 \mathrm{e}-05$ & $2.479 \mathrm{e}-04$ & $3.363 \mathrm{e}-04$ & $2.485 \mathrm{e}-04$ & $3.368 \mathrm{e}-04$ \\
$\mathrm{~A}=\mathrm{C} 2$ & $3.207 \mathrm{e}-05$ & $3.928 \mathrm{e}-04$ & $4.554 \mathrm{e}-04$ & $3.903 \mathrm{e}-04$ & $4.497 \mathrm{e}-04$ \\
$\mathrm{~A}=\mathrm{H} 2 \mathrm{a}$ & $1.722 \mathrm{e}-03$ & $5.859 \mathrm{e}-03$ & $8.449 \mathrm{e}-03$ & $6.546 \mathrm{e}-03$ & $8.652 \mathrm{e}-03$ \\
$\mathrm{~A}=\mathrm{H} 2 \mathrm{~b}$ & $1.799 \mathrm{e}-03$ & $5.380 \mathrm{e}-03$ & $7.425 \mathrm{e}-03$ & $5.975 \mathrm{e}-03$ & $7.668 \mathrm{e}-03$ \\
$\mathrm{~A}=\mathrm{C} 3$ & $1.154 \mathrm{e}-04$ & $3.731 \mathrm{e}-04$ & $5.349 \mathrm{e}-04$ & $3.715 \mathrm{e}-04$ & $5.238 \mathrm{e}-04$ \\
$\mathrm{~A}=\mathrm{H} 3 \mathrm{a}$ & $5.085 \mathrm{e}-03$ & $6.341 \mathrm{e}-03$ & $8.333 \mathrm{e}-03$ & $6.837 \mathrm{e}-03$ & $8.576 \mathrm{e}-03$ \\
$\mathrm{~A}=\mathrm{H} 3 \mathrm{~b}$ & $2.668 \mathrm{e}-03$ & $5.464 \mathrm{e}-03$ & $9.420 \mathrm{e}-03$ & $5.976 \mathrm{e}-03$ & $9.838 \mathrm{e}-03$
\end{tabular}

Table S5: Positional difference (in $\AA$ ) between atoms in $\mathbf{x}_{\mathrm{num}}, \mathbf{x}_{\mathrm{appr}}$, and $\mathbf{x}_{\text {spher }}$ and their comparison with uncertainty bounds. Red indicates a bound smaller than the difference, whilst green represents a bound larger than the difference (epoxide). 
$\mathrm{H} 3 \mathrm{~b}$
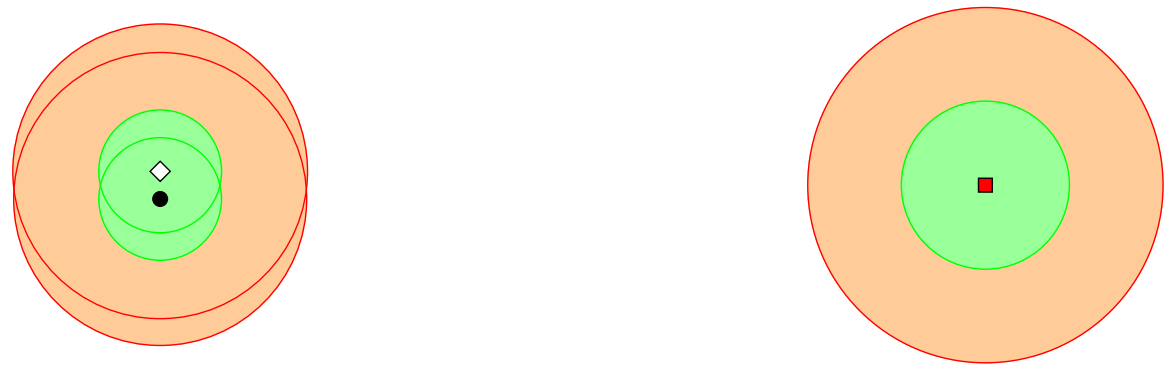

H3a
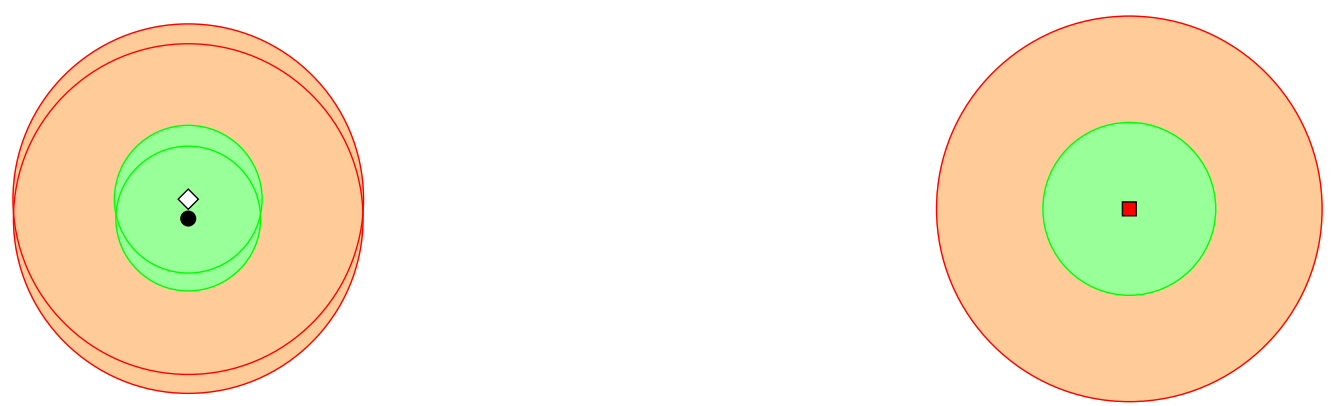

$\mathrm{H} 2 \mathrm{~b}$
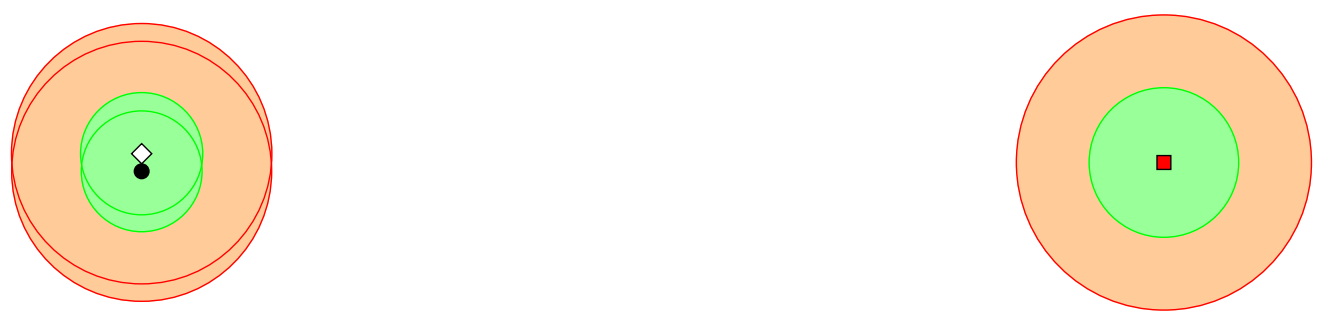

$\mathrm{H} 2 \mathrm{a}$

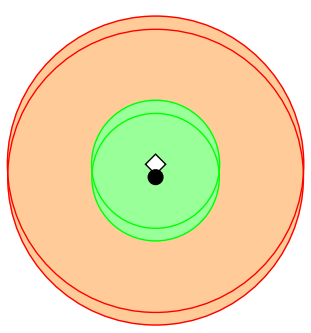

$0.01 \AA^{2}$

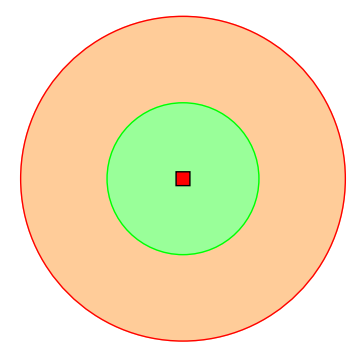

Figure S37: ADPs of the hydrogen atoms in $\mathbf{x}_{\text {num }}$ (white $\diamond$ ), $\mathbf{x}_{\text {appr }}$ (black $\bullet$ ) and $\mathbf{x}_{\text {spher }}$ (red $\boldsymbol{\square}$ ), and their uncertainty balls. Green balls represent inner uncertainty balls and red balls represent outer uncertainty balls. (epoxide) 
C3
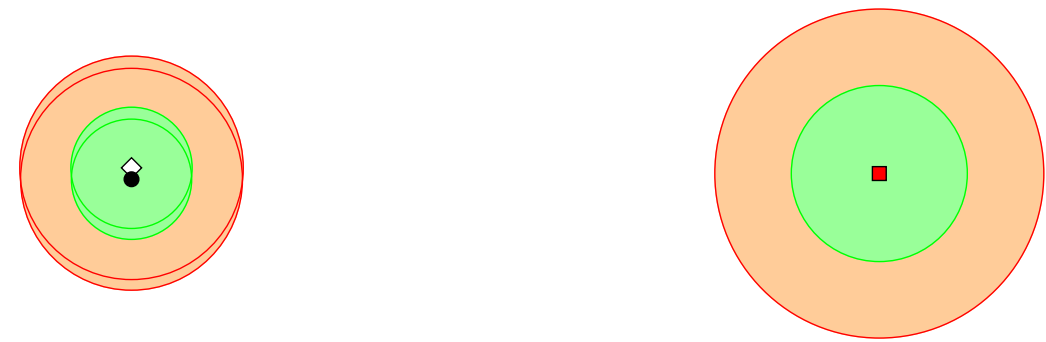

$\mathrm{C} 2$
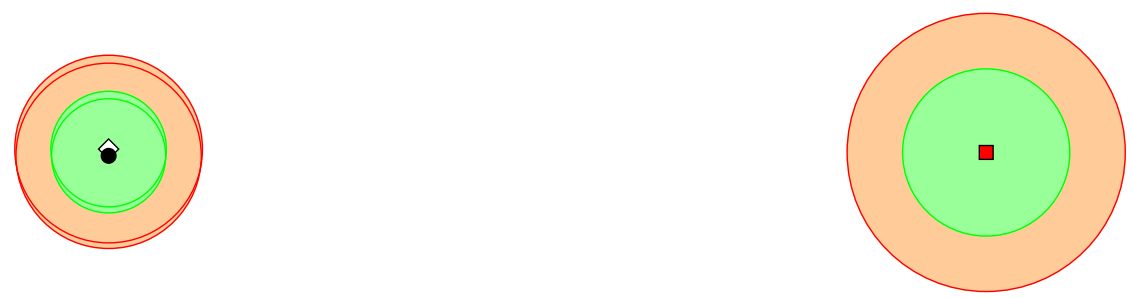

O1

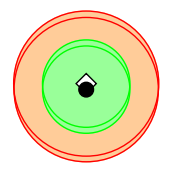

$0.001 \AA^{2}$

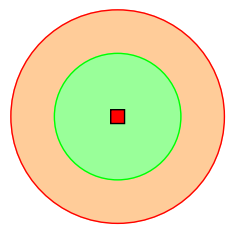

Figure S38: ADPs of the non-hydrogen atoms in $\mathbf{x}_{\text {num }}($ white $\diamond), \mathbf{x}_{\text {appr }}$ (black $\bullet$ ) and $\mathbf{x}_{\text {spher }}($ red $\boldsymbol{\square}$ ), and their uncertainty balls. Green balls represent inner uncertainty balls and red balls represent outer uncertainty balls. (epoxide)

\begin{tabular}{c|c|cccc} 
& $\left\|A_{\text {num }}-A_{\text {spher }}\right\|$ & $r\left(A_{\text {num }}\right)$ & $R\left(A_{\text {num }}\right)$ & $r\left(A_{\text {spher }}\right)$ & $R\left(A_{\text {spher }}\right)$ \\
\hline $\mathrm{A}=\mathrm{O} 1$ & $2.679 \mathrm{e}-03$ & $9.246 \mathrm{e}-05$ & $1.535 \mathrm{e}-04$ & $1.338 \mathrm{e}-04$ & $2.259 \mathrm{e}-04$ \\
$\mathrm{~A}=\mathrm{C} 2$ & $1.853 \mathrm{e}-03$ & $1.222 \mathrm{e}-04$ & $1.985 \mathrm{e}-04$ & $1.769 \mathrm{e}-04$ & $2.942 \mathrm{e}-04$ \\
$\mathrm{~A}=\mathrm{H} 2 \mathrm{a}$ & $4.276 \mathrm{e}-02$ & $2.854 \mathrm{e}-03$ & $6.604 \mathrm{e}-03$ & $3.384 \mathrm{e}-03$ & $7.235 \mathrm{e}-03$ \\
$\mathrm{~A}=\mathrm{H} 2 \mathrm{~b}$ & $4.525 \mathrm{e}-02$ & $2.723 \mathrm{e}-03$ & $5.802 \mathrm{e}-03$ & $3.333 \mathrm{e}-03$ & $6.576 \mathrm{e}-03$ \\
$\mathrm{~A}=\mathrm{C} 3$ & $1.583 \mathrm{e}-03$ & $1.282 \mathrm{e}-04$ & $2.364 \mathrm{e}-04$ & $1.862 \mathrm{e}-04$ & $3.480 \mathrm{e}-04$ \\
$\mathrm{~A}=\mathrm{H} 3 \mathrm{a}$ & $4.159 \mathrm{e}-02$ & $3.291 \mathrm{e}-03$ & $7.811 \mathrm{e}-03$ & $3.851 \mathrm{e}-03$ & $8.591 \mathrm{e}-03$ \\
$\mathrm{~A}=\mathrm{H} 3 \mathrm{~b}$ & $3.668 \mathrm{e}-02$ & $2.736 \mathrm{e}-03$ & $6.566 \mathrm{e}-03$ & $3.746 \mathrm{e}-03$ & $7.917 \mathrm{e}-03$ \\
\hline \hline & $\left\|A_{\text {num }}-A_{\text {appr }}\right\|$ & $r\left(A_{\text {num }}\right)$ & $R\left(A_{\text {num }}\right)$ & $r\left(A_{\text {appr }}\right)$ & $R\left(A_{\text {appr }}\right)$ \\
\hline $\mathrm{A}=\mathrm{O} 1$ & $1.271 \mathrm{e}-05$ & $9.246 \mathrm{e}-05$ & $1.535 \mathrm{e}-04$ & $9.236 \mathrm{e}-05$ & $1.527 \mathrm{e}-04$ \\
$\mathrm{~A}=\mathrm{C} 2$ & $1.430 \mathrm{e}-05$ & $1.222 \mathrm{e}-04$ & $1.985 \mathrm{e}-04$ & $1.207 \mathrm{e}-04$ & $1.960 \mathrm{e}-04$ \\
$\mathrm{~A}=\mathrm{H} 2 \mathrm{a}$ & $5.745 \mathrm{e}-04$ & $2.854 \mathrm{e}-03$ & $6.604 \mathrm{e}-03$ & $2.841 \mathrm{e}-03$ & $6.589 \mathrm{e}-03$ \\
$\mathrm{~A}=\mathrm{H} 2 \mathrm{~b}$ & $7.845 \mathrm{e}-04$ & $2.723 \mathrm{e}-03$ & $5.802 \mathrm{e}-03$ & $2.692 \mathrm{e}-03$ & $5.793 \mathrm{e}-03$ \\
$\mathrm{~A}=\mathrm{C} 3$ & $2.415 \mathrm{e}-05$ & $1.282 \mathrm{e}-04$ & $2.364 \mathrm{e}-04$ & $1.272 \mathrm{e}-04$ & $2.347 \mathrm{e}-04$ \\
$\mathrm{~A}=\mathrm{H} 3 \mathrm{a}$ & $8.633 \mathrm{e}-04$ & $3.291 \mathrm{e}-03$ & $7.811 \mathrm{e}-03$ & $3.225 \mathrm{e}-03$ & $7.790 \mathrm{e}-03$ \\
$\mathrm{~A}=\mathrm{H} 3 \mathrm{~b}$ & $1.232 \mathrm{e}-03$ & $2.736 \mathrm{e}-03$ & $6.566 \mathrm{e}-03$ & $2.733 \mathrm{e}-03$ & $6.528 \mathrm{e}-03$
\end{tabular}

Table S6: ADP difference (in $\AA^{2}$ ) between atoms in $\mathbf{x}_{\text {num }}, \mathbf{x}_{\text {appr }}$, and $\mathbf{x}_{\text {spher }}$ and their comparison with uncertainty bounds. Red indicates a bound smaller than the difference, whilst green represents a bound larger than the difference (epoxide). 


\section{$5.3 \quad$ L-Alanine}

\begin{tabular}{|c|c|c|c|c|c|}
\hline & $\| A_{\text {num }}-A_{\text {spher }} \mid$ & $r\left(A_{\text {num }}\right)$ & $R\left(A_{\text {num }}\right)$ & $r\left(A_{\text {spher }}\right)$ & $R\left(A_{\text {spher }}\right)$ \\
\hline $\mathrm{A}=\mathrm{N} 1$ & $8.932 \mathrm{e}-04$ & $2.510 \mathrm{e}-04$ & $2.803 \mathrm{e}-04$ & $4.813 \mathrm{e}-04$ & $5.322 \mathrm{e}-04$ \\
\hline $\mathrm{A}=\mathrm{H} 1 \mathrm{a}$ & $1.076 \mathrm{e}-01$ & $5.681 \mathrm{e}-03$ & $7.998 \mathrm{e}-03$ & $9.731 \mathrm{e}-03$ & $1.310 \mathrm{e}-02$ \\
\hline $\mathrm{A}=\mathrm{H} 1 \mathrm{~b}$ & $9.296 \mathrm{e}-02$ & $5.480 \mathrm{e}-03$ & $7.790 \mathrm{e}-03$ & 8.991e-03 & $1.330 \mathrm{e}-02$ \\
\hline $\mathrm{A}=\mathrm{H} 1 \mathrm{c}$ & $7.742 \mathrm{e}-02$ & $6.125 \mathrm{e}-03$ & $6.901 \mathrm{e}-03$ & $8.844 \mathrm{e}-03$ & $1.754 \mathrm{e}-02$ \\
\hline $\mathrm{A}=\mathrm{C} 1$ & $2.624 \mathrm{e}-03$ & $2.497 \mathrm{e}-04$ & $2.920 \mathrm{e}-04$ & $4.727 \mathrm{e}-04$ & $5.498 \mathrm{e}-04$ \\
\hline $\mathrm{A}=\mathrm{H} 1$ & $9.049 \mathrm{e}-02$ & $4.513 \mathrm{e}-03$ & $6.608 \mathrm{e}-03$ & $8.260 \mathrm{e}-03$ & $1.059 \mathrm{e}-02$ \\
\hline $\mathrm{A}=\mathrm{C} 2$ & $2.788 \mathrm{e}-04$ & $2.884 \mathrm{e}-04$ & $3.335 \mathrm{e}-04$ & $5.488 \mathrm{e}-04$ & $6.320 \mathrm{e}-04$ \\
\hline $\mathrm{A}=\mathrm{H} 2 \mathrm{a}$ & $1.114 \mathrm{e}-01$ & $5.375 \mathrm{e}-03$ & $6.711 \mathrm{e}-03$ & $9.842 \mathrm{e}-03$ & $1.374 \mathrm{e}-02$ \\
\hline $\mathrm{A}=\mathrm{H} 2 \mathrm{~b}$ & $1.281 \mathrm{e}-01$ & $5.426 \mathrm{e}-03$ & $7.179 \mathrm{e}-03$ & $9.036 \mathrm{e}-03$ & $1.253 \mathrm{e}-02$ \\
\hline $\mathrm{A}=\mathrm{H} 2 \mathrm{c}$ & $8.655 \mathrm{e}-02$ & $5.073 \mathrm{e}-03$ & $8.260 \mathrm{e}-03$ & $8.993 \mathrm{e}-03$ & $1.228 \mathrm{e}-02$ \\
\hline $\mathrm{A}=\mathrm{C} 3$ & $7.201 \mathrm{e}-04$ & $2.465 \mathrm{e}-04$ & $2.792 \mathrm{e}-04$ & $4.656 \mathrm{e}-04$ & $5.279 \mathrm{e}-04$ \\
\hline $\mathrm{A}=\mathrm{O} 1$ & $2.022 \mathrm{e}-03$ & $2.022 \mathrm{e}-04$ & $2.452 \mathrm{e}-04$ & $3.811 \mathrm{e}-04$ & $4.624 \mathrm{e}-04$ \\
\hline \multirow[t]{2}{*}{$\mathrm{A}=\mathrm{O} 2$} & $8.635 \mathrm{e}-04$ & $2.043 \mathrm{e}-04$ & $2.365 \mathrm{e}-04$ & $3.863 \mathrm{e}-04$ & $4.480 \mathrm{e}-04$ \\
\hline & $\left\|A_{\text {num }}-A_{\text {appr }}\right\|$ & $r\left(A_{\text {num }}\right)$ & $R\left(A_{\text {num }}\right)$ & $r\left(A_{\text {appr }}\right)$ & $R\left(A_{\text {appr }}\right)$ \\
\hline $\mathrm{A}=\mathrm{N} 1$ & $3.137 \mathrm{e}-05$ & $2.510 \mathrm{e}-04$ & $2.803 \mathrm{e}-04$ & $2.499 \mathrm{e}-04$ & $2.772 \mathrm{e}-04$ \\
\hline $\mathrm{A}=\mathrm{H} 1 \mathrm{a}$ & $723 \mathrm{e}-03$ & $5.681 \mathrm{e}$ & $7.998 \mathrm{e}-03$ & $6.385 \mathrm{e}-03$ & $8.082 \mathrm{e}-03$ \\
\hline $\mathrm{A}=\mathrm{H} 1 \mathrm{~b}$ & $1.736 \mathrm{e}-03$ & $5.480 \mathrm{e}-03$ & $7.790 \mathrm{e}-03$ & $6.129 \mathrm{e}-03$ & $7.868 \mathrm{e}-03$ \\
\hline $\mathrm{A}=\mathrm{H} 1 \mathrm{c}$ & $4.864 \mathrm{e}-03$ & $6.125 \mathrm{e}-03$ & $6.901 \mathrm{e}-03$ & $6.264 \mathrm{e}-03$ & $8.056 \mathrm{e}-03$ \\
\hline $\mathrm{A}=\mathrm{C} 1$ & $7.121 \mathrm{e}-06$ & $2.497 \mathrm{e}-04$ & $2.920 \mathrm{e}-04$ & $2.494 \mathrm{e}-04$ & $2.930 \mathrm{e}-04$ \\
\hline $\mathrm{A}=\mathrm{H} 1$ & $2.242 \mathrm{e}-03$ & $4.513 \mathrm{e}-03$ & $6.608 \mathrm{e}-03$ & $4.981 \mathrm{e}-03$ & $6.509 \mathrm{e}-03$ \\
\hline $\mathrm{A}=\mathrm{C} 2$ & $1.933 \mathrm{e}-05$ & $2.884 \mathrm{e}-04$ & $3.335 \mathrm{e}-04$ & $2.884 \mathrm{e}-04$ & $3.308 \mathrm{e}-04$ \\
\hline $\mathrm{A}=\mathrm{H} 2 \mathrm{a}$ & $1.990 \mathrm{e}-03$ & $5.375 \mathrm{e}-03$ & $6.711 \mathrm{e}-03$ & $5.785 \mathrm{e}-03$ & $7.175 \mathrm{e}-03$ \\
\hline $\mathrm{A}=\mathrm{H} 2 \mathrm{~b}$ & $2.074 \mathrm{e}-03$ & $5.426 \mathrm{e}-03$ & $7.179 \mathrm{e}-03$ & $5.692 \mathrm{e}-03$ & 7.394e-03 \\
\hline $\mathrm{A}=\mathrm{H} 2 \mathrm{c}$ & $1.359 \mathrm{e}-03$ & $5.073 \mathrm{e}-03$ & $8.260 \mathrm{e}-03$ & $5.429 \mathrm{e}-03$ & $8.263 \mathrm{e}-03$ \\
\hline $\mathrm{A}=\mathrm{C} 3$ & $7.515 \mathrm{e}-06$ & $2.465 \mathrm{e}-04$ & $2.792 \mathrm{e}-04$ & $2.470 \mathrm{e}-04$ & $2.807 \mathrm{e}-04$ \\
\hline $\mathrm{A}=\mathrm{O} 1$ & $2.556 \mathrm{e}-05$ & $2.022 \mathrm{e}-04$ & $2.452 \mathrm{e}-04$ & $2.036 \mathrm{e}-04$ & $2.461 \mathrm{e}-04$ \\
\hline $\mathrm{A}=\mathrm{O} 2$ & $2.130 \mathrm{e}-05$ & $2.043 \mathrm{e}-04$ & $2.365 \mathrm{e}-04$ & $2.055 \mathrm{e}-04$ & $2.375 \mathrm{e}-04$ \\
\hline
\end{tabular}

Table S7: Positional difference (in $\AA$ ) between atoms in $\mathbf{x}_{\mathrm{num}}, \mathbf{x}_{\mathrm{appr}}$, and $\mathbf{x}_{\mathrm{spher}}$ and their comparison with uncertainty bounds. Red indicates a bound smaller than the difference, whilst green represents a bound larger than the difference (L-alanine). 
$\mathrm{H} 2 \mathrm{c}$
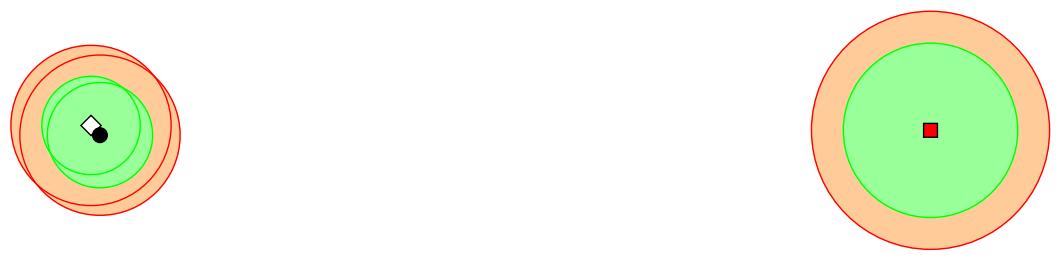

H2b
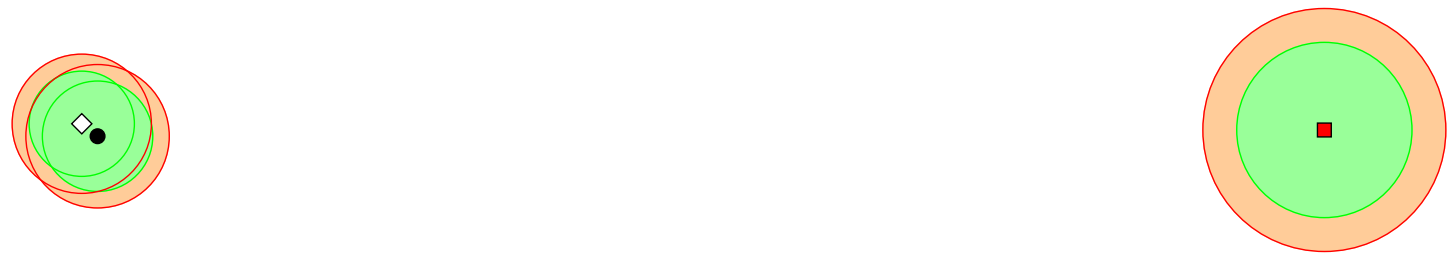

$\mathrm{H} 2 \mathrm{a}$
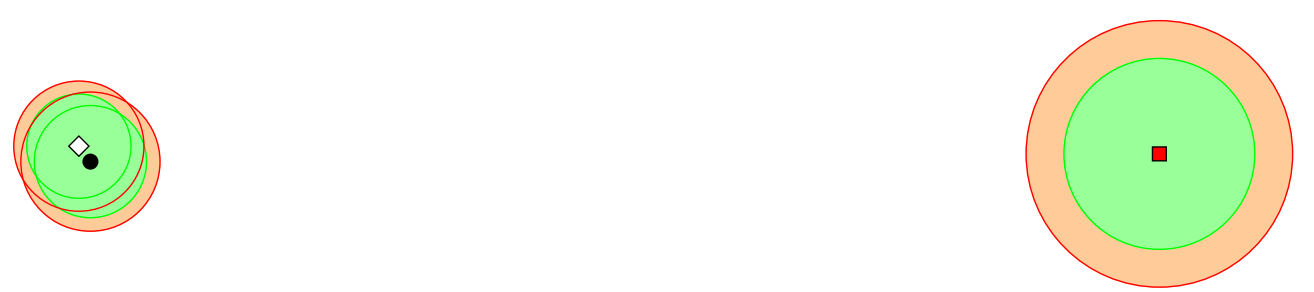

H1
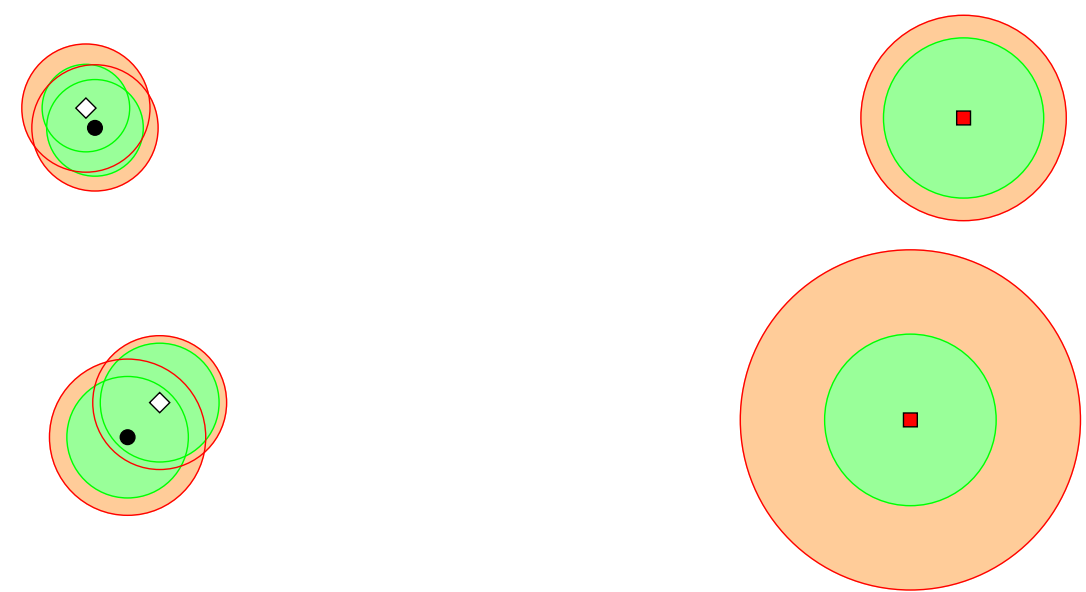

H1b
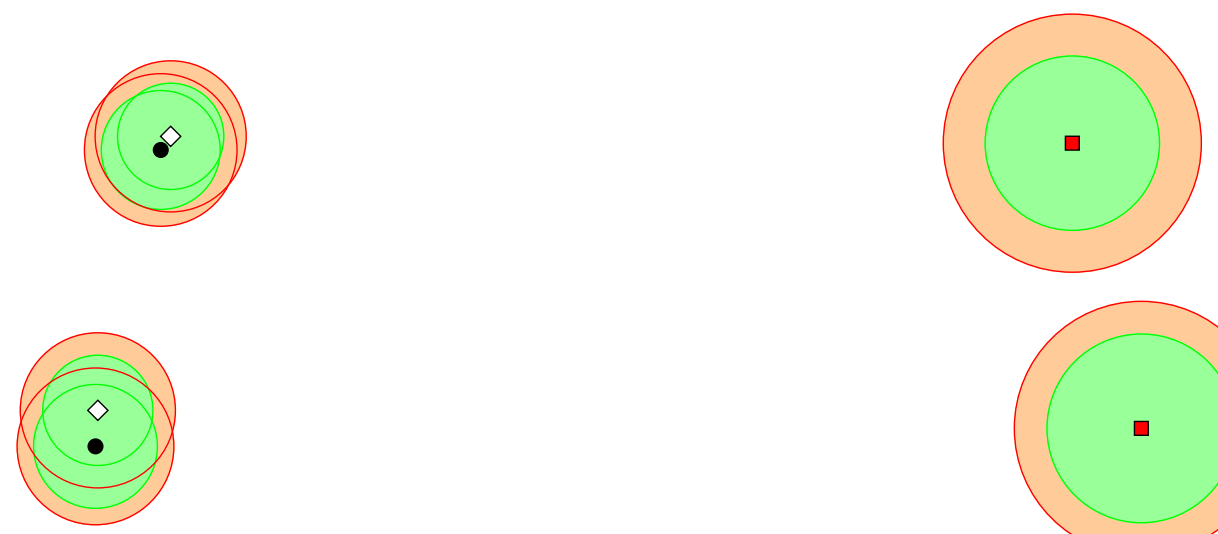

$$
\longmapsto_{0.01 \AA}
$$

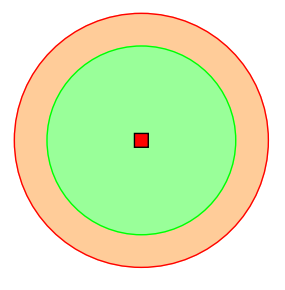

Figure S39: Positions of the hydrogen atoms in $\mathbf{x}_{\text {num }}($ white $\diamond), \mathbf{x}_{\text {appr }}$ (black $\mathbf{0}$ ) and $\mathbf{x}_{\text {spher }}($ red $\mathbf{\square}$ ), and their uncertainty balls. Green balls represent inner uncertainty balls and red balls represent outer uncertainty balls. (L-alanine) 


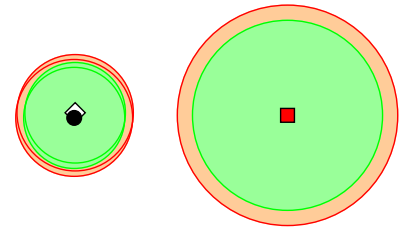

O1

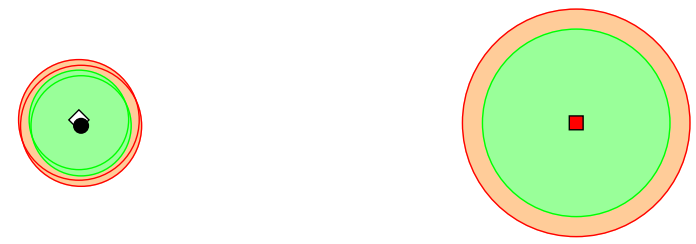

C3

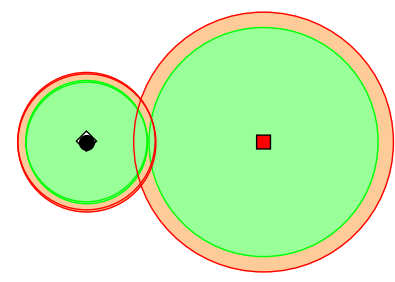

$\mathrm{C} 2$

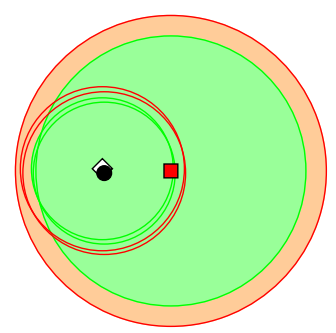

C1
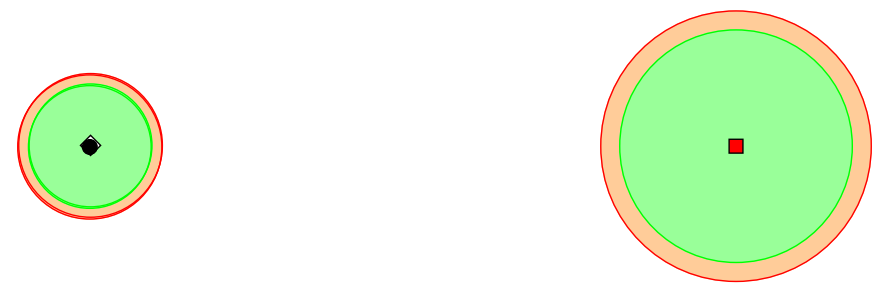

N1

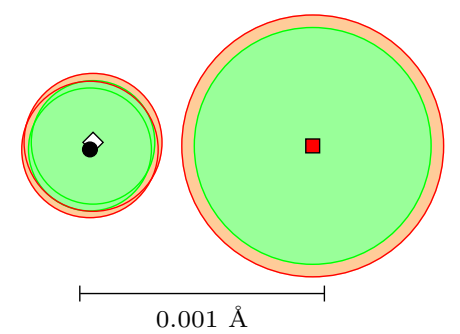

Figure S40: Positions of the non-hydrogen atoms in $\mathbf{x}_{\text {num }}($ white $\diamond), \mathbf{x}_{\text {appr }}$ (black $\bullet$ ) and $\mathbf{x}_{\text {spher }}($ red $\boldsymbol{\nabla})$, and their uncertainty balls. Green balls represent inner uncertainty balls and red balls represent outer uncertainty balls. (L-alanine) 


\begin{tabular}{|c|c|c|c|c|c|}
\hline & $\left\|A_{\text {num }}-A_{\text {spher }}\right\|$ & $r\left(A_{\text {num }}\right)$ & $R\left(A_{\text {num }}\right)$ & $r\left(A_{\text {spher }}\right)$ & $R\left(A_{\text {spher }}\right)$ \\
\hline $\mathrm{A}=\mathrm{N} 1$ & $6.211 \mathrm{e}-04$ & $5.645 \mathrm{e}-05$ & $9.182 \mathrm{e}-05$ & $1.061 \mathrm{e}-04$ & $1.702 \mathrm{e}-04$ \\
\hline $\mathrm{A}=\mathrm{H} 1 \mathrm{a}$ & $5.186 \mathrm{e}-02$ & $2.876 \mathrm{e}-03$ & $5.015 \mathrm{e}-03$ & $4.265 \mathrm{e}-03$ & $9.627 \mathrm{e}-03$ \\
\hline$A=H 1 b$ & $2.991 \mathrm{e}-02$ & $2.741 \mathrm{e}-03$ & $4.949 \mathrm{e}-03$ & $3.551 \mathrm{e}-03$ & $8.364 \mathrm{e}-03$ \\
\hline $\mathrm{A}=\mathrm{H} 1 \mathrm{c}$ & $1.041 \mathrm{e}-01$ & $2.765 \mathrm{e}-03$ & $5.553 \mathrm{e}-03$ & $3.631 \mathrm{e}-03$ & $1.711 \mathrm{e}-02$ \\
\hline $\mathrm{A}=\mathrm{C} 1$ & $9.630 \mathrm{e}-04$ & $6.001 \mathrm{e}-05$ & $9.864 \mathrm{e}-05$ & $1.139 \mathrm{e}-04$ & $1.858 \mathrm{e}-04$ \\
\hline $\mathrm{A}=\mathrm{H} 1$ & $2.593 \mathrm{e}-02$ & $2.216 \mathrm{e}-03$ & $4.100 \mathrm{e}-03$ & $3.224 \mathrm{e}-03$ & $6.255 \mathrm{e}-03$ \\
\hline $\mathrm{A}=\mathrm{C} 2$ & $7.760 \mathrm{e}-04$ & $6.677 \mathrm{e}-05$ & $1.101 \mathrm{e}-04$ & $1.265 \mathrm{e}-04$ & $2.068 \mathrm{e}-04$ \\
\hline $\mathrm{A}=\mathrm{H} 2 \mathrm{a}$ & $2.999 \mathrm{e}-02$ & $2.800 \mathrm{e}-03$ & $5.158 \mathrm{e}-03$ & $4.847 \mathrm{e}-03$ & $9.370 \mathrm{e}-03$ \\
\hline $\mathrm{A}=\mathrm{H} 2 \mathrm{~b}$ & $2.103 \mathrm{e}-02$ & $2.766 \mathrm{e}-03$ & $5.404 \mathrm{e}-03$ & $4.173 \mathrm{e}-03$ & $8.846 \mathrm{e}-03$ \\
\hline $\mathrm{A}=\mathrm{H} 2 \mathrm{c}$ & $3.582 \mathrm{e}-02$ & $2.624 \mathrm{e}-03$ & $5.858 \mathrm{e}-03$ & $4.554 \mathrm{e}-03$ & $8.060 \mathrm{e}-03$ \\
\hline $\mathrm{A}=\mathrm{C} 3$ & $1.002 \mathrm{e}-03$ & $5.717 \mathrm{e}-05$ & $9.384 \mathrm{e}-05$ & $1.076 \mathrm{e}-04$ & $1.770 \mathrm{e}-04$ \\
\hline $\mathrm{A}=\mathrm{O} 1$ & $9.886 \mathrm{e}-04$ & $5.171 \mathrm{e}-05$ & $8.777 \mathrm{e}-05$ & $9.836 \mathrm{e}-05$ & $1.653 \mathrm{e}-04$ \\
\hline \multirow[t]{2}{*}{$\mathrm{A}=\mathrm{O} 2$} & $7.778 \mathrm{e}-04$ & $5.263 \mathrm{e}-05$ & $8.164 \mathrm{e}-05$ & $9.986 \mathrm{e}-05$ & $1.533 \mathrm{e}-04$ \\
\hline & $\left\|A_{\text {num }}-A_{\text {appr }}\right\|$ & $r\left(A_{\text {num }}\right)$ & $R\left(A_{\text {num }}\right)$ & $r\left(A_{\text {appr }}\right)$ & $R\left(A_{\text {appr }}\right)$ \\
\hline $\mathrm{A}=\mathrm{N} 1$ & $1.197 \mathrm{e}-05$ & $5.645 \mathrm{e}-05$ & $9.182 \mathrm{e}-05$ & $5.629 \mathrm{e}-05$ & $8.993 \mathrm{e}-05$ \\
\hline $\mathrm{A}=\mathrm{H} 1 \mathrm{a}$ & $4.618 \mathrm{e}-04$ & $2.876 \mathrm{e}-03$ & $5.015 \mathrm{e}-03$ & $2.833 \mathrm{e}-03$ & $5.017 \mathrm{e}-03$ \\
\hline $\mathrm{A}=\mathrm{H} 1 \mathrm{~b}$ & $3.718 \mathrm{e}-04$ & $2.741 \mathrm{e}-03$ & $4.949 \mathrm{e}-03$ & $2.649 \mathrm{e}-03$ & $4.917 \mathrm{e}-03$ \\
\hline $\mathrm{A}=\mathrm{H} 1 \mathrm{c}$ & $8.752 \mathrm{e}-04$ & $2.765 \mathrm{e}-03$ & $5.553 \mathrm{e}-03$ & $2.701 \mathrm{e}-03$ & $5.576 \mathrm{e}-03$ \\
\hline $\mathrm{A}=\mathrm{C} 1$ & $6.396 \mathrm{e}-06$ & $6.001 \mathrm{e}-05$ & $9.864 \mathrm{e}-05$ & $5.981 \mathrm{e}-05$ & $9.860 \mathrm{e}-05$ \\
\hline $\mathrm{A}=\mathrm{H} 1$ & $3.791 \mathrm{e}-04$ & $2.216 \mathrm{e}-03$ & $4.100 \mathrm{e}-03$ & $2.219 \mathrm{e}-03$ & $4.101 \mathrm{e}-03$ \\
\hline $\mathrm{A}=\mathrm{C} 2$ & $4.975 \mathrm{e}-06$ & $6.677 \mathrm{e}-05$ & $1.101 \mathrm{e}-04$ & $6.665 \mathrm{e}-05$ & $1.092 \mathrm{e}-04$ \\
\hline $\mathrm{A}=\mathrm{H} 2 \mathrm{a}$ & $1.276 \mathrm{e}-03$ & $2.800 \mathrm{e}-03$ & $5.158 \mathrm{e}-03$ & $2.797 \mathrm{e}-03$ & $5.173 \mathrm{e}-03$ \\
\hline $\mathrm{A}=\mathrm{H} 2 \mathrm{~b}$ & $3.321 \mathrm{e}-04$ & $2.766 \mathrm{e}-03$ & $5.404 \mathrm{e}-03$ & $2.728 \mathrm{e}-03$ & $5.396 \mathrm{e}-03$ \\
\hline $\mathrm{A}=\mathrm{H} 2 \mathrm{c}$ & $1.033 \mathrm{e}-03$ & $2.624 \mathrm{e}-03$ & $5.858 \mathrm{e}-03$ & $2.608 \mathrm{e}-03$ & $5.892 \mathrm{e}-03$ \\
\hline $\mathrm{A}=\mathrm{C} 3$ & $6.221 \mathrm{e}-06$ & $5.717 \mathrm{e}-05$ & $9.384 \mathrm{e}-05$ & $5.707 \mathrm{e}-05$ & $9.384 \mathrm{e}-05$ \\
\hline $\mathrm{A}=\mathrm{O} 1$ & $5.503 \mathrm{e}-06$ & $5.171 \mathrm{e}-05$ & $8.777 \mathrm{e}-05$ & $5.164 \mathrm{e}-05$ & $8.777 \mathrm{e}-05$ \\
\hline $\mathrm{A}=\mathrm{O} 2$ & $4.666 \mathrm{e}-06$ & $5.263 \mathrm{e}-05$ & $8.164 \mathrm{e}-05$ & $5.255 \mathrm{e}-05$ & $8.167 \mathrm{e}-05$ \\
\hline
\end{tabular}

Table S8: ADP difference (in $\AA^{2}$ ) between atoms in $\mathbf{x}_{\text {num }}, \mathbf{x}_{\text {appr }}$, and $\mathbf{x}_{\text {spher }}$ and their comparison with uncertainty bounds. Red indicates a bound smaller than the difference, whilst green represents a bound larger than the difference (L-alanine). 
$\mathrm{H} 2 \mathrm{c}$
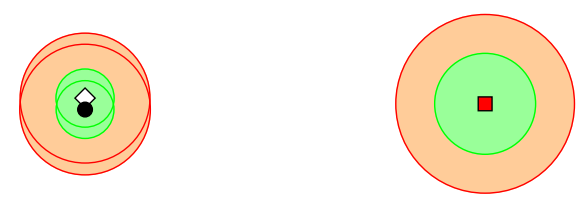

$\mathrm{H} 2 \mathrm{~b}$
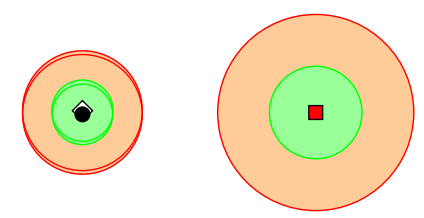

H2a
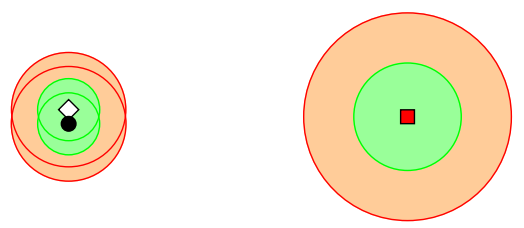

H1
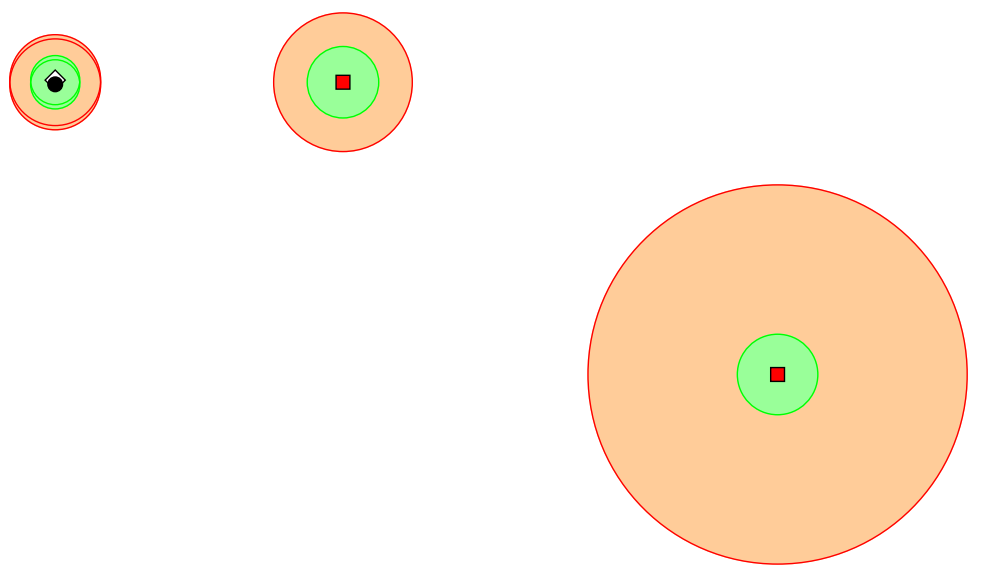

$\mathrm{H} 1 \mathrm{~b}$
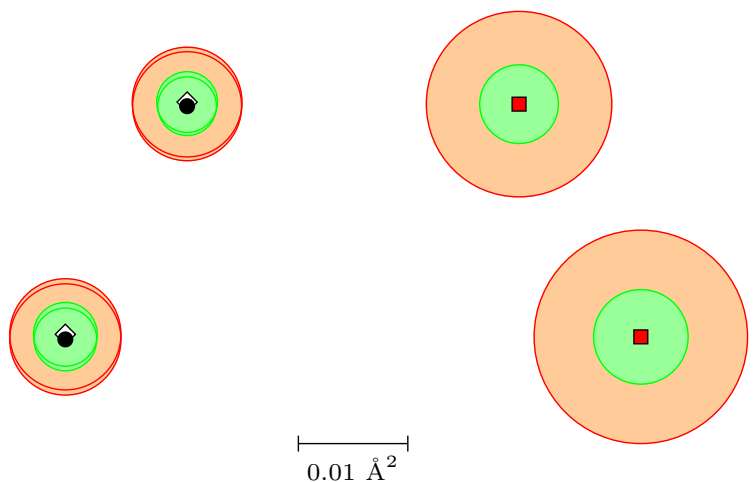

Figure S41: ADPs of the hydrogen atoms in $\mathbf{x}_{\text {num }}($ white $\diamond), \mathbf{x}_{\text {appr }}$ (black $\bullet$ ) and $\mathbf{x}_{\text {spher }}($ red $\boldsymbol{\square}$ ), and their uncertainty balls. Green balls represent inner uncertainty balls and red balls represent outer uncertainty balls. (L-alanine) 
$\mathrm{O} 2$
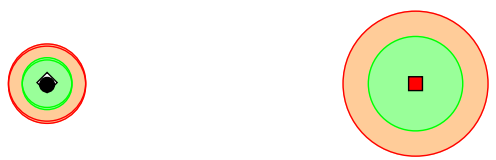

O1
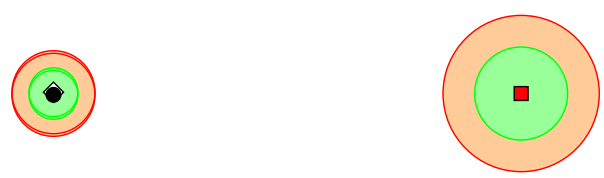

$\mathrm{C} 3$

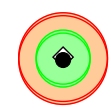

$\mathrm{C} 2$
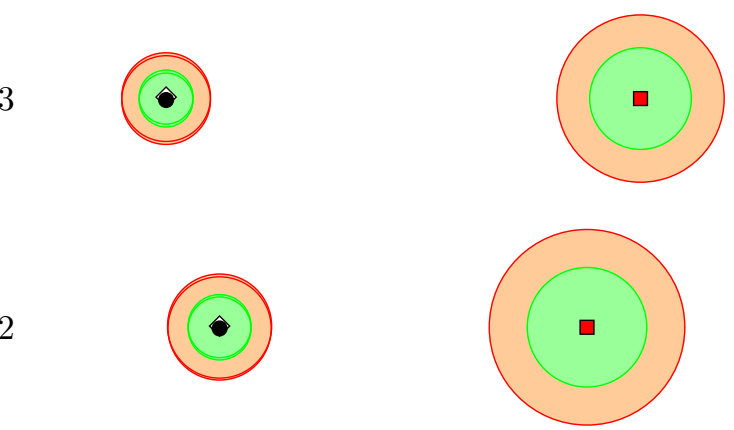

C1
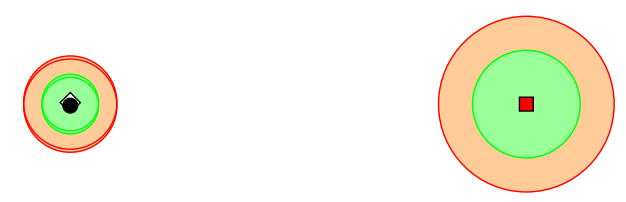

N1

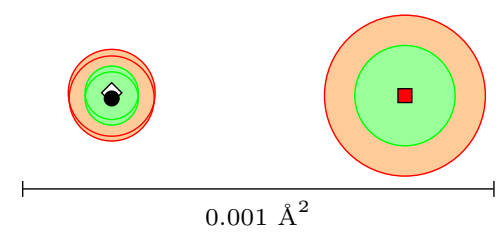

Figure S42: ADPs of the non-hydrogen atoms in $\mathbf{x}_{\text {num }}$ (white $\left.\diamond\right), \mathbf{x}_{\text {appr }}$ (black $\bullet$ ) and $\mathbf{x}_{\text {spher }}$ (red $\mathbf{\square}$ ), and their uncertainty balls. Green balls represent inner uncertainty balls and red balls represent outer uncertainty balls. (L-alanine) 


\section{Conclusion \& Outlook}

\subsection{Neutron data}

Here we present additional comparison with neutron data in Figures S43 to S46. Recall that the purple dot now represents the atom in the neutron model. 


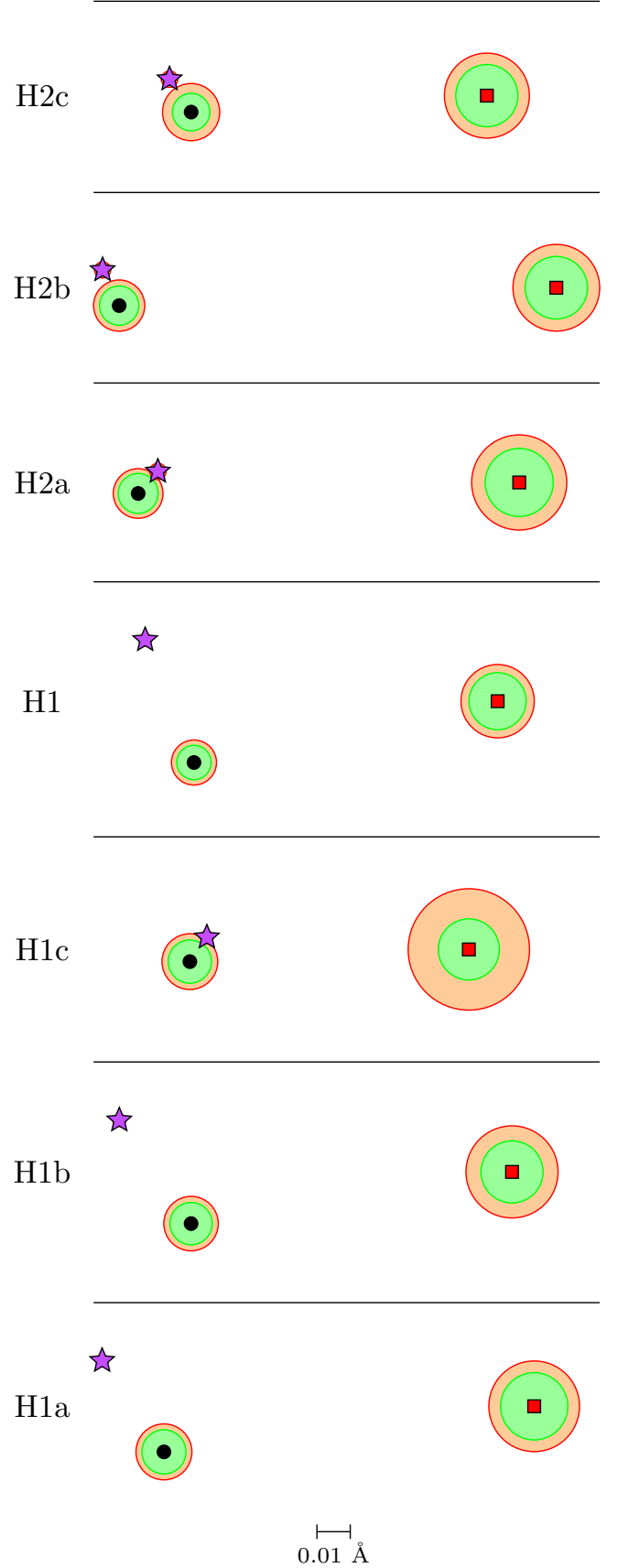

Figure S43: Positions of the hydrogen atoms in $\mathbf{x}_{\text {neutron }}$ (purple $\star$ ), $\mathbf{x}_{\mathrm{appr}}$ (black $\mathbf{\bullet}$ ) and $\mathbf{x}_{\mathrm{spher}}$ (red $\mathbf{\square}$ ), and their uncertainty balls. Green balls represent inner uncertainty balls and red balls represent outer uncertainty balls. (L-alanine) 
$\mathrm{O} 2$

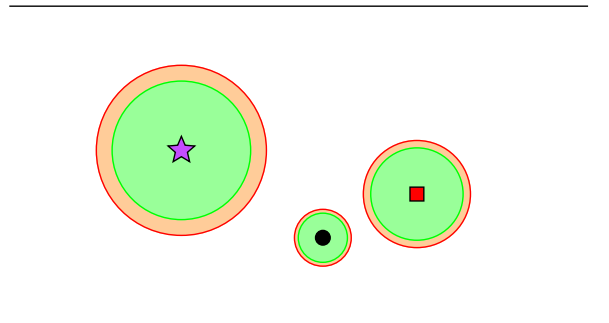

O1
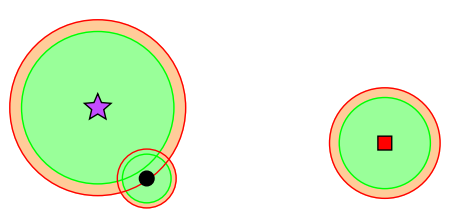

C3
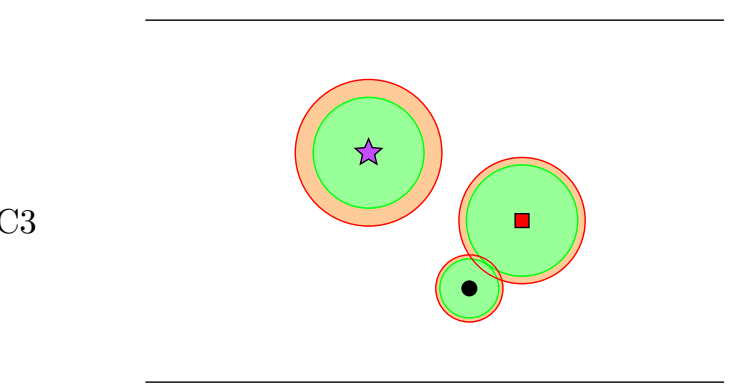

C2
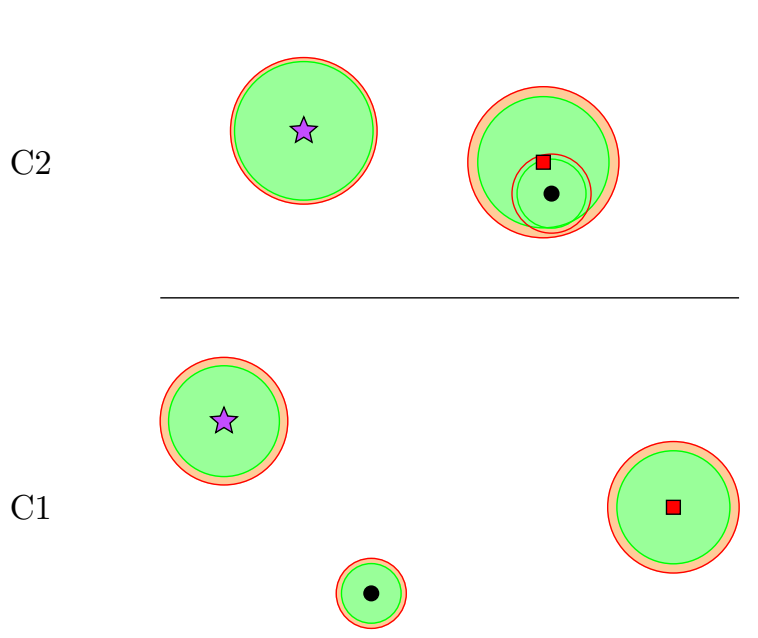

N1

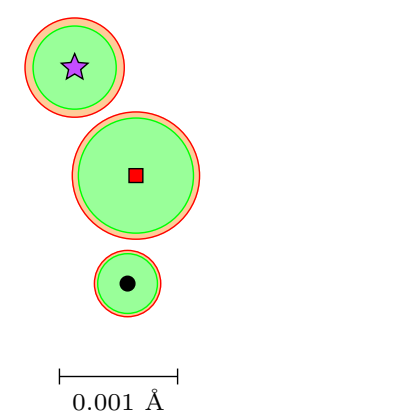

Figure S44: Positions of the non-hydrogen atoms in $\mathbf{x}_{\text {neutron }}\left(\right.$ purple $\star$ ), $\mathbf{x}_{\text {appr }}$ (black $\left.\mathbf{0}\right)$ and $\mathbf{x}_{\text {spher }}($ red $\mathbf{\square})$, and their uncertainty balls. Green balls represent inner uncertainty balls and red balls represent outer uncertainty balls. (L-alanine) 
H2c

*

(

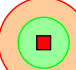

$\mathrm{H} 2 \mathrm{~b}$

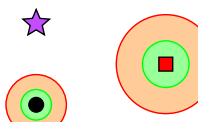

ㅁ)

H2a

5

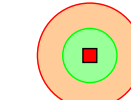

(2)

H1

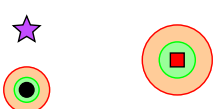

5

H1c
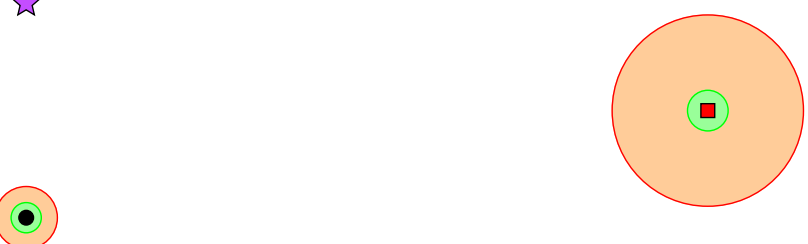

H1b

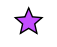

(๑)
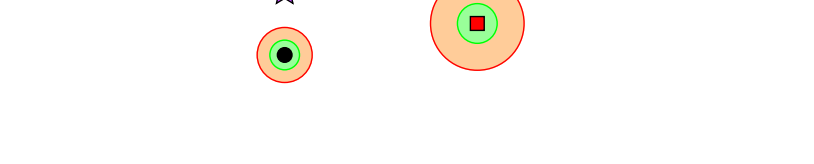

H1a

放
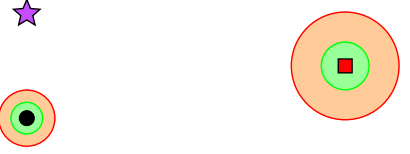

$\stackrel{\longmapsto}{0.01 \AA^{2}}$

Figure S45: ADPs of the hydrogen atoms in $\mathbf{x}_{\text {neutron }}$ (purple $\star$ ), $\mathbf{x}_{\text {appr }}$ (black $\bullet$ ) and $\mathbf{x}_{\text {spher }}($ red $\boldsymbol{\square}$ ), and their uncertainty balls. Green balls represent inner uncertainty balls and red balls represent outer uncertainty balls. (L-alanine) 


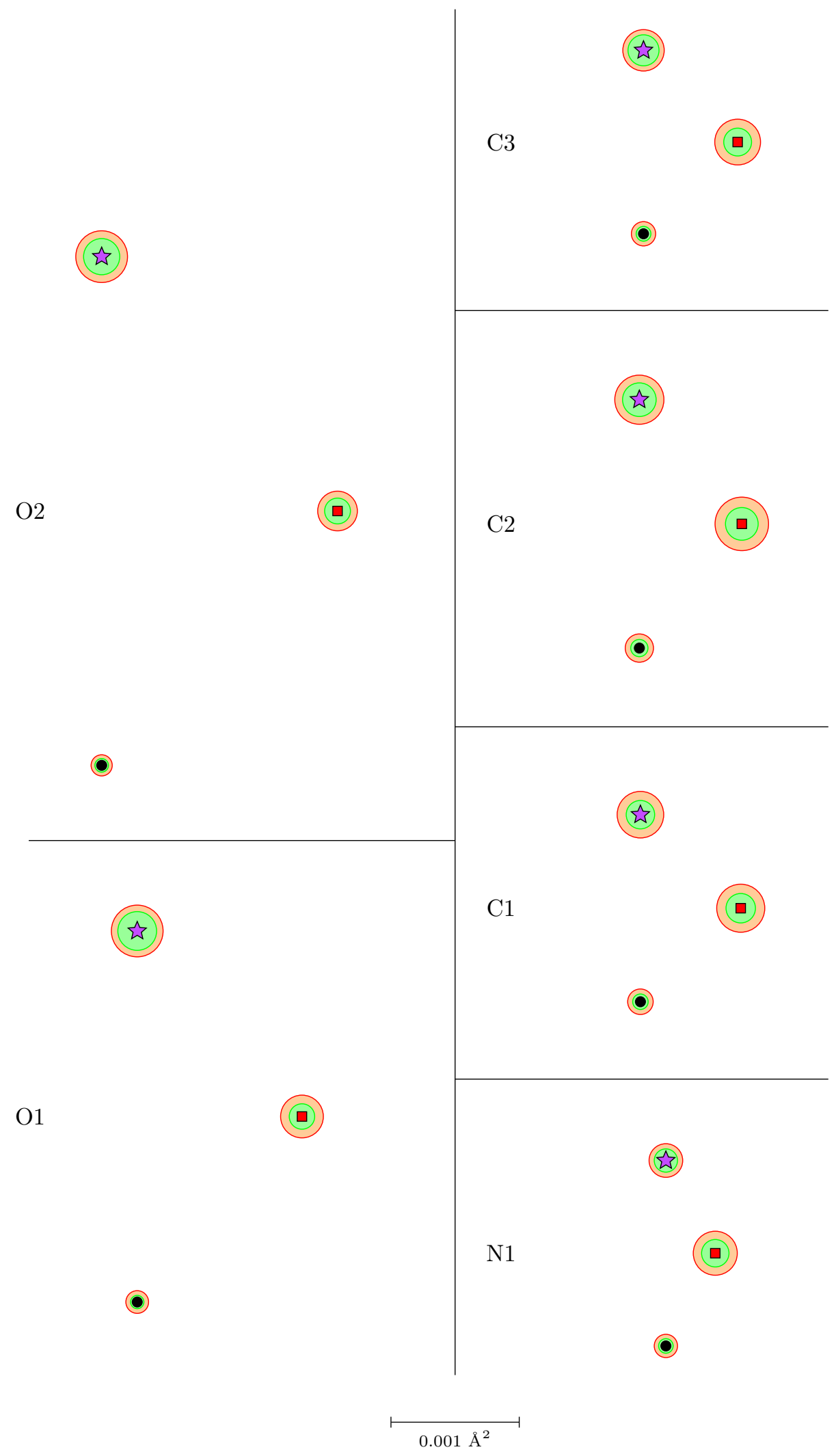

Figure S46: ADPs of the non-hydrogen atoms in $\mathbf{x}_{\text {neutron }}$ (purple $\star$ ), $\mathbf{x}_{\text {appr }}$ (black $\bullet$ ) and $\mathbf{x}_{\text {spher }}$ (red $\mathbf{\square}$ ), and their uncertainty balls. Green balls represent inner uncertainty balls and red balls represent outer uncertainty balls. (L-alanine) 


\section{B Uncertainty balls}

\section{B.1 The matrix $J$ for ammonia}

The matrix ' $\mathrm{J}$ ' for ammonia, which expands the model vector $\mathbf{x}$ to the full vector $\mathbf{y}$ of all crystallographic parameters, is presented in Equation (S1).

$$
J=\left[\begin{array}{cc}
J_{0} & 0_{3,9} \\
0_{9,9} & \mathrm{Id}_{9}
\end{array}\right]
$$

with $0_{p, q}$ the $p \times q$ matrix with all entries equal to $0, \operatorname{Id}_{p}$ the identity matrix of size $p$ and

$$
J_{0}=\left[\begin{array}{lllllllll}
1 & 1 & 1 & 0 & 0 & 0 & 0 & 0 & 0 \\
0 & 0 & 0 & 1 & 1 & 1 & 0 & 0 & 0 \\
0 & 0 & 0 & 0 & 0 & 0 & 1 & 1 & 1
\end{array}\right]
$$

